\title{
Influencing the Operations and Outcomes of the UN Peacebuilding Architecture in Sierra Leone: North-South Dynamics at Work
}

by

Shawna R. Meister

\author{
A thesis submitted to \\ the Faculty of Graduate Studies and Research \\ in partial fulfillment of \\ the requirements for the degree of \\ Master of Arts
}

Department of Political Science

Carleton University

Ottawa, Ontario

Canada

으 2010 Shawna R. Meister 


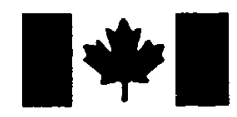

Library and Archives

Canada

Published Heritage

Branch

395 Wellington Street Ottawa ON K1A ON4 Canada
Bibliothèque et

Archives Canada

Direction du

Patrimoine de l'édition

395 , rue Wellington

Ottawa ON K1A ON4

Canada
Your file Votre référence
ISBN: 978-0-494-68687-4
Our file Notre référence
ISBN: $978-0-494-68687-4$
NOTICE:

The author has granted a nonexclusive license allowing Library and Archives Canada to reproduce, publish, archive, preserve, conserve, communicate to the public by telecommunication or on the Internet, loan, distribute and sell theses worldwide, for commercial or noncommercial purposes, in microform, paper, electronic and/or any other formats.

The author retains copyright ownership and moral rights in this thesis. Neither the thesis nor substantial extracts from it may be printed or otherwise reproduced without the author's permission.
AVIS:

L'auteur a accordé une licence non exclusive permettant à la Bibliothèque et Archives Canada de reproduire, publier, archiver, sauvegarder, conserver, transmettre au public par télécommunication ou par l'Internet, prêter, distribuer et vendre des thèses partout dans le monde, à des fins commerciales ou autres, sur support microforme, papier, électronique et/ou autres formats.

L'auteur conserve la propriété du droit d'auteur et des droits moraux qui protège cette thèse. Ni la thèse ni des extraits substantiels de celle-ci ne doivent être imprimés ou autrement reproduits sans son autorisation.
In compliance with the Canadian Privacy Act some supporting forms may have been removed from this thesis.

While these forms may be included in the document page count, their removal does not represent any loss of content from the thesis.
Conformément à la loi canadienne sur la protection de la vie privée, quelques formulaires secondaires ont été enlevés de cette thèse.

Bien que ces formulaires aient inclus dans la pagination, il n'y aura aucun contenu manquant. 


\begin{abstract}
The United Nations (UN) Peacebuilding Architecture (the Peacebuilding Commission, the Peacebuilding Support Office and the Peacebuilding Fund) has experienced numerous challenges since its establishment in 2005. Analyses of these challenges have focused primarily on procedural and programmatic aspects. Although important, there has been almost no analysis based upon the institutional context of the Architecture within the UN system. One of the most significant systemic problems confronting the UN is the continued presence of a North-South divide. This thesis therefore analyzes the effects of North-South dynamics on the Architecture and the outcomes in one of its country cases, Sierra Leone. The thesis identifies five significant dimensions to North-South divergence - development, economic practices, aid, sovereignty and the UN system - and applies this framework to the Architecture. Findings suggest North-South divergence is impeding the operations of the Architecture, with strongest effects around development, economic practices and aid. These understandings have important implications for future work of the Architecture and the effectiveness of international organizations with North-South membership.
\end{abstract}




\section{Acknowledgments}

This thesis would not have been possible were it not for the many people I am fortunate to know or to have met while completing this work. All have generously provided me with their invaluable advice, guidance, time and most importantly encouragement.

First, I would like thank my supervisor, Professor James Milner, who eagerly took on the role of mentor. His guidance allowed me to see and critically assess the various layers to my argument, as well as refine and clarify its presentation. Finally, his unfailing enthusiasm helped to sustain my momentum, especially during those challenging moments.

I would also like to thank Professor Chris Brown who offered both his time and advice in guiding me through the composition and process of writing the thesis. His alternative perspectives and suggestions helped to ensure I maintained a balance in the writing process.

To the people who were a part of the interview process, thank you for offering your time and insights into both the Peacebuilding Architecture and Sierra Leone.

Additionally, I am also grateful to my friends and colleagues who offered support in various ways. To Altynai Teshebaeva and Brian Darling who generously allowed me to stay with them and conduct my research out of their home. Also, thank you to my many friends in Ottawa, as well as the many long-time friends from Alberta and British Columbia for their enduring friendship, continual patience and academic advice while I worked through various drafts of the thesis.

Finally, I offer a special and heartfelt thank you to my family, who despite the distance ensured I never felt far away. To my mom, in particular, who listens to everything and always supports me even if it means there will be great distances and risks involved. Thank you for understanding the importance my ambitions hold for me.

Family, friends and colleagues all have been essential to completing this work. Thank you. 


\section{Table of Contents}

Abstract

Acknowledgments iii

Table of Contents $\quad$ iv

Abbreviations vi vi

1 Alternative Influences on and within the Peacebuilding Architecture 1

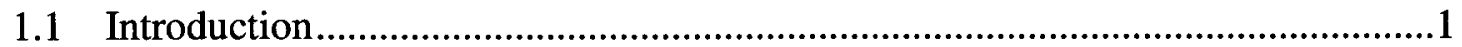

1.2 Research Question and Hypotheses ............................................................5

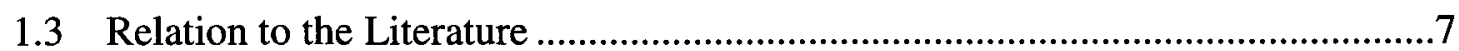

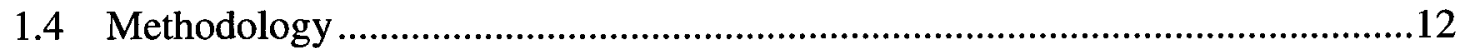

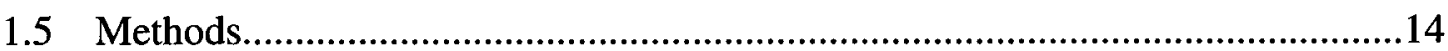

1.6 Defining Complicated Concepts: "Peacebuilding," "North" and "South" ........18

1.7 Outline of Thesis....................................................................................22

2 A Global Dichotomy: The "North" and the "South" 26

2.1 Introduction.................................................................................26

2.2 Development: Responsibilities and Priorities................................................37

2.3 Economic Practices: Setting the Agenda ...................................................40

2.4 Aid: Control, Commitment and Quality ...................................................43

2.5 Sovereignty: Challenging Long-Held Assumptions ........................................46

2.6 UN System: Membership \& Participation, Power Struggles and Leadership ....49

2.7 Chapter Summary ...............................................................................53

3 The Peacebuilding Architecture: Old Influences? 56

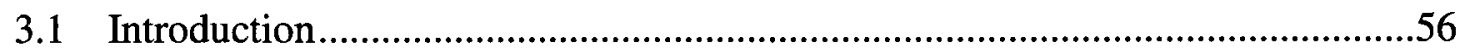

3.2 Development: Where Priorities Lie ..........................................................62

3.3 Economic Practices: Disconnected Agendas ..................................................64

3.4 Aid: Arms-length Control, Minimal Commitments and Quality Concerns........67

3.5 Sovereignty: Early Divisions ............................................................. 70

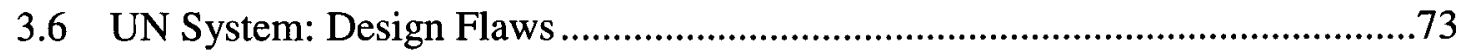

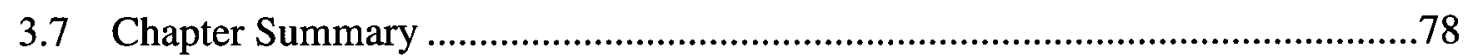

4 Sierra Leone $\quad 81$

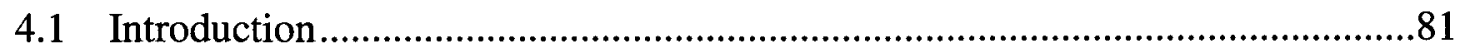

4.2 Development: Only if a Security Threat? .................................................86

4.3 Economic Practices: Cooperation Impeded ...............................................89

4.4 Aid: Limited Access and Reduced Predictability ......................................91

4.5 Sovereignty: Agreement but Mixed Results .................................................94

4.6 UN System: Trickle-Down Effects......................................................96

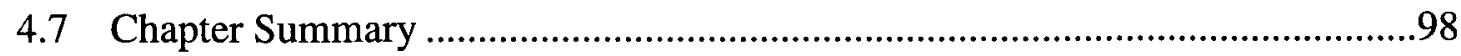


5 Synthesis and Conclusion $\quad 101$

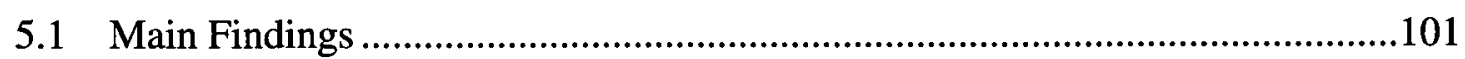

5.2 Implications of Research.......................................................................110

5.3 Concluding Remarks...........................................................................112

References: Interviews $\quad 114$

$\begin{array}{ll}\text { References: Works Cited } & 115\end{array}$ 


\section{Abbreviations}

APC

CSC

CSM

CSO

DfID

DPA

ECOSOC

ERSG

G-77

HDI

IFI

IMF

NAM

NGO

NIEO

OC

OECD

OPEC

P5

PBC

PBCF

PBF

PBSO

PRSP

RUF

SAP

SLA

SLPP

SRSG

TRC

UN

UNDP

UNGA

UNGA/SC

UNHLP

UNSC
All People's Party, Sierra Leone

Country-Specific Configuration, UN Peacebuilding Commission

Country-Specific Meetings, UN Peacebuilding Commission

Civil society organization

Department for International Development, United Kingdom

Department of Political Affairs, UN

Economic and Social Council

Executive Representative of the Secretary-General

Group of 77

Human Development Index

International Financial Institutions

International Monetary Fund

Non-Aligned Movement

Non-governmental organization

New International Economic Order

Organizational Committee

Organization for Economic Cooperation and Development

Organization of the Petroleum Exporting Countries

Permanent 5 of the Security Council

Peacebuilding Commission

Peacebuilding Cooperation Framework, Sierra Leone

Peacebuilding Fund

Peacebuilding Support Office

Poverty Reduction Strategy Paper

Revolutionary United Front

Structural Adjustment Program

Sierra Leone Army

Sierra Leone People's Party

Special Representative of the Secretary-General

Truth and Reconciliation Commission

United Nations

United Nations Development Programme

United Nations General Assembly

United Nations General Assembly/Security Council

UN High-level Panel

United Nations Security Council 


\section{ALTERNATIVE INFLUENCES ON AND WITHIN THE PEACEBUILDING} ARCHITECTURE

\subsection{Introduction}

Peacebuilding is one of today's greatest conflict-related challenges. According to Doyle and Sambanis, since the end of the Cold War the limited number of mixed successes seen in post-civil war countries has been overshadowed by a corresponding number of daunting relapses. ${ }^{1}$ Moreover, notwithstanding the internal implications of civil conflict, these fragile or failing states have at times produced considerable consequences for surrounding countries, as well as far beyond their own borders. Employing effective peacebuilding strategies thus is important at national, regional and international levels. In response, conceptual and practical efforts to understand and improve peacebuilding have seen increased attention and rapid development since its introduction into mainstream conflict management debates following the end of the Cold War. Yet, these efforts have also highlighted the presence of weaknesses and significant difficulties in undertaking peacebuilding. Some of the most recent and prominent practical challenges include issues of poor coordination between actors involved in the post-conflict country, a lack of integration between peacebuilding strategies in critical areas (such as security, development, political, economic or judiciary), insufficient and short-term funding and lack of long-term engagement by significant actors. ${ }^{2}$

\footnotetext{
${ }^{1}$ Michael W. Doyle and Nicholas Sambanis, Making War \& Building Peace, (Princeton: Princeton UP, 2006) 1.

${ }^{2}$ See: Taisier M. Ali and Robert O. Mathews, "Conclusion: The Long and Difficult Road to Peace," Durable Peace: Challenges for Peacebuilding in Africa, Ed. Taisier M. Ali and Robert O. Mathews, (Toronto: U of Toronto P, 2004) 394-5; Charles T. Call, "Ending Wars, Building States" Building States to Build Peace. Ed. Charles T. Call with Vanessa Wyeth. (Boulder: Lynne Rienner Publishers, 2008) 116; Elizabeth M. Cousens, Introduction, Peacebuilding as Politics: Cultivating Peace in Fragile Societies, Ed. Elizabeth M. Cousens and Chetan Kumar, (Boulder: Lynne Rienner, 2001) 2-5; Alexander Costy,"The Peace Dividend in Mozambique, 1987-1997," Durable Peace: Challenges for Peacebuilding in Africa, Ed. Taisier M. Ali and Robert O. Mathews. (Toronto: U of Toronto P, 2004) 171; Anne M. Street et al., "Experiences of the United Nations Peacebuidlling Commission in Sierra Leone and Burundi," Journal of Peacebuilding \& Development, 4.2 (2008) 33-34.
} 
Since the end of the Cold War, the United Nations (UN) has emerged as the leading global actor both to address these peacebuilding problems and to lead peacebuilding initiatives. In the last two decades, it has increasingly become the focal point for peacebuilding, either involved in or leading many international peace efforts. However, its shortcomings in undertaking peacebuilding in post-civil war countries, especially during the 1990s, contributed to questions of its effectiveness and continued utility. ${ }^{3}$ As part of ongoing evaluations both to revitalize the organization and to improve its operations, assessments of its role in peacebuilding emerged. In particular, it was determined that 'nowhere in the organization did there exist a department or body to deal specifically with peacebuilding and its unique needs. ${ }^{4}$ In response, the UN Peacebuilding Architecture was established in late 2005 with three components: the Peacebuilding Commission (PBC), the Peacebuilding Support Office (PBSO) and the Peacebuilding Fund (PBF). ${ }^{5}$ The work of the main body, the Commission (supported by the PBSO and the PBF), is mandated by three fundamental objectives in large part to address the abovenoted peacebuilding issues. First, it is to coordinate relevant actors and help marshal resources. Second, it focuses on reconstruction and institution building, while also suggesting methods to integrate various recovery strategies that support continual development. Third, it is to offer advice and suggestions on peacebuilding strategies, help to establish predictable financing and aim to increase long-term international attention. ${ }^{6}$

\footnotetext{
${ }^{3}$ David M. Malone and Lotta Hagman, "The North-South Divide at the United Nations: Fading at Last?" Security Dialogue 33.4 (2002): 399. There were many long-standing issues that contributed to concerns around the organization that are beyond the scope of this thesis; however, its inability to maintain peace and security - its primary purpose - in various instances was a significant component to criticisms of the organization.

${ }^{4}$ United Nations Report of the Secretary General's High-level Panel on Threats, Challenges and Change (UNHLP), A More Secure World: Our Shared Responsibility, (New York: UN Department of Publice Information, 2004) par. 261 and art. XV.

${ }^{5}$ The specifics of these three components will be presented in Chapter 3.

${ }^{6}$ United Nations General Assembly (UNGA), Resolution A/RES/60/180, 30 Dec. 2005: par. 2; United Nations Security Council (UNSC), Resolution S/RES/1645 (2005), 20 Dec. 2005: par. 2. Since both resolutions are identical in content, only the General Assembly resolution subsequently will be referenced unless otherwise noted.
} 
Despite these objectives to address several peacebuilding problems and improve UN responses to post-conflict countries, the Architecture's impact has not lived up to expectations. In its short existence it has faced many challenges to carrying out its peacebuilding objectives, including slow decision-making, confrontations with other actors, insufficient funds raised, limited results translated to the country level and more importantly, a recurrent characterization that it lacks substantial 'added value.' Although important and significant to understanding impediments to the ability of the Architecture to carry out its objectives; the majority of these issues have been analyzed based upon procedural and programmatic aspects. ${ }^{7}$ There has been almost no analysis of the effects of the institutional and political setting of the Peacebuilding Architecture and the impact of this setting on the peacebuilding work of the Architecture.

The Architecture's emergence, development and ultimate success is, at least partially, dependent upon its placement within the United Nations, an organization affected by a broad list of internal problems, often impeding its many operations. ${ }^{8}$ Of these, one of the longest standing systemic issues has been a division between Northern industrialized states and Southern developing states, often referred to as the 'North-South divide. ${ }^{9}$ Generally speaking, each side tends to disagree over the way in which the

${ }^{7}$ See: ActionAid et al., Consolidating the Peace? Views from Sierra Leone and Burundi on the United Nations Peacebuilding Commission, June 2007, ActionAid, Web, 9 Mar. 2009: 2-3; Street et al., 2008, 33; CERI Program for Peace and Human Security (CPHS), Integrating for Peace: A Reflection on the Peacebuilding Commission's Strategies for Integration, Conf. Report, Paris, 7 Nov. 2007: 7-13; Rob Jenkins, "The UN Peacebuilding Commission and the Dissemination of International Norms," Crisis States Research Center, Crisis States Research Center and the London School of Economics, Working Paper 38.2, (2008) 3; Tim Murithi, "Peacebuilding or 'UN-Building'? African Institutional Responses to the Peacebuilding Commission," Journal of Peacebuilding \& Development 4.2 (2008): 90; NYU Center on International Cooperation and the International Peace Institute (NYU CIC and the IPI), Taking Stock, Looking Forward: A Strategic Review of the Peacebuilding Commission, April 2008: 2.

${ }^{8}$ See: Thomas G.Weiss, What's Wrong with the United Nations and How to Fix It, (Malden, MA: Polity, 2009) 1-16.

${ }^{9}$ See: Stephen D. Krasner, Structural Conflict: The Third World Against Global Liberalism, (Berkeley: U of Calfornia P, 1985) 26; Soo Yeon Kim and Bruce Russett, "The New Politics of Voting Alignments in the United Nations General Assembly," International Organization 50.4 (1996): 629-30; Malone and Hagman, 2002, 408-410; John Ravenhill, "The North-South Balance of Power," International Affairs 66.4 (1990): 732. 
international system is managed, especially through the work of the UN. ${ }^{10}$ Over the years, these divisions have played out within the UN as each side has frequently used their influence to oppose or override the other's objectives, preventing many UN bodies and agencies from making decisions or performing their intended functions. In particular, through a critical examination of the literature the author has identified five dimensions in which these divisions typically occur: development, economic practices, sovereignty, aid and the internal operations and structure of the UN system. ${ }^{11}$ Equally important, these five dimensions were found to all have significant links to and strong bearing upon postconflict peacebuilding. At the same time, there also have been some instances of convergence that have produced important and positive results; each side forming alliances in specific areas such as anti-apartheid actions, the ban on anti-personal landmines or the formation of the International Criminal Court. ${ }^{12}$ Nonetheless, disagreements and confrontations around the five dimensions appear to dominate and hinder many UN deliberations and operations.

In recent years, however, there have been arguments that the North-South divide has largely disappeared within the UN. ${ }^{13}$ Yet, it appears that the divide instead continues under other titles such as 'globalization,' making use of terms such as developeddeveloping or industrialized-underdeveloped. ${ }^{14}$ Furthermore, the Peacebuilding Commission was in part designed to deal with this very issue, where the Resolution document establishing the PBC called for equal representation of Northern and Southern members. ${ }^{15}$ Not only does this suggest that the North-South divide continues, but that there is concern that it will affect the operations of the Commission.

\footnotetext{
${ }^{10}$ The origins and development of this position will be explored in detail in Chapter 2.

${ }^{11}$ The identification of these five dimensions will be explored in Chapter 2.

${ }^{12}$ Malone and Hagman, 2002, 408, 410.

${ }^{13}$ Malone and Hagman, 2002, 408; Jean-Philippe Thérien, "Beyond the North-South Divide: The Two Tales of World Poverty," Third World Quarterly, 20.4 (1999): 727.

${ }^{14}$ This will be explained further within Chapter 2.

${ }^{15}$ UNGA, Resolution A/RES/60/180, 2005, par. 4.
} 
There has been surprisingly little analysis of the Peacebuilding Architecture within this broader context. As Murithi points out, "Like all other bureaucracies, the UN system has a genetic propensity towards its self-replication, multiplication and expansion." 16 This suggests that North-South issues inherent to the system are likely to be reproduced around and within the Architecture, putting it at risk of the same challenging and often paralyzing effects. Taking into consideration that North-South divisions afflict the operations and outcomes of the UN and many of its bodies, that the PBC was in part designed to address North-South issues, and that five of the most problematic dimensions of North-South divergence are strongly connected to peacebuilding activities, it is important to examine whether the institutional and political context of the Architecture is impeding its ability to perform its peacebuilding objectives.

\subsection{Research Question and Hypotheses}

Given the potential significance of the North-South divide within the UN system on the work of the UN Peacebuilding Architecture, this thesis asks two related questions: First, what has been the prevailing state of North-South relations within the UN system? Second, what are the effects of North-South relations on the operations and outcomes of the new Peacebuilding Architecture of the United Nations? This thesis argues that NorthSouth relations within the UN system can be characterized by divergence and convergence around a number of issue areas, the most significant being: development, economic practices, aid, sovereignty and the UN system. Building from a critical examination of these five dimensions, this thesis argues that the Peacebuilding Architecture has been affected by North-South dynamics both endogenously (from within the Architecture) and exogenously (from the greater UN system). Furthermore, this thesis argues that these North-South dynamics affect the work of the Architecture differently at

\footnotetext{
${ }^{16}$ Murithi, 2008, 90.
} 
the institutional level and at the country level, suggesting characteristics of the nature of the impact of North-South relations.

Recognizing the significant impact that North-South confrontations and agreements have had on the operations of the UN through much of its history, it is unlikely that the Peacebuilding Architecture will be an exception to this influence. This thesis argues that any examination of the Architecture must take into consideration the institutional environment to which it is embedded, the United Nations, as well as the often highly politicized nature of North-South dynamics on its operations. Moreover, this thesis argues that the five dimensions frequently at the core of North-South tensions also form integral components to post-conflict peacebuilding, further exposing the Architecture to disagreements and divisions. Although the Architecture has undergone several valuable examinations, the focus has been largely around its procedural and programmatic aspects; there has been little discussion around the systemic effects of North-South divisions within the UN organization on the three bodies. In response to this important gap in the literature, this thesis will examine how these North-South dynamics may offer an alternative explanation to both challenges and outcomes related to the new Architecture.

At the same time, while North-South divisions within the UN appear to continue today, they were originally shaped during the Cold War period. However, the creation of the Architecture well after the Cold War may demonstrate differences in North-South dynamics as originally understood. This thesis therefore also seeks to investigate whether the experiences of the Peacebuilding Architecture contribute to new understandings of North-South engagement. This thesis argues that five significant dimensions of the North-South divide can be identified, and that these dimensions can usefully be employed to analyze critically the Peacebuilding Architecture. This represents another original 
contribution to this study, as this framework of North-South tensions has not been previously described as such within the literature.

Historically, these North-South dynamics frequently have been characterized as confrontations and disagreements. As discussed below, the North-South literature suggests that these divergences have hindered the capabilities of UN bodies, at times preventing decision-making or from taking action. By critically examining the work of the Peacebuilding Architecture at the institutional and country levels, this thesis will illustrate how such instances of North-South divergence have impeded the ability of the Peacebuilding Architecture to carry out its objectives and perform its operations. It is important to note, however, that the literature also suggests that moments of North-South convergence do sometimes occur. Here, when each side has managed to overcome differences by finding common ground, UN bodies have been better able to fulfill their mandates. Thus, this thesis will additionally consider how instances of North-South convergence are less likely than instances of divergence, but if present will improve the ability of the Peacebuilding Architecture to carry out its objectives and perform its operations.

\subsection{Relation to the Literature}

As noted above, this thesis seeks to make three key contributions to the literature by developing more critical understandings of North-South dynamics and the Peacebuilding Architecture. The first contribution is to help address an important gap in the current scholarly analyses of the Architecture. The majority of the literature has been centered upon evaluation of procedural and programmatic components, that is, the technical operations of the Architecture. Several works, for instance, examine how well 
the Architecture is meeting the objectives of its mandate, ${ }^{17}$ while others have focused on the impact it is making within its country cases. ${ }^{18}$ These analyses are expected given the newness of the three bodies and the need to make early assessments, strategize and help develop each of their peacebuilding roles. However, there is practically no analysis of the effects of North-South dynamics within the UN system upon the Architecture. ${ }^{19}$ This absence is critical considering the institutional setting and the organization's long history of North-South tensions.

Some authors, such as Malone and Hagman or Thérien, argue that the NorthSouth divide is non-existent or irrelevant in the post-Cold War era, ${ }^{20}$ which may largely explain this missing analysis. Yet Hewson argues that "Several cycles... between [NorthSouth] unity and division, have been prominent over the course of the UN's past." ${ }^{21} \mathrm{He}$ states that recently there was a long period of unity from the end of the Cold War until the 2003 US invasion of Iraq, which saw the re-emergence of divisive divisions within the UN. While this long period of reduced tensions also may have partly contributed to the lack of North-South analysis, Chapter 2 of this thesis will highlight this cyclical pattern of North-South divisions and argue for their continued impact on the UN system. Given the lack of analysis of the effects of institutional North-South divisions on the peacebuilding work of the Architecture, this thesis' critical examination of this relationship represents one original contribution to the literature.

${ }^{17}$ See CPHS, 2007; International Peace Institute (IPI), "The UN Peacebuilding Commission: Benefits and Challenges," 6 June 2006; David M. Malone, "UN Reform: A Sisyphean Task," Canada Among Nations: Minorities and Priorities, Ed. Andrew F. Cooper and Dane Rowlands, (Montreal: McGillQueen's UP, 2006); C.S.R. Murthy, "New Phase in UN Reforms: Establishment of the Peacebuilding Commission and Human Rights Council," International Studies 44.1 (2007); Amy Scott, "The United Nations Peacebuilding Commission: An Early Assessment," Journal of Peacebuilding \& Development, 4.2 (2008).

${ }^{18}$ See ActionAid et al., 2007; NYU CIC and the IPI, 2008,; Street et al., 2008.

19 A few works make mention of North-South issues, but no extensive exploration, although Jenkins, 2008, does take it the furthest with his examination of North-South differences in international norms. See Jenkins, 2008,; NYU CIC and the IPI, 2008; Scott, 2008,.

${ }^{20}$ Malone and Hagman, 2002, 408; Thérien, 1999, 727.

${ }^{21}$ Martin Hewson, "The UN After Sixty Years: Progress or Recurrence?" Journal of Military and Strategic Studies 8.1 (2005) n. pag. 
Second, this thesis seeks to contribute to the literature on North-South relations within the UN system. Although there have been significant discussions around the understandings of North-South divisions, as discussed below, the breadth of its exploration has been limited and has tapered off since the end of the Cold War. ${ }^{22}$ The $^{2}$ majority of analyses discuss critical moments of division and the potential reasons behind them, ${ }^{23}$ which benefited the author in defining the five dimensions of division, while other important works have analyzed the broader picture of North-South divisions and reforming the UN to respond to these problems. ${ }^{24}$ Furthermore, authors such as Krasner argue that as long as the South views the international system as unfair, Southern countries will continue to use the UN and other international organizations as vehicles to press for favourable changes. ${ }^{25}$ Additionally, if, as Hewson argues, the UN is currently in another cycle of North-South division, then this research is also timely and pertinent as it both re-engages with and develops further the North-South literature. Specifically in the latter, although existing scholarly works analyze different components to North-South

${ }^{22}$ For critical works on North-South divisions, see: Roger D. Hansen, Beyond the North-South Stalemate, (New York: McGraw-Hill Book Company, 1979); Krasner, 1985,; Malone and Hagman, 2002, 408-410; Ravenhill, 1990,; and Thérien, 1999,; or, for a quantitative analysis of voting patterns amongst states, see: Hayward Alker, Jr., "Dimensions of Conflict in the General Assembly," American Political Science Association 58.3 (1964); Steven K. Holloway and Rodney Tomlinson, "The New World order and the General Assembly: Bloc Realignment at the UN in the Post-Cold War World," Canadian Journal of Political Science / Revue canadianne de science politique, 28.2 (1995); Kim and Russett, 1996,.

${ }^{23}$ Although the majority of authors analyzed issues related to all five dimensions, most focused on one or two aspects for specific discussions. For example, in development see Hewson, 2005,; Thérien, 1999,; for economic practices see Krasner, 1985,; Kunibert Raffer and H.W. Singer, The Economic NorthSouth Divide: Six Decades of Unequal Development, (Northampton, MA: Edward Elgar Publishing, 2001); for Sovereignty see Krasner, 1985,; Malone and Hagman, 2002,; for aid see Raffer and Singer, 2001,; and for the UN system see Malone, "UN Reform," 2006; Thomas G. Weiss et al., 2001, The United Nations and Changing World Politics, 3rd ed. (Boulder: Westview Press, 2001); or, for works on particular areas of the UN see, for instance, Javier Pérez de Cuéllar, "The Role of the UN Secretary-General" United Nations, Divided World: The UN's Roles in International Relations, Ed. Adam Roberts and Benedict Kingsbury. 2nd. (New York: Oxford UP, 1993) on the Secretary-General; M. J. Peterson, "General Assembly," The Oxford Handbook on the United Nations, Ed. Thomas G. Weiss and Sam Daws, (New York: Oxford UP, 2007) on the General Assembly; or David M. Malone, "Security Council," The Oxford Handbook on the United Nations, Ed. Thomas G. Weiss and Sam Daws, (New York: Oxford UP, 2007)."

${ }^{24}$ For analysis of UN reform and North-South divisions see Maurice Bertrand, "The Historical Development of Efforts to Reform the UN," United Nations, Divided World: The UN's Roles in International Relations, Ed. Adam Roberts and Benedict Kingsbury, 2nd ed, (New York: Oxford UP, 1993) or Malone, "UN Reform," 2006."

${ }^{25}$ Krasner, 1985, 14-16. 
divisions, no author has synthesized a general conceptual framework of the North-South divide within the UN system. A framework not only helps to improve the analysis of North-South dynamics by identifying key points of potential division or convergence, in this case the five dimensions (development, economic practices, aid, sovereignty and the UN system), it offers more flexibility in analyzing divisions across different areas, such as the Peacebuilding Architecture. Therefore, this thesis seeks to address gaps within the North-South literature by making connections to UN peacebuilding, but equally as important, offers another original contribution to the field by providing a general framework for understanding North-South dynamics within the UN system.

Third, this thesis will contribute to the literature on the Peacebuilding Architecture and its peacebuilding activities. Examinations of the Architecture, being a new UN entity, inevitably have been limited; therefore, this research will help to deepen existing understandings. ${ }^{26}$ Moreover, analysis through the political lens rather than the existing dominant technical lens will contribute to broadening the literature, presenting alternative explanations and approaches to improving the performance of the Architecture. In connection to this, a study of the Architecture and its role in peacebuilding will also help to fill gaps in the peacebuilding literature. Within the literature, many questions around peacebuilding remain, such as sequencing of activities; how to integrate security, development, economics and governance; or how to improve

${ }^{26}$ For instance, existing scholarly analysis is relatively small, where only a limited number of key works were found, such as those by Jenkins, 2008,; Murithi, 2008,; Murthy, 2007,; Scott, 2008,; Street et al., 2008,; Weiss, 2009; and is complemented by only a handful of NGO and think tank assessments. 
coordination between multiple peacebuilding actors. ${ }^{27}$ For instance, the Architecture is an important component to helping achieve so-called "positive peace," that is, the ability of a post-civil war society to develop the appropriate mechanisms to self-sustain their peace. ${ }^{28}$ Yet, within this positive peace, both Cousens and Barnett et al. describe a 'supply' vs. 'demand' approach to peacebuilding, where actors will define peacebuilding on what they can supply (i.e. their mandates, objectives and resources) compared to others who define the post-conflict situation based on needs (i.e. disarmament, demobilization and reintegration needs; re-establishing rule of law, etc.). ${ }^{29}$ The Architecture becomes the connection between these two sides, appealing to actors for support (supply) while working with the post-conflict country to determine what it needs (demand). Therefore, analysis of the political and institutional context of the Architecture may help to expand on this and other areas within the study of peacebuilding.

${ }^{27}$ See Michael Barnett et al., "Peacebuilding: What Is in a Name?" Global Governance 13.1 (2007); James Busumtwi-Sam et al., "Structural Deficits and Institutional Adaptations to Conflict and Peacebuilding in Africa," Durable Peace: Challenges for Peacebuilding in Africa, (Toronto: U of Toronto P, 2004); Charles T. Call, "Knowing Peace When You See It: Setting Standards for Peacebuilding Success," Civil Wars 10.2 (2008); Cousens, 2001,; Francis Fukuyama, State-Building: Governance and World Order in the 21st Century, Ithaca, NY: Cornell UP, 2004; Krishna Kumar, Rebuilding Societies After Civil War: Critical Roles of International Assistance, Boulder, CO: Lynne Rienner Publishers, Inc., 1997; John Lederach, Building Peace: Sustainable Reconciliation in Divided Societies, (Washington: United States Institute of Peace P, 1997); Roland Paris, At War's End: Building Peace After Civil Conflict, (New York: Cambridge UP, 2004).

${ }^{28}$ Whereas negative peace is simply the absence of conflict. Call, "Ending Wars," 2008, 6; Cousens, 2001, 13; Johan Galtung, "Three Approaches to Peace: Peacekeeping, Peacemaking, and Peacebuilding." Peace, War and Defense, Vol. 2. (Copenhagen: Christian Ejlers, 1976) 297.

${ }^{29}$ Barnett et al., 2007, 45-48. Similarly, Cousens, 2001, explains supply-demand as deductiveinductive (Cousens, 2001, 5-10). 


\subsection{Methodology}

In order to investigate the effects of North-South relations on the work of the Peacebuilding Architecture, this study was principally guided by political science methodology, in addition to the broader literature on methodology in the social sciences. $^{30}$ The overall aim of the research is explanatory in nature, intended to investigate the effects of North-South dynamics in and around the UN Peacebuilding Architecture and one of its country cases, Sierra Leone. ${ }^{31}$ This study thus uses an inductive approach, as it is attempting to explain a phenomenon affecting the operations of the Architecture, where no existing theory exists. It is based upon a qualitative approach encompassing three units of analysis, one of which includes a single case study. ${ }^{32}$ The primary unit is the Peacebuilding Architecture, while the two secondary units are the UN - to establish the foundations of key North-South divisions - and Sierra Leone - to analyze North-South effects within the context of a country case on the agenda of the Architecture. In this last unit, the decision to employ a case study and the choice of a single case study over a comparative case study methodology was the result of a number of considerations.

To begin, the choice to use a case study was necessary for two reasons. First, the objective of this research is to examine how North-South dynamics are affecting the ability of the Architecture to carry out its mandates. This analysis is enhanced by considering the actions and decisions of the Architecture at both the institutional level

${ }^{30}$ See: Martyn Denscombe, Ground Rules for Good Research: A 10 Point Guide for Social Researchers, Philadelphia: Open University P., 2002; Harry Eckstein, "Case Study and Theory in Political Science," Handbook of Political Science: Strategies of Inquiry. Eds. Fred I. Greenstein and Nelson W. Polsby. Vol. 7. London: Addison-Wesley Publishing Co., Inc., 1975; David E. McNabb, Research Methods for Political Science: Quantitative and Qualitative Methods, Armonk, NY: M.E. Sharp Inc., 2004; Robert K. Yin, Case Study Research: Design and Methods,. $3^{\text {rd }}$ ed. (Thousand Oaks, CA: Sage Publications, Inc., 2003).

${ }^{31}$ Note that in general, the use of the term 'country case' refers to the countries on the agenda of the 'PBC.' However, this thesis will generalize the term country case as being on the agenda of the Architecture. It is within reason to extend this application to the PBF and PBSO given that they support or compliment the PBC.

${ }^{32} \mathrm{McNabb}, 2004,105-106$; Yin, 2003, 22-25, 39. 
and at the country level. Second, analysis at the country level helps to consider and/or eliminate other potential influencing factors beyond the Architecture, which will help to strengthen conclusions. For instance, the occurrence of a North-South division in the Architecture does not mean that it will have an effect at the country level.

While the incorporation of a case study was consequently found to be an important component of the methodology of this thesis, it was important to consider the relative merits of a single case study versus a comparative case study approach. There are both benefits and limitations to using a single case study. Eckstein argues for the "crucial case" - that it can be more informative than a comparative case study (which he considers as supporting evidence to the single case) - in an attempt to offer evidence that counters or disproves a "candidate theory." 33 Likewise, $\mathrm{McNabb}$ states that a single case may be "superior" in nature to other cases. ${ }^{34}$ The use of a single case in this study, however, is not a not a crucial case and does not fit the criteria in either of these instances. Instead, the choice of a single case study over a comparative case study approach was principally the result of the nature of the question posed by this thesis - the primary objective being to examine the Architecture at both the institutional and the country level - and the limits of time and resources, which reduced the ability of the researcher to explore other country cases.

The selection of Sierra Leone itself as the single case to view decision-making within the Architecture was determined by a combination of factors. To begin, the choice was partly limited by the newness of the Architecture and thus, the limited number of cases available for study. Having only four country cases on its agenda, two of which being added only recently, Sierra Leone and Burundi were the only cases with substantial involvement and experience. They were the first two country cases placed on the PBC's

33 Eckstein, 1975, 93-94, 118. Eckstein, 1975, explains that candidate theories cannot be considered 'law.'

${ }^{34} \mathrm{McNabb}, 2004,368$. 
agenda during its launch in 2006. The study was therefore largely limited to a choice between only two cases. Additionally, the researcher had easier access to interviewees involved in the Sierra Leone peace process, in large part due to the principle language of interviewees connected to Sierra Leone was English.

The use of a single case study, however, brings inherent limitations in the ability to generalize to other case studies. ${ }^{35}$ Even so, as Yin explains, “... a single case study is analogous to a single experiment, and many of the same conditions that justify a single experiment also justify a single-case study." ${ }^{36}$ Thus, a well-conducted single case study can still reveal important understandings. It is expected that the study of Sierra Leone will help to establish initial understandings of North-South effects on UN peacebuilding at the country level, which could then be usefully developed through the future consideration of other cases.

Finally, to improve the rigour and breadth of this research, examinations of NorthSouth influences upon the Architecture were made from two different sources. Analysis has included both external effects (those originating from the UN system) and internal effects (those being replicated from within the Architecture). North-South influences were also examined from two different periods. Analysis has included effects during the conceptualization and lead-up to the establishment of the Architecture; as well as considers the actions and operations in and around the Architecture since its inception. These two approaches will help to clarify the source of North-South effects and at what times effects have been strongest.

\subsection{Methods}

The primary sources of information for this thesis were the UN documents and resolutions, secondary literature, and grey literature of NGO reports, while primary

${ }^{35}$ Denscombe, 2002, 152-54; Yin, 2003, 53-54.

${ }^{36}$ Yin, 2003, 39. Yin, 2003, goes onto explain that there may be other justifiable reasons to undertake a single case study, but that they require careful investigation to minimize errors of analysis (42). 
research in the form of interviews provided important supporting information. To begin the research, a literature review was conducted in four areas, three of them corresponding to the three units of analysis. In the first areas, preliminary research began with a literature review on peacebuilding. Here a gap in the literature was discovered between the North-South divide and peacebuilding, eventually forming the basis of the research question. Following this, a literature review was conducted on scholarly works of the first unit of analysis, North-South dynamics within and outside of the UN from its founding in 1945 to the present. Although the literature was not expansive, existing works allowed the author to identify five key areas of North-South divergence. These five areas development, economic practices, aid, sovereignty and the UN system - are thus the independent variables for this research. They will be used to analyze the presence of North-South divisions within the Architecture, the dependent variable, and will consider the effects at both the country level and institutional level. Chapter 2 is devoted to the examination of the five independent variables and lays out in greater detail the process and effects of the North-South dimensions within the UN. Chapter 3 examines the effects on the dependent variable, the Architecture, at the institutional level, while Chapter 4 examines the effects on the Architecture at the country level, in Sierra Leone.

Next, a review of the literature on the PBC, PBSO and PBF was conducted revealing very limited information on the three bodies (especially that of the PBSO and the PBF), but also a exposing a gap in analysis of the effects of the institutional setting on their operations. In order to help fill in gaps, UN documents (in particular meeting summaries), non-governmental organization (NGO) reports and round table discussions were also included as sources of debates and secondary interviews, but in particular for analysis of discussions during decision-making sessions. Combined with interviews (discussed below) these will be the basis of analysis for Chapter 3. 
A literature review on the remaining unit of analysis, the Sierra Leone case study, revealed problems similar to that found with the review of North-South literature. In particular, a relatively small number of scholarly works depicting the experiences of Sierra Leone and Burundi - and little on Sierra Leone by itself - with the Peacebuilding Architecture were present. The same process for improving research on the Architecture was used for gathering research on Sierra Leone, i.e. reviewing UN documents, NGO reports, interviews, but also added to the review were government documents.

Interviews formed the secondary source of data gathered for this thesis. ${ }^{37}$ As opposed to random sampling, interviews were conducted with eight individuals who were chosen for two key reasons: first, for their expertise and intricate connections to either the Architecture or Sierra Leone, and second, for their availability and willingness to be interviewed. ${ }^{38}$ The majority included those directly involved with the Architecture within the UN, while others had either done work with the Architecture or conducted work in Sierra Leone. Furthermore, their perspectives of the various interviews spanned the period prior to the establishment of the Peacebuilding Architecture in 2005-06 to the present.

The majority of interviews were conducted in New York at the UN, the offices of Permanent Missions to the UN or of the International Peace Institute, while the remaining interviews were conducted by telephone. Semi-structured interviews using open-ended questions were used, ${ }^{39}$ focusing largely on the decisions made by those involved in the Architecture, the reasoning behind decisions and actions and challenges and accomplishments. All interviewees gave permission to be sourced (refer to Interviewees

${ }^{37}$ This research received Ethics approval from Carleton University in March of 2009.

${ }^{38}$ Denscombe, 2002, explains that as opposed to taking a large sample, selections may be based upon "strategic decisions" to focus on sources of greater relevancy and depth to the study, being mindful of using other techniques such as triangulation (146-48).

${ }^{39}$ Yin, 2003, 90. 
in the References section), however some requested that particular comments were made non-attributable; therefore, all comments have been made anonymous within the thesis. ${ }^{40}$

A noteworthy limitation to the interviews conducted was the inability to secure interviews with actors from Southern states. The author made several unsuccessful attempts to contact individuals from both the Sierra Leone Mission and other Southern countries involved in either the PBC or the Sierra Leone country configuration. Furthermore, financial constraints prevented the author from conducting field research in Sierra Leone, although interviews provided the insights of individuals who had worked at a field level in Sierra Leone.

In order to address the above limitations and reduce the potential for bias, ${ }^{41}$ given the limited literature available as well as the small number and Northern-based sources of interviewees, the study made use of the process of triangulation. ${ }^{42}$ Information gathered, both within the scholarly literature and from interviewees was compared and contrasted between each other, as well as with NGO reports and government and UN documents. Interviews had a strong potential to represent only a Northern viewpoint; therefore, documents and NGO reports (particularly those that were based on country level interviews) provided an additional point of reference. ${ }^{43}$ Additionally, the choice to rely on written works was both necessary due to limitations in gathering interviews and critical since UN documents recorded deliberations during meetings, identifying Northern and Southern speakers.

Overall, this combination of literature review and interviews was found to be the most appropriate means of addressing the central questions of this thesis within the

${ }^{40}$ As Yin, 2003, suggests, when attempting to ensure appropriate documentation, a "chain of evidence" was maintained through the use of labels coded to identify sources in the author's research notes (105-106).

${ }^{41}$ Denscombe, 2002, 160-62; Yin, 2003, 61-62.

${ }^{42}$ Denscombe, 2002, 104; Yin, $2003,97$.

${ }^{43}$ Denscombe, 2002, notes that this represents only one type of validity. Triangulation only presents 'alternative perspectives' that are not necessarily known facts. Furthermore, the information gathered has better potential to be verified by others (104-5). 
constraints of time and resources inherent in Master's-level research. Although limitations are present, they have been accounted for within the methodology in order to conduct this study around the two research questions posed. Furthermore, the identification of five key dimensions (development, economic practices, aid, sovereignty and the UN system) helps both to connect the examination of the various units of analysis (institutional level and country level) and improve consistency in approach.

\subsection{Defining Complicated Concepts: "Peacebuilding," "North" and "South"}

Investigating the relationship between North-South divisions within the UN system and the Peacebuilding Architecture, as well as the potential effects on Sierra Leone's peace process requires defining the concepts "peacebuilding," "North" and "South." It is not the intention of this thesis to engage with the broader debates surrounding 'what is peacebuilding' and 'what constitutes the North and the South,' which are extensive; but instead to look at if and how peacebuilding within the Architecture is affected by the North-South environment within the UN. Thus, for the purposes of this thesis, this section seeks to provide a general conceptualization of these concepts in order to engage with the objectives of this research.

The term "peacebuilding" has varied meanings and applications amongst scholars and practitioners. At best, there is a common thread of agreement that peacebuilding is not passively obtained, but that actions (usually external interventions) are undertaken to promote positive peace as described above. ${ }^{44}$ At worst, definitions are vague and contradictory. ${ }^{45}$ Galtung first introduced the concept of peacebuilding as positive peace,

${ }^{44}$ See: Barnett et al., 2007, 37, 42; Cousens, 2001, 13; Hevina Dashwood, "Zimbabwe and Sustainable Peace," Durable Peace: Challenges for Peacebuilding, Ed. Taisier M. Ali and Robert O. Mathews. (Toronto: U of Toronto P, 2004) 244; Michelle I. Gawerc, "Peace-building: Theoretical and Concrete Perspectives," Peace \& Change 31.4 (2006): 438-39.

${ }^{45}$ See Barnett et al., 2007,'s work, "Peacebuilding: What's in a Name?" which provides a study of the term peacebuilding and its differing use within state and intergovernmental bodies. In addition to the above, they discovered that peacebuilding concepts frequently focused on the early recovery stage and causes of conflict. Despite the increased exposure and presence of peacebuilding in the international community, it was also noted that funding to support peacebuilding was significantly less than other areas. 
but it was the UN Secretary-General's report, An Agenda for Peace: Preventive Diplomacy, Peacemaking and Peace-Keeping, which advanced peacebuilding to the fore of international discussions. ${ }^{46}$ The document was drafted in response to the dramatic increase in the number of civil wars following the end of the Cold War. Within it, a strong precedent was set where peacebuilding was an 'international responsibility' that would occur 'after a peace agreement' was reached and 'peacekeeping had stabilized' the state. As Cousens explains, this provided a basis from which to start from; however, it also had several limitations and assumptions. ${ }^{47}$ Peacebuilding continued to evolve, and experienced another significant shift after 11 September 2001. Call argues that peacebuilding was no longer only about post-conflict states; it was incorporated into a broader scope of 'failing' and 'fragile' states. Peacebuilding in many areas shifted to become equated with 'statebuilding.' 48 Today, definitions for peacebuilding largely depend upon who is employing the term and the nature of the conflict it is attempting to address. $^{49}$ It is however generally agreed that peacebuilding involves 'external interventions that avert a return to conflict. ${ }^{50}$ According to Barnett et al, the three common links are establishing stability, restoring basic functioning state institutions and dealing with the 'socioeconomic' issues connected to the conflict. ${ }^{51}$ Within these areas, peacebuilding is the establishment of 'legitimate authorities' and a society that is able to handle its internal differences peacefully. ${ }^{52}$

${ }^{46}$ See: Call, "Ending Wars," 2008, 4-5; Gawerc, 2006, 439; Galtung, 1976, 282-304; Lederach, 1997,; United Nations Secretary General (UNSG), An Agenda for Peace: Preventive Diplomacy, Peacemaking and Peace-Keeping, A/47/277-S/24111, 1992: par. 55-56.

${ }^{47}$ For example, Cousens, 2001, notes that the Agenda placed peacebuilding as the final phase of the peace process and it made peacebuilding so broad that it was difficult to identify individual objectives and processes to follow (6-7).

${ }^{48}$ Call, "Knowing Peace," 2008, 184-85.

49 For instance, the International Monetary Fund has a distinctly different definition of peacebuilding - "Activities to restore assets and production levels in the disrupted economy" - than does the US Agency for International Development - "Immediate interventions to build momentum in support of the peace process including supporting peace negotiations; building citizen security; promoting reconciliation; and expanding democratic political processes" (See Table 1, 38-39 in Barnett et al., 2007,).

${ }^{50}$ Barnett et al., 2007, 36.

${ }^{51}$ Barnett et al., 2007, 49-50.

${ }^{52}$ Barnett et al., 2007, 50; Call, "Knowing Peace," 2008, 185; Cousens, 2001, 12. 
Although the terms North and South have been around somewhat longer than peacebuilding, they, too, did not originate with the formation of the United Nations. However, the divisions they represent have been a feature of the UN for most of its existence. During the early years of the organization, the very first lines of division between the North and the South to a certain extent were framed as a colonial-postcolonial dichotomy, as newly independent Southern states looked to their previous colonizers for support. ${ }^{53}$ In the 1960 s, the terms center-periphery came into wider usage as the two main organizing bodies of the South, the Group of 77 (G-77) and the NonAligned Movement (NAM), came to symbolize the periphery states. ${ }^{54}$ It was the $1970 \mathrm{~s}$ when the terms 'North' and 'South' emerged, but came into wider usage through the 1980 report North-South: A Programme for Survival produced by the Brandt Commission. The Commission had spent several years analyzing global poverty culminating in the report (and subsequent report, Common Crisis) which outlined reforms to 'better integrate the Third World into the international economy. ${ }^{55}$ The majority of underdeveloped poor countries resided in the South while the majority of industrialized wealthy countries resided in the North. Furthermore, the Brandt Report not only defined two separate global regions, but also, it furthered the terminology to recognize the interdependent nature between the North and the South. ${ }^{56}$

Dividing the world into two global groups based on location has the potential to be overly generalized and partly inaccurate. For instance, during the Cold War period, the

${ }^{53}$ Hewson, 2005, n. pag.; Kim and Russett, 1996, 630.

${ }^{54}$ The specifics and importance of these two groups will be discussed within Chapter 2. Kenneth Dadzie, "The UN and the Problem of Economic Development," United Nations, Divided World: The UN's Roles in International Relations, Ed. Adam Roberts and Benedict Kingsbury, 2nd ed. (New York: Oxford UP, 1993): 300-1; Raffer and Singer, 2001, 35.

${ }_{55}$ Commission for Africa, Our Common Interest: Report of the Commission for Africa, 21 March 2005: 65 .

56 "Broadly speaking, the Brandt Commission's reports gave new life to earlier North-South proposals by placing them in a new context, which emphasized a dual relationship: the northern nations dependent on the poor countries for their wealth, and the poor countries dependent on the North for their development." "The Brandt Equation: 21st Century Blueprint for the New Global Economy," n.d. Center for Global Negotiations (CGN), Web, 20 Oct. 2009. 
North was internally differentiated based on political systems, that is, capitalistcommunist. Similarly, within the South countries also have been divided into newly industrialized, developing, least developed, Third World and Fourth World groupings. Nonetheless, established industrialized countries, such as the United States, Canada, Japan, Australia, New Zealand and several European countries overall are distinguishably different on many combinations of socioeconomic, military, industrial and political systems relative to the majority of other states. ${ }^{57}$ Thus, for the purposes of this research, the term 'North' encompasses the world's wealthiest and most industrialized nations, generally states from North America and Western Europe or members of the Organization for Economic Cooperation and Development (OECD). ${ }^{58}$ While the 'South' encompasses less developed and developing states largely residing within Africa, Asia and Latin America. Additionally, many of the countries within each group (but not all) share other characteristics. Among Northern countries, similarities include former colonial powers, long-standing democracies, and industrialized economies. Among the South, connections include former colonies, past socialist governments and commodity/raw material export-oriented economies. ${ }^{59}$

As noted above, however, some authors argue that the usage of the terms North and South are no longer relevant and have lost their need in recent years. Thérien, for example, argues that “...the conditions which legitimised this bipolar representation of the world have changed considerably," and that "North-South studies have...fallen out of

${ }^{57}$ See: Dadzie, 1993, 301; Hansen, 1979, 3-4; Peterson, 2007, 106-7; Timothy Shaw, "The South in the 'New World (Dis)Order': Towards a Political Economy of Third World Foreign Policy in the 1990s," Third World Quarterly 15.1 (1994): 19; Weiss et al., 2001,, 2001, 15-16.

${ }_{58}$ The OECD is a convening body of mostly Northern industrialized states with a focus to cooperate on and promote economic and development growth among its members. The organization also seeks to assist others in their economic development. "About OECD," n.d. Organization for Economic Cooperation and Development, Web, 11 Aug. 2009.

${ }^{59}$ Dennis Conway and Nik Heynen, "The Ascendancy of Neoliberalism and Emergence of Contemporary Globalization," Globalization's Contradictions: Geographies of Discipline, Destruction and Transformation, Ed. Dennis Conway and Nik Heynen, (New York: Routledge, Taylor and Francis Group, 2006) 27-28; Hewson, 2005, n. pag.; Weiss et al., 2001,, 2001, 16, 248. 
fashion." 60 It appears, though, that the categories of North and South have largely been replaced by those under the currently prominent umbrella of 'globalization,' using other terms such as developed-developing, industrialized-underdeveloped or First WorldThird World. Although useful, this thesis argues that they do not capture the importance of the enduring tensions between the North and the South. In addition, there are also moments where states will take actions motivated by self-interest, and act independent of their group or temporarily regroup with the other side; however, states frequently fall back into North-South dynamics. Furthermore, Southern countries within the UN often continue to present themselves with 'one voice' as members of the G-77. ${ }^{61}$ Although North-North and South-South divisions do occur and will be noted within this research, the findings of this thesis illustrate that North-South divisions remain a significant characteristic of the UN system.

Overall, issues between the North and the South seem to persist, if under newer terminology, hence the concept of 'North-South' and its significance to ongoing problems within the UN system maintain relevance. Both academically and in practice the term 'North-South' conjures a broader concept that connotes the debate and problematic divergence that occurs between these two groups. As Weiss states "[ $t]$ he artificial division of the world into a global North and a global South is a simplification; and, like all simplifications, it overlooks substantial parts of reality. It is frequently the default option, if so because no other template is readily available." 62

\subsection{Outline of Thesis}

This thesis seeks to analyze the nature of North-South divisions along five dimensions, examine the effects that these dimensions have had upon the Architecture

\footnotetext{
${ }^{60}$ Thérien, 1999, 727.

${ }^{61}$ Weiss, 2009, 47-48. For example, after the 2007 UN Conference on Climate Change, the "G77 " -rather than individual Southern states - expressed their disappointment with the outcome.

${ }^{62}$ Weiss, 2009, 71.
} 
and the effects this has had on its ability to carry out peacebuilding in one of its country cases, Sierra Leone. Although there has been some valuable analysis of the Architecture, it has been from a largely structural and procedural viewpoint. There has been no substantial analysis of the institutional setting of the Architecture within the UN and the effects of one of the organization's strongest systemic issues, the North-South divide. This thesis argues that North-South dynamics are having an impact on the operations and outcomes of the Peacebuilding Architecture and one of its country cases, Sierra Leone. Furthermore, it argues that instances of divergence impede the ability of the Architecture to carry out its objectives, while instances of convergence help to improve its ability to realize its goals. The remaining chapters will make detailed examinations of these arguments.

Chapter 2 will present a more critical understanding of the nature and evolution of North-South relations within the UN system. It begins by presenting a brief historical review of the development of North-South divisions within the UN system. In particular, this review will highlight the emergence of the five dimensions - development, economic practices, sovereignty, aid and issues connected to the UN system - throughout the record of North-South interactions within the organization. The chapter will then specifically consider each dimension, presenting sub-factors of divisions within each area. For example, the development dimension will be explored along two points of common disagreement: what are the drivers behind development and the priority of development $v i s-\grave{a}$-vis security. In general, this chapter will encompass exploring the foundations behind disagreements, the outcomes that have resulted from these confrontations, as well as investigate any points of convergence that may have occurred within each area. The general objective of the chapter is to establish a thorough understanding of the five dimensions of confrontation between the North and the South, and their effects upon decision-making within the UN. 
Chapter 3 will then introduce the Peacebuilding Architecture. A brief background explaining the lead-up to and development of the Architecture will start the discussion, followed by a description of its key features. Here, the PBC, PBSO and PBF will be discussed in detail along with any aspects of these bodies that have potential to be affected by North-South divisions (for instance, membership). The framework developed in Chapter 2 (i.e. the five dimensions) will then be used as the basis to analyze the effects of North-South interactions (whether divergent or convergent) within and around the Architecture. Like the preceding Chapter, each dimension will be explored individually, both along decisions made outside of but concerning the Architecture (such as from the Security Council or the General Assembly), as well as decisions made within the Architecture. The outcomes of these decisions will be also presented. The main objective of this chapter is to analyze the presence and effects of North-South relations on the decisions made, operations and outcomes related to the Peacebuilding Architecture.

Chapter 4 will examine how these effects translate to one of the Architecture's country cases: Sierra Leone. The chapter will begin with a brief history of Sierra Leone and the factors contributing to and present during its conflict. Specifically, those factors that may affect the current peace and the peacebuilding process in Sierra Leone will be given emphasis. Following the same analytical procedure in the previous chapters, Chapter 4 will analyze how each dimension of North-South divergence in and around the Architecture is affecting the peacebuilding process in Sierra Leone.

The concluding chapter will synthesize and comment on the findings from the above three areas. The overall finding is that North-South divergence has impeded the work of the Peacebuilding Architecture. The most divisive areas are those around development, aid and economic practices related to the international financial institutions (IFIs). There appeared to be no points of convergence in these areas and outcomes at times in part contributed to risking peace in Sierra Leone. There were also some sub- 
factors where there appeared to be little or no divergence, such as responsibility for development, economic policy and leadership of the Secretary-General. There were also areas of mixed outcomes involving some level of convergence, such as in the sub- factors of membership and participation or the sovereignty dimension. Although not as prominent, other divisions were also present concerning North-North and South-South relationships. The chapter will also use the findings to reflect back on the North-South debate and suggest areas for future research. It will finish with a discussion on implications for the broader field.

Finally, this thesis ends with important implications for understandings around North-South divisions in various areas. This will be explored in detail in the concluding chapter. In brief, improved understandings around North-South divisions will help the UN and the Architecture to understand limitations to its operations and functions. In addition, this thesis contributes a new tool for analyzing and understanding the presence of North-South divisions within the institutional context. This research also has implications for other institutions and organizations engaging in activities involving both Northern and Southern actors, and may provide a basis for future research in this area. 


\section{A GLOBAL DICHOTOMY: THE "NORTH" AND THE "SOUTH"}

\subsection{Introduction}

One of the most prevalent systemic challenges affecting the United Nations since the 1960s has been the division between Northern industrialized states and Southern developing states. ${ }^{63}$ At its worst, divisions between each group have impeded UN decision-making and action. Malone and Hagman argue that the very relevancy of the organization has been called into question due to this ongoing impasse. ${ }^{64}$ In contrast, moments of agreement have produced important achievements. Thus, recognizing and understanding factors to which the North and South diverge upon is critical to improving UN effectiveness as well as overcoming challenges for those working inside and in conjunction with the UN system.

The North-South divide itself is extensive and encompasses various debates and issues that are not possible to discuss within the constraints of this chapter. Instead, the overall objectives of the chapter are to convey the main understandings of the NorthSouth debate, and identify and examine the five dimensions of confrontation between each side - development, economic practices, aid, sovereignty and the UN system. The chapter will begin with a brief history of the development of North-South confrontations, making note of the emergence of each dimension. The remainder of the chapter will examine the five-dimensional framework, conducting an individual analysis of each element and their sub-factors that underpin divergence. This analysis will also include any evidence of potential North-South convergence. The chapter will then conclude with a summary of the key findings.

Overall, this chapter identifies five key areas to North-South divergence. Within the first, the development dimension, the literature suggests that the North and South are

${ }^{63}$ Krasner, 1985, 26; Kim and Russett, 1996, 629-30; Malone and Hagman, 2002, 408-410; Ravenhill, 1990, 732.

${ }^{64}$ Malone and Hagman, 2002, 412. 
likely to diverge on issues related to who holds responsibility for developmental problems and the priority development receives vis-à-vis security. In the second dimension, economic practices, analysis implies that the North and South have confronted each other over economic policies and the role of IFIs. In the third dimension, the literature proposes that both sides are likely to disagree with who controls aid, the commitments to supply aid and with the quality of aid provided. Analysis of the fourth dimension, sovereignty, suggests that the two sides will disagree as to its interpretation (in principle) and the actions of the Security Council (in practice). Finally, analysis of the dimension of the UN system suggests that the North and South are prone to divergence around membership, participation, authority or 'power struggles' and leadership. Additionally, a few instances of North-South convergence were revealed and will also be analyzed in an attempt to explain their emergence.

\subsubsection{History of North-South Tensions}

Despite the long-standing division between the North and the South within the United Nations, there was no real distinguishable differentiation between each group during the organization's first few years. ${ }^{65}$ The primary focus of the UN was to promote state cooperation on issues of peace and security in order to address both the failings of the League of Nations and to respond to causes of the Second World War. It was largely conceived by a handful of industrialized states from the North, thus its design, Charter, purposes and principles, structure and operations were in part shaped by Northern conceptions of global order. ${ }^{66}$ Notwithstanding some of these shared conceptions and original cooperation in forming the $\mathrm{UN}$, the first lines of division instead emerged between Northern states. East-West confrontations and security concerns, namely

${ }^{65}$ Krasner, 1985, 88-89.

${ }^{66}$ Malone and Hagman, 2002, 400; Peterson, 2007,, 106; United Nations, The United Nations Today, (New York: United Nations, Department of Public Information, 2008) 3-5. 
between the two superpowers, became the dominant preoccupation of the international community and within the organization.

North-South tensions did not begin to surface until the decolonization period of the late 1950s and early 1960s, which saw a dramatic increase and prominence of newly independent countries from the South admitted to the UN, eventually occupying the majority of seats within the General Assembly. ${ }^{67}$ However, the initial euphoria of independence began to give way to the realities of economic and developmental differences between Southern states and Northern states. The South pushed the North to recognize Southern problems as not only a result of Northern practices, but also a responsibility of the North to correct: “...international conditions (guilt or at least unease over the colonial past in the North, optimism in the South) favored narratives of grievance and claims for redress and assistance." ${ }^{, 68}$ With the Southern states now holding a majority of UN membership, discussions increasingly focused on development and saw it take center stage when the UN declared the 1960s the Development Decade. Development issues thus became a prominent division and forms the first dimension of the framework.

The 1960s, therefore, also marked the period where the South began to coalesce into 'formal' divisions from the North. Many developing countries had already been meeting to discuss common concerns amongst each other for some time. In 1960, a handful of Southern oil producing countries joined together to establish the Organization of the Petroleum Exporting Countries (OPEC) as a means to gain greater control over the international oil market, seen as dominated by companies from Northern industrialized states. ${ }^{69}$ Stemming from meetings begun in 1956, the first prominent broad Southern group to be formed was the Non-Aligned Movement (NAM) in 1961. The NAM was

\footnotetext{
${ }^{67}$ Hewson, 2005, n. pag.; Malone and Hagman, 2002, 400; Peterson, 2007, 106.

${ }^{68}$ Malone and Hagman, 2002, 400.

69 "Brief History," n.d. The Organization of the Petroleum Exporting Countries (OPEC), Web. 2
} June 2009. 
launched as a 'political response' to the growing East-West split, which sought to establish its neutrality between the two superpowers but also to advance its own interests within each bloc. However, the NAM was not originally designed as a counter to the North, but rather as a neutral third alternative to the East and West. Nonetheless, there were strong undercurrents running through the group to go a step further and become a unified opposition of developing countries. ${ }^{70}$

In 1964 the Group of 77 (G-77) was formed by 77 Southern states from Asia, Africa and Latin America as a way to 'organize and coordinate their behaviour' at the first UN Conference on Trade and Development (UNCTAD). Unlike the NAM, the focus of the G-77 was on economic and development objectives. ${ }^{71}$ The conference also signified a formal division, whereby the South "asserted the existence of a process of inequalizing exchange between the North and South.... Persistent divergence between North and South was seen as the natural order." ${ }^{, 72}$ Thus, without a significant transformation of the international system, it was believed that the South and any prospects of substantial development would continually be suppressed by Northern economic and trade policies. Through their large numbers, unified objectives and shared grievances, the South was able to push forward their agenda in various multilateral institutions for the remainder of the decade. Divisions around economic factors became a focal point and another dimension to the framework of this thesis.

The 1970s would see both the height of Southern power as well as the entrenchment of North-South divisions. Initially, the South was able to exercise its strength in several ways. First, Krasner explains that because the North continued to engage with international organizations such as the $\mathrm{UN}$, they were in effect legitimizing and reinforcing Southern objectives since the South was now largely defining the

${ }^{70}$ Bahgat Korany, "End of History, or its Continuation and Accentuation? The Global South and the 'New Transformation' Literature," Third World Quarterly 15.1 (1994): 12.

${ }^{71}$ Krasner, 1985, 89.

${ }^{72}$ Dadzie, 1993, 300-1. 
direction and influencing decisions of various international bodies. ${ }^{73}$ Second, Hewson adds that Northern (or more specifically Western) power in relation to Southern affairs came into question during the 1970 s, which saw the US defeated in the Vietnam War as well as the occurrence of several social revolutions in some Third World countries. ${ }^{74}$ Third, OPEC (which had taken on more Southern members) launched an oil embargo and significantly raised oil prices, causing an 'oil crisis' severely affecting the global economy. ${ }^{75}$ Fourth, Weiss et al. point out that the South dominated the membership of the UN General Assembly and was thus able to push through objectives based on majority votes. $^{76}$ The combination of these factors leveraged significant power in favour of the South, which in 1974 was able to 'force' the adoption of its demands for a New International Economic Order (NIEO) within the UN:

The Sixth Special Session [of the General Assembly], without a dissenting vote, endorsed the view that major changes in existing regimes for trade, aid, investment, technology, and international finance were required to reduce the "inequities" inherent in the international economic system of the 1970 s. $^{77}$

The objective of the NIEO was to transform the fundamental characteristics of the international trade system to correct its problems and imbalances that favoured the North. The South and the North had been effectively and unequivocally divided. The second half of the 1970 s saw the South apply considerable pressure on the North to support the NIEO agenda and the North, in its 'weakened' position, had to take into consideration Southern demands. Strong tensions began to develop between the two groups.

${ }^{73}$ Krasner, 1985, 60; Thérien, 1999, 727-28.

${ }^{74}$ Hewson, 2005, n. pag.

${ }^{75}$ OPEC's show of power was in reaction to a combination of incidents in the 1970s. In part, was an attempt to raise profits, but also to demonstrate its leveraging power in the international market as oil is a crucial component of the global economy. Additionally, the oil embargo was in reaction to US support of Israel during the 1973 Arab-Israeli war (Yom Kippur War). Hewson, 2005, n. pag.; Raffer and Singer, 2001, 123; Weiss et al., 2001, 249.

${ }^{76}$ Weiss et al., 2001, 239.

${ }^{77}$ Hansen, 1979, 24. 
The 1980s, however, were subsequently labeled the "lost decade" for developing countries as the factors giving substance and momentum to the NIEO drive began to diminish. ${ }^{78}$ The South lacked the ability to maintain a stronghold over the North or to realize any significant outcomes from the NIEO. The oil price hikes by OPEC weakened the general economies of all states, North and South alike; but also, OPEC itself was experiencing internal divisions which affected its capacity to maintain a unified stance. Despite the South's ability to apply significant pressure on the North and push through its objectives in the UN, without sufficient 'economic and military' strength the South was unable to force the North to follow through on Southern demands. ${ }^{79}$ The debt crisis experienced during the 1980 s - in part, a result of the actions of the 1970 s - further weakened many in the South and its collective capabilities in challenging the North. ${ }^{80}$ The acrimonious atmosphere created between the two sides also served to discourage many in the North from dealing with the South, as well, many in the North began to disengage from UN activities. ${ }^{81}$

At the same time, the Northern dominated IFIs emerged as the primary means to manage international lending and aid to the South and began to attach conditionalities to loans promoting market liberalization, deregulation and privatization. This weakened many Southern states that were unable to compete on the international market or handle market volatility. ${ }^{82}$ The role of the IFIs added to economic divisions, while the management of aid became another strong division, therefore its incorporation as another dimension to North-South dynamics. The shift in Northern engagement away from the UN as well as the US default on the payment of substantial amounts of UN dues also

${ }^{78}$ Thérien, 1999, 725.

${ }^{79}$ Dadzie, 1993, 304; Weiss et al., 2001, 242-43.

${ }^{80}$ S. Mansoob Murshed, "Globalisation, Marginalisation and Conflict," Globalisation, Poverty and Conflict: A Critical 'Development' Reader, Ed. Max Spoor. (New York: Kluwer Academic Publishers, 2004) 74; Thérien, 1999, 725; Weiss et al., 2001, 249.

${ }^{81}$ Weiss et al., 2001, 242-43.

${ }^{82}$ Raffer and Singer, 2001, 48. 
served to weaken the organization itself. ${ }^{83}$ Realizing that a confrontational approach with the North was not productive, developing states had become more collaborative with the North by the end of the 1980s. However, a combination of the above factors had, by this time, largely inhibited practical exchange between the North and the South. ${ }^{84}$

Many hoped the end of the Cold War would bring about a 'New World Order' with an era of greater cooperation among all states and change the previous international dynamics. Although the 1990s saw East-West rivalry dissipate, several authors argue that North-South differences within the UN became the new prevalent division. ${ }^{85}$ The North continued to divert attention to other regions, such as the emergence of new post-Soviet states, and the South lost its advantage to use East-West rivalries to elevate their position. ${ }^{86}$ Contrary to achieving a New World Order, a significant marker of the early 1990s was the rapid breakout of several civil wars, the majority in Africa. ${ }^{87}$ These served to intensify North-South tensions, but the focus this time was on interpretations of state sovereignty vs. intervention. Yet, paradoxically tensions also surfaced around selective and inconsistent Northern interventionism, such as lack of action in extreme crises like Rwanda but extensive actions taken in the Balkans. Issues surrounding sovereignty and its interpretation therefore became another area for strong disagreement, as well as another dimension to the North-South framework.

On the development front, the introduction of the Washington Consensus also strained North-South relations. The Consensus, a list of prescriptions deemed necessary for improving the economies of developing states, suggested that financial systems were to be regulated and shaped by the private sector and market forces rather than by the government. Like the market liberalization wave of the 1980s, for many countries, the

\footnotetext{
${ }^{83}$ Holloway and Tomlinson, 1995, footnote 23, 236; Krasner, 1985, 300; Weiss et al., 2001, 242.

${ }^{84}$ Ravenhill, 1990, 735; Weiss et al., 2001, 243.

${ }^{85}$ Holloway and Tomlinson, 1995, 251; Kim and Russett, 1996, 636, 651; Weiss, 2009 , 52.

${ }^{86}$ Shaw, 1994, 22; Thérien, 1999, 727; Weiss et al., 2001, 268.

${ }^{87}$ Weiss, 2009, 28.
} 
policies instead weakened the presence of the government domestically and further exposed developing states to fluctuating and potentially unstable international markets. ${ }^{88}$ The Asian Financial Crisis of 1997-98 demonstrated the risks associated with market liberalization, especially for developing countries and questioned the tenets of the Consensus. ${ }^{89}$ As the decade came to a close, although the high level of antagonism and confrontation between the North and the South that had been seen in the 1970s and early 1980s had considerably diminished, the differences between a largely weakened South ${ }^{90}$ and an increasingly indifferent North continued to separate the two. Development and economic priorities of the South also appeared to fall off the UN radar as the "organization had resigned itself to being more of an 'aid' organization." ${ }^{91}$ Furthermore, the UN came under increased criticism and challenges to the justification of its existence. Funding shortfalls, disengaging Northern actors, unable to prevent or at least respond to some of the decade's worst conflicts and growing Southern poverty combined to create general loss in confidence in the organization. ${ }^{92}$ The divide between the North and much of the South continued to deepen.

The start of the new millennium was heading along the same trajectory. The attacks of 11 September, however, called dramatic attention to the connection between development in the South and international security of the North and the risk of indifference to failed and failing states. International attention refocused on the global South, the US re-engaged with the UN and the North and South appeared to have found common ground in factors related to security and socioeconomic development through

${ }^{88}$ Raffer and Singer, 2001, 51-54; Shaw, 1994, 25; Weiss, 2009, 251.

${ }^{89}$ Conway and Heynen, 2006, 31; Raffer and Singer, 2001, 62-63.

${ }^{90}$ Although some countries in the South experienced improvements (e.g. Brazil) and were steadily approaching the level of a "developed" country, the majority continued to be experiencing decline. "The [UNDP] reports that between 1960 and 1993 the gap in annual per capita income between the developed and the developing countries rose from $\$ 5,700$ to $\$ 15,400$ " (Thérien, 1999, 733).

${ }^{91}$ Weiss et al., 2001, 245.

${ }^{92}$ Doyle and Sambanis, 2006, 2. 
peacebuilding objectives. ${ }^{93}$ This changed with the unilateral decision by the US and support from a few other Northern countries to attack Iraq without UN authorization, thus intensifying Southern suspicions of Northern intervention. ${ }^{94}$ The lack of support from remaining Northern countries, however, demonstrated that divisions between the North and South were not clear cut.

In 2005, the UN World Summit also displayed a mixture of North-South divergence and convergence. The Summit was brought about by a culmination of concerns around the utility of the UN and targeted among other things international security, the state of developing countries and the effectiveness of UN operations. Agreement was reached to establish the Peacebuilding Architecture and the Human Rights Council (to address the issues in the former Commission for Human Rights); however, reform and improvements in other UN areas, such as the Security Council, were not forthcoming. ${ }^{95}$ These and other internal UN problems had been a recurring issue between the North and the South leading up to the Summit, thus the UN system itself forms another dimension to the framework.

During this same period, the Monterrey Consensus (2001) saw a merger among many of the North and South around development and economic issues, with acknowledgement by the North that some of its wealth needed to be transferred to the South, while the South acknowledged that internal reforms needed to be made if they were to improve their situation. ${ }^{96}$ The global effects of environmental issues connected through sustainable development have also become a concern between the two sides. ${ }^{97}$ Despite recognition of the various shared concerns above, much has yet to be put into practice. The overriding characteristic of North-South divisions within the first decade of

\footnotetext{
${ }^{93}$ Hewson, 2005, n. pag.; Weiss, 2009, 26.

${ }^{94}$ Weiss, 2009, 26-7.

${ }^{95}$ Murthy, 2007, 41; Weiss, 2009, 38-39, 58.

${ }^{96}$ Weiss, 2009, 168.

${ }^{97}$ Lyn Jaggard, "Climate Change Politics, the UN and National Interests," Environmental Policy
} and Law, 38.5 2008: 230. 
the millennium is the recognition of the impact individual states have on the greater global community, thus increasingly shared concerns between the North and South, yet taking action has largely has been unilateral or absent.

At the same time, there have been some moments of North-South convergence, such as the International Campaign to Ban Landmines, the establishment of the International Criminal Court and the setting of the Millennium Development Goals. ${ }^{98}$ According to Weiss, the ability of the two sides to converge in these areas owes itself to several factors. Many of the states involved were key actors from both sides, as well as a diverse mixture of NGOs. Those involved decided to continue to work on the process even in the absence of "universal support" and attempted to look for common ground when faced with disagreement. There was a willingness to challenge and redefine old assumptions, as well as focus upon alternative approaches and ideas. Most importantly, all those involved chose to focus on "substance" (the practical) rather than on "traditional boundaries' (the ideological). ${ }^{99}$ Another form of convergence, such as the acceptance of the 'responsibility to protect' principle by the UN in 2005 - that states have a responsibility to protect their own citizens or face potential international intervention had to be reduced in scope from the original proposal in order to be accepted by all involved. ${ }^{100}$ The author of this thesis describes this as a convergence 'trade-off,' where benefits and impediments are both produced or where something is given up in order to receive something else in order to reach agreement, both with the potential to cancel each other out. Thus, another potential concern raised is that agreement based upon reduced expectations in some instances may be beneficial if what are removed are ideological or unhelpful aspects, however end results may not produce the intended benefits of original proposals if substantial components are eliminated. Finally, Krasner has also argued that

\footnotetext{
${ }^{98}$ Weiss, 2009, 154-172.

${ }^{99}$ Weiss, 2009, 154-172.

${ }^{100}$ Weiss, 2009, 142.
} 
moments of North-South cooperation have occurred when there were "mutual interests" around short-term gains for both sides rather than for long-term objectives. ${ }^{101}$ Taken a step further, this raises concerns that in these instances, cooperation may not be substantial enough to overcome divisions in the long term and are moreover not necessarily mutually complimentary.

Nevertheless, after nearly six and half decades of UN operations, the longest running internal division is that between the North and the South. Whether it is overt, as it was in the 1970s, or more subtle, as in the 1980s and early 1990s, the North and the South generally have defined themselves along opposing objectives that continue to create tensions often resulting in problems within the UN. In particular, five areas can be identified as the most prominent. Lagging development became the first point of contention. Economic policies (market liberalization) and IFIs, as well as conditionalities attached to aid created other breaks in North-South relations. Internal problems within the $\mathrm{UN}$, such as membership in the Assembly and the role of the Security Council have also produced strong debates. While, more recently questions surrounding the interpretation of state sovereignty have maintained tensions. Finally, although there have been moments of North-South convergence, divergence appears to be the more common interaction.

The remainder of the chapter will be devoted to analyzing key characteristics of the North-South divide. Although there are numerous points of division, five dimensions have been identified where the North and South both repeatedly and most strongly divide. Within each dimension, the author also has identified sub-factors, that is, specific points of North-South confrontation.

${ }^{101}$ Krasner, 1985, 13. 


\section{DIMENSIONS OF NORTH-SOUTH DIVISIONS}

\subsection{Development: Responsibilities and Priorities}

According to Hewson, within the United Nations, development was the initial 'fracture' between the North and the South, and will be the first dimension under examination. ${ }^{102}$ In general, the literature suggests that the North and the South will diverge upon how each perceives responsibility for development problems and on the priority each side allocates to development. Given that developmental issues and the actions associated with them are frequently the basis for various North-South confrontations, understanding the place of development in the North-South divide will be important to following discussions on other dimensions of divergence.

In the first sub-factor, differences as to which side holds the main responsibility in creating the problems that have hindered development of the South have been an ongoing debate. From the perspective of many in the South, external factors connected to the North have been the cause of most problems, such as the systems inherited from colonial rule, unequal and extractive international trade policies, limited technology transfer to the South, growing debt burden, externally driven development policies and environmental degradation. ${ }^{103}$ The South has long argued for the North to take responsibility for many of these problems and rectify them through, among other things, financial contributions, debt relief and making changes to international policies and practices to reduce imbalances. ${ }^{104}$

${ }^{102}$ Hewson, 2005, n. pag.

${ }^{103}$ Bertrand, 1993, 433; Dadzie, 1993, 300-304; Hansen, 1979, 98; Malone and Hagman, 2002, 400, 408; Weiss, 2009, 67; Weiss et al., 2001, 238. Note that within the factors listed above, several are strongly associated with and often viewed as economic policies. Economic policies are a significant component to the North-South debate and as such are considered separately in the following section. The focus of this section is the disagreement over taking responsibility for many of the problems of achieving development, not the practices intended to promote development themselves.

${ }^{104}$ Malone, "UN Reform," 2006, 92; Malone and Hagman, 2002, 408; Peterson, 2007, 107; Thérien, 1999, 730-31. 
In contrast, the North has often attributed the bulk of problems that restrain development to internal mismanagement by the state. ${ }^{105}$ Developing states thus needed to liberalize their economies and further integrate themselves into the international system in order to realize gains. ${ }^{106}$ Along with this have been concerns around questionable practices in the domestic affairs of some Southern countries, such as kleptocracy, nepotism, or misuses of aid and funding. As a result, the North has placed increased emphasis and responsibility on the state where improved development also requires good governance (with preference for democratic systems), respect for human rights, and the importance of rule of law. ${ }^{107}$ Therefore, internal causes imply state responsibility while external causes imply international responsibility.

Since the decline of the NIEO, the North has taken considerable control over the development agenda and a focus on internal causes; however, more recently Northern actors have shown increasing recognition of external causes. ${ }^{108}$ Space limitations of this thesis prevent examining these instances in detail, however examples include the creation of the Millennium Development Goals (MDGs), a list of critical international development issues, or the design of the Human Development Index (HDI) by the United Nations Development Programme (UNDP), which measures the quality of life in the majority of countries. ${ }^{109}$ Although there are debates associated with these, each recognizes a multitude of broad factors contributing to development problems. Despite

105 Robert H. Jackson and Carl G. Rosberg, "Sovereignty and Underdevelopment: Juridical Statehood in the African Crisis," The Journal of Modern African Studies 24.1 (1986): 19.

${ }^{106}$ Weiss et al., 2001, 248-49.

${ }^{107}$ Dadzie, 1993, 308; Weiss et al., 2001, 248-51.

${ }^{108}$ Krasner, 1985, 61; Murshed, 2004, 74; Raffer and Singer, 2001, 95.

${ }^{109}$ Jan Vandemoortele, "The MDG Conundrum: Meeting the Targets Without Missing the Point," Development Policy Review 27.4 (2009): 356; UNGA, Resolution A/RES/55/2, United Nations Millennium Declaration. 18 Sep. 2000: par. 2; Weiss et al., 2001, 250-52; Human Development Report 2009 Overcoming Barriers: Human Mobility and Development. New York: Palgrave Macmillan, 2009. 217. Human Development Report. 
these instances of convergence, the North and South continue to divide over who holds responsibility for development problems. ${ }^{110}$

Closely related to divisions around responsibility are criticisms by the South of the North for not always giving development high priority. After the confrontational period of the NIEO and the subsequent decline in the global economy, the 1980s launched an era of Northern apathy towards Southern development; yet international indifference received new attention with the events of 11 September. However, the North - focusing on peacebuilding activities in fragile and failing states - were now looking at development issues through a security lens. As argued by Pugh, “...there is a widespread consensus that underdevelopment is a threat and therefore a security issue." 111 Policies to promote peacebuilding became subject to North-South differences since early-recovery efforts focusing on Northern security concerns must eventually transition into laterecovery efforts that focus on Southern sustainable development goals. The North's security agenda frequently emphasized short-term objectives, yet causes of conflict are often considered a result of "long-standing or structural factors" that require long-term initiatives. ${ }^{112}$ Malone stressed this mounting North-South division within peacebuilding after the release of the UN report by the High-level Panel (UNHLP) on Threats, Challenges and Change: "While the inter-linkages [between security and development] were widely accepted at the UN, the focus on security rather than on development rankled many." $" 113$ In the report, development was construed as a part of the larger

${ }^{110}$ Jaggard, 2008, 231-34; Weiss et al., 2001, 272.

${ }^{111}$ Michael Pugh, "Why a Merger of Peacebuilding and Development would Reform rather than Transform War-Torn Societies," The RUSI Journal 151.4 (2006): 29.

112 James Busumtwi-Sam, "Development and Peacebuilding: Conceptual and Operational Deficits in International Assistance," Durable Peace: Challenges for Peacebuilding in Africa, Ed. Taisier M. Ali and Robert O. Mathews. (Toronto: U of Toronto P, 2004) 317; Call, "Knowing Peace," 2008, 190; Costy, 2004, 8, 171.

113 Malone, "UN Reform," 2006, 82; The report had aimed to identify potential threats to international security, as well as assess the ability of the UN to respond to these threats, and recommend ways in which the UN could be strengthened (UNHLP on Threats, Challenges and Change, 2004, vii-x). 
security threat, raising concerns in the South that development would fall behind the security agenda. ${ }^{114}$

These divisions followed the peacebuilding trajectory into the 2005 World Summit, where competing interests between the North and the South over priorities concerning development and security hindered discussions to a degree. ${ }^{115}$ Beyond the Summit, other authors have also noted that peacebuilding activities have been further criticized for treating development, security, economics and governance in isolation from each other, often with development priorities falling behind the others. ${ }^{116}$ Overall, the North-South debate around the priority of development, especially as it relates to security, continues to see divergence within the newest arena that of peacebuilding.

In summary, this section has argued that the North and South have been divided over who holds responsibility for development problems and over the priority of development vs. security. In the former, the South attributes problems to external or international factors while the North attributes problems to internal or state factors. In the latter, development is frequently minimized in favour of security issues, and when it receives attention from the North, it is often considered within the context of security. As a consequence, the recent international focus on peacebuilding has favoured short-term security goals of the North over building long-term development objectives favoured by the South.

\subsection{Economic Practices: Setting the Agenda}

Closely related to development are the economic decisions that guide many of its objectives. In this respect, economic policy and the financial institutions that set the policies have become a significant component to the North-South divide. Combined, these economic practices make up the second dimension to the North-South framework.

\footnotetext{
${ }^{114}$ Korany, 1994, 10; Malone and Hagman, 2002, 404-5; Pugh, 2006, 31.

115 Malone, "UN Reform," 2006, 85.

${ }^{116}$ NYU CIC and the IPI, 2008, par. 18.
} 
An analysis of the literature suggests that the South often will strongly resist prevailing economic policies set out by the North and the IFIs that set these policies.

Economic policies to improve development as often promoted by the North have been one of the primary divisors between the North and the South. For many Western states within the North, development is largely premised on what Thérien explains as "... an unprecedented consensus that trade is the engine of economic growth." "117 Market liberalization, as one of the key components to Northern policy, is intended to open Southern economies, allowing them to grow by becoming more efficient. This includes such actions as removing barriers to trade (deregulation, elimination of protective measures) and improving internal management (decentralization, balancing budgets, privatization) in order to realize economic gains. ${ }^{118}$ In contrast, critics argue that the economies of developing countries, among many other things, are too weak (often lacking infrastructure, expertise and necessary institutions), are undiversified (generally producing only a few commodity-based products with little manufactured products) and overly exposed to the effects that international shocks can have on them (lack of alternative industries to compensate or lack of technology to further develop raw materials). ${ }^{119}$ Connected to this, the South view the North's promotion of economic policies as insincere, citing Northern protectionism, subsidies and tariffs that impede Southern access to and competition among the large economies. ${ }^{120}$ These and other economic policies have formed the basis for Southern discontent and confrontations with the North within the UN since UNCTAD, and were part of the driving force behind the call for the NIEO.

117 Thérien, 1999, 730.

118 Jeremy Brecher et al., "Globalization and Its Specter," Globalization: The Transformation of Social World,. Ed. D. Stanley Eitzen and Maxine Baca Zinn, (Belmont, CA: Thomson Wadsworth, 2006) 33.

119 James J. Gillespie and Max H. Bazerman. "Parasitic Integration: Win-Win Agreements Containing Losers." Negotiation Journal 13.3 (1997): 278; Murshed, 2004, 75.

${ }^{120}$ Conway and Heynen, 2006, 30; Krasner, 1985, 67; Murshed, 2004, 75; Thérien, 1999, 733. 
Although the UN has been the location for these and other North-South disagreements surrounding economic policies, it is not the primary venue for what is put into practice. Instead, other actors, in particular the IFIs, have set and reinforced the majority of global economic policy, using their position to provide financial assistance to enforce adherence amongst the South. As originally designed, the IFIs - namely the World Bank ${ }^{121}$ and the IMF - are considered 'specialized agencies' of the UN, but operating wholly separate from the world organization. ${ }^{122}$ For the South, economic policy formulated through the IFIs creates two substantial problems. First, both institutions vastly overpower the UN in determining economic policies that promote development. However, the North prefers that economic policy be dealt with in the IFIs, thus the two receive the bulk of Northern funds and, according to Raffer and Singer, have essentially incapacitated the UN. "By withholding resources [from the UN], the [UN] system has become crippled and incapable of playing its assigned role in development."123

Second, unlike the UN, the decision-making structure of the IFIs is not one-state, one-vote, but is instead based upon "weighted voting" whereby the largest financial contributors have the largest say. Most of the South does not have the monetary influence to direct voting and therefore, the most financially powerful states - the majority from the North - dictate IFI processes and decision-making. ${ }^{124}$ This situation has created a serious cleavage in the North-South debate. Despite any objections the South may have, the structure of the most important forums for economic discussion prevents them from influencing or effectively presenting Southern alternatives, while their dependency on

${ }^{121}$ Note that the World Bank Group is made up of five institutions, while the World Bank refers to two of these, the International Bank for Reconstruction and Development (IBRD) and the International Development Association (IDA). Both the IBRD and the IDA perform similar functions in that they focus on poverty reduction and assistance to developing countries, but differentiate themselves between the 'middle-income and poor countries' and the 'poorest countries in the world,' respectively. United Nations, The United Nations Today, 2008, 56.

${ }^{122}$ Raffer and Singer, 2001, 9; Weiss, 2009, 184; United Nations, The United Nations Today, $2008,24-25$.

${ }^{123}$ Raffer and Singer, 2001, 10

${ }^{124}$ Malone and Hagman, 2002, 409; Krasner, 1985, 121. 
these institutions compels them to accept the policies as dictated. Since the South has a stronger voice within the UN, confrontations over economic policy are carried out there. ${ }^{125}$ Weiss therefore argues that the UN must make efforts to connect itself to the IFIs if economic policy, and its effects on development, are to improve for the South. ${ }^{126}$

Overall, this section has put forth that the North and South frequently have divided over international economic practices in two areas. First, the literature suggests that the South is likely to oppose Northern economic policies, considering them to be largely unfair or problematic. Second, the South is likely to oppose the involvement of the IFIs in economic policy making, whereas the North prefers and supports the IFIs in managing financial decisions. As a result, North-South confrontations around economic practices are carried out within the UN, where the South has a stronger voice.

\subsection{Aid: Control, Commitment and Quality}

Many of the transformative processes necessary not only to halt but also reverse development and economic decline in the majority of developing countries require substantial financial and other forms of assistance. ${ }^{127}$ Much of the North, with its relatively stronger economies and more substantial resources often have provided some of this aid. However, the literature suggests that relinquishing control of the assistance as well as providing sufficient and quality support has become key components to NorthSouth disagreements. ${ }^{128}$ Analysis of aid thus becomes the third dimension to the NorthSouth framework.

Access to and thereby control of aid has received extensive discussion within the literature under the concept of conditionalities. The South argues that assistance frequently comes with conditions that require adherence to Northern agendas and

\footnotetext{
${ }^{125}$ Hansen, 1979, 24; Thérien, 1999, 725.

${ }^{126}$ Weiss, 2009, 184.

${ }^{127}$ Call, "Ending Wars," 2008, 2.

${ }^{128}$ Krasner, 1985, 130; Raffer and Singer, 2001, 71-72.
} 
norms. ${ }^{129}$ Hansen notes that the North has rationalized the need for some Northern control given the misuse of aid by various Southern elites, as their motives have not always benefited the country or its people. ${ }^{130}$ Various authors explain that many in the South feel that conditionalities not only infringe upon their sovereignty, but several have been problematic. Raffer and Singer state that to a certain extent, conditionalities embrace assumptions about what the North deems should be done, and not necessarily what the South needs. ${ }^{131}$ For instance, structural adjustment programs (SAPs) during the 1980s considerably weakened developing states. ${ }^{132}$ They were a set of conditions that outlined economic reforms to be followed by removing control away from the state, such as market liberalization, elimination of protectionist features and privatization of many state-run institutions. Problems associated with SAPs lead to the introduction of Poverty Reduction Strategy Papers (PRSPs) as a form of 'client-owned' assistance, whereby aid is provided based upon recipient country-determined priorities. However, these have also been criticized as Northern controlled and a subtle form of conditionality since the Southern country must still meet Northern criteria to be 'considered' for loans. ${ }^{133}$ Although space limitations prevent a detailed examination here, recently there has been some movement towards improved Southern control seen in the 2005 Paris Declaration on Aid Effectiveness. ${ }^{134}$ Nevertheless, control of most aid continues to reside with Northern donors, thus remains a point of North-South disagreement.

${ }^{129}$ Krasner, 1985, 127-28; Raffer and Singer, 2001, 95.

${ }^{130}$ Hansen, 1979, 48.

${ }^{131}$ Raffer and Singer, 2001, 232.

${ }_{132}^{132}$ Conway and Heynen, 2006, 30; Murshed, 2004, 73-74; Weiss, 2009, 29.

${ }^{133}$ Palash Kamruzzaman, "Poverty Reduction Strategy Papers and the Rhetoric of Participation," Development in Practice 19.1 (2009): 61-62, 69; Murshed, 2004, 74; Raffer and Singer, 2001, 55.

${ }_{134}$ Paris Declaration on Aid Effectiveness: Ownershp, Harmonisation, Alignemnt, Results and Mutual Accountability, 28 Feb. - 2 Mar. 2005, Organization for Economic Co-operation and Develeopment, Web, 17 July 2009. Also see Elaine Venter for a counter to the Declaration, "A Work in Progress: The Paris Declaration Renews Focus on Aid Reform but is Still Donor-Centric" Finance and Development 45.3 (2008). 
Disagreements around the control of aid are compounded by its small commitments. According to the literature, insufficient aid has been attributed to 'donor fatigue' or 'aid fatigue' - where the North is growing tired of being asked for repeated help. ${ }^{135}$ Nevertheless, in 1969 at the request of the World Bank to identify means of improving development, the Pearson Report suggested that assistance to developing countries was significant to their improvement and that economically strong countries needed to increase resource flows to developing countries. ${ }^{136}$ Member states of the UN (as well as other institutions) eventually decided and adopted in principle that $0.7 \%$ of GNI would be the target for official development assistance. ${ }^{137}$ However, foreign aid is well below - and has never reached - the $0.7 \%$ level of GNI that the North has agreed to commit to the South, and more importantly, it has declined over time. ${ }^{138}$ Thus, both sides continue to disagree on the some of the requirements of the North to meet aid commitments.

Likewise, critics have challenged the North over the quality of aid it provides. According to Raffer and Signer, what is recorded as aid has included 'just about anything originating from the North' such as commercial investments, high-interest loans or even the expenditures associated with dispersing aid. ${ }^{139}$ Additionally, aid often has been slowly disbursed, not reached the people it is meant to help, has been poorly implemented or it has been dispersed as tied aid (where the recipient country in turn must purchase products from the donor country or countries). ${ }^{140}$ For many in the South, aid has

${ }^{135}$ Other North-South issues not possible to discuss here include whether aid makes a difference and faulty aid practices. For instance, see Weiss et al., 2001, 269 and Raffer and Singer, 2001, 77-8, respectively.

${ }_{136}^{13}$ Raffer and Singer, 2001, 158-59.

137 UNGA, International Development Strategy for the Second United Nations Development Decade (A/8124 and Add.1): Resolution 2626 (XXV). 24 Oct. 1970, par. 43.

${ }^{138}$ Hansen, 1979, 48-9; Krasner, 1985, 121; Raffer and Singer, 2001, 70 (Fig. 5.1). For example, according to Raffer and Singer, 2001, who refer to OECD data, overseas development assistance declined by more than half from its height of $0.54 \%$ of GNI in 1961 to $0.23 \%$ in 1998 .

${ }^{139}$ Raffer and Singer, 2001, 71-72, 88.

${ }^{140}$ Raffer and Singer, 2001, 78, 87. 
contributed to their dependency on the North with little opportunity to break from the cycle, and thus has become another point of North-South divergence.

Finally, the South prefers aid be managed through the UN, but much of the North largely has bypassed the UN in preference to other actors, such as the IFIs. ${ }^{141}$ However, several Southern focused UN bodies do not have conditionalities attached to their aid, such as the UNDP, which attempts to distance itself from interfering in the "economic policies of recipient countries." 142 At the same time, these less restrictive bodies tend to be dependent upon voluntary contributions, creating unreliable and often insufficient funding. ${ }^{143}$ Thus, it appears that the trade-off for increased Southern control over funding is reduced and less reliable amounts of aid.

In summary, analysis of the literature in this section has suggested that the North and South are likely to divide around the control of aid, level of commitments to aid and the quality of aid provided. In some areas there may be signs of improved agreement between the North and South, such as the Paris Declaration; however, the general atmosphere surrounding aid is that of divisions. A notable observation is that there appears to be a trade-off between control and commitments to aid, where greater Northern control (i.e. conditionalities) suggests higher aid commitments, whereas less Northern control suggests lower and unreliable aid commitments.

\subsection{Sovereignty: Challenging Long-Held Assumptions}

Issues around the fourth dimension, sovereignty, represent one of the largest and most consistent North-South divisions within the United Nations. ${ }^{144}$ As one of the fundamental pillars to the UN Charter, sovereignty has been formally established as the right to self-determination and non-interference within a state's borders. ${ }^{145}$ However,

\footnotetext{
141 Weiss et al., 2001, 245.

142 Krasner, 1985, 169.

143 Krasner, 1985, 167.

144 Alker, 1964, 652; Kim and Russett, 1996, 636.

${ }^{145}$ See: United Nations, Charter of the United Nations, 26 June 1945, articles 1(2), 2(1), 2(7).
} 
changing global dynamics have come to challenge this long-held conception of sovereignty, which has intensified North-South disagreements around sovereignty both in principle and in practice.

The principle of state sovereignty has its roots in the 1648 Peace of Westphalia, which established an agreement amongst European rulers that the leader of a territory could determine its religion without interference from leaders of other territories. ${ }^{146}$ Sovereignty had taken on a broader meaning by the time of its enshrinement in the UN Charter, legitimizing the right of states to govern and protect their territories from outside interference. This is based on empirical sovereignty, the traditional form where states received their authority to govern a territory based on their legitimacy and capacity to do so. In contrast, the majority of Southern states originated from the decolonization period thus they were established through juridical sovereignty, that is recognition from other states. ${ }^{147}$ Statehood was not based upon internal legitimacy, but on legitimacy from the international community.

Jackson and Rosberg argue that states established through juridical sovereignty are often weak internally because they lack the traditional method of state formation where leaders or governments develop and make use of military, economic and/or political power to bring a country together. ${ }^{148}$ In contrast, many Southern states rely upon respect for the traditional UN definition of sovereignty as their source of power. Furthermore, the General Assembly of the UN provides a second source of leverage, where its 'one-state, one-vote' practice of decision-making ensures sovereign equality among all states. ${ }^{149}$ Jointly, these give Southern states a level of power they do not necessarily have outside of the organization, their sovereign status and large voting

${ }^{146}$ Weiss et al., 2001, 5. The Peace of Westphalia is frequently attributed to the start of the modern international state system. The two peace treaties of Westphalia ended two major European wars that originally had their basis in conflict over the right of a territory to practice the religion of their choice.

${ }^{147}$ Krasner, 1985, 7-8; Jackson and Rosberg, 1986, 4-6.

148 Jackson and Rosberg, 1986, 13-14.

${ }^{149}$ Krasner, 1985, 6-8; Malone and Hagman, 2002, 406-7. 
numbers allow them to reject undesirable 'Northern' policies. ${ }^{150}$ More recently, however, interpretations of sovereignty have come into question.

Near the end of the Cold War and soon after, the rise in civil wars saw the disregard for the lives and well-being of citizens in numerous developing states. Many in the North began to stress the need to intervene in state affairs in order to safeguard the citizens. Protection of the state was now challenged by protection of the individual. Within the UN, and especially the General Assembly, the South has frequently opposed attempts to diminish state sovereignty in favour of human rights. ${ }^{151}$ As Krasner explains, the South does not oppose humanitarian assistance but instead attempts to dictate or exercise control within the internal operations of another country. ${ }^{152}$ Lacking the ability to prevent intervention in practice, attempts to change sovereignty in principle became a threat to their main source of power. ${ }^{153}$ As a result, the North and the South frequently divide over the principle of sovereignty and any attempts to change it. ${ }^{154}$

North-South divisions around sovereignty have also created problems in UN practice. Through numbers, the South dominates various UN bodies such as the Economic and Social Council (ECOSOC), the UNDP and most importantly the General Assembly. ${ }^{155}$ The one notable exception is the Security Council, where the South has a considerably weak voice. It is regarded as the most powerful UN body due both to its Permanent 5 (P5) membership who hold veto power and that it presides over security actions that the UN might undertake. ${ }^{156}$ With the exception of China as a 'potential'

${ }^{150}$ Malone and Hagman, 2002, 406-7.

${ }^{151}$ Weiss et al., 2001, 214.

${ }^{152}$ Krasner, 1985, 118.

${ }^{153}$ Weiss et al., 2001, 214.

${ }^{154}$ Other issues connected to threats to sovereignty, but not possible to explore here due to the limits of space, include conflict prevention and pre-emptive intervention, as well as debate around Western norms and the citizen. For instance, see Barbara Crossette, "The Battle for Human Rights," The Nation 287.21 (2008) 20-21, Malone and Hagman, 2002, 407; and Weiss, 2009, 141.

${ }^{155}$ Hewson, 2005, n. pag.

${ }^{156}$ Malone, "Security Council," 2007, 131; Waheguru Pal Singh Sidhu, "Regional Groups and Alliances," The Oxford Handbook on the United Nation,. Ed. Thomas G. Weiss and Sam Daws, (New York: Oxford UP, 2007) 219. 
Southern partner, much of the global South, especially large regional areas such as South America and Africa, have no representation within the P5. ${ }^{157}$ (Although China and Russia are often strong proponents for respect for sovereignty, it is often in pursuit of selfinterest rather than in upholding the rights of Southern states.) ${ }^{158}$ This imbalance poses a problem for the South since new emerging conceptions of sovereignty make the Security Council, dominated by the North, the interpreter of what guides human rights intervention. Moreover, the actions of the P5 - taking action in Kuwait and Bosnia, not taking action in Rwanda, withdrawing from Somalia - revealed that the Security Council was inconsistent. ${ }^{159}$ The overriding concern of the South is the inability to be heard by and to influence the P5 within the Security Council. Intervention was still largely guided by the interests of a few Northern powers. As a result, the South through the General Assembly has frequently been at odds with the Security Council and its decisions or lack thereof. ${ }^{160}$

In general, this section has briefly analyzed North-South divisions around the sovereignty dimension. As the literature suggests, North-South divisions are likely to emerge in principle when the North attempts to change the concept of sovereignty or in practice over the role of the Security Council to intervene in state affairs.

\subsection{UN System: Membership \& Participation, Power Struggles and Leadership}

The final dimension to the framework analyzing North-South divisions is that of the UN System itself. Although the United Nations may be the primary convening forum for the South to challenge the North, many of the organization's internal systems and operations are aggravated by North-South divisions. Although there are several points of

${ }^{157}$ However, Weiss et al., 2001, state that within the Security Council, the "...unity of the NonAligned Movement on most issues has essentially introduced a type of 'sixth veto' when developing countries coalesce against a particular action" (30). Malone and Hagman, 2002, also make a similar argument (403).

${ }^{158}$ Weiss, 2009, 64-65; Weiss et al., 2001, 214.

${ }^{159}$ Weiss et al., 2001, 324.

${ }^{160}$ Korany, 1994, 11. 
North-South tensions within the system, much of the literature has focused upon divisions around membership, participation, power struggles and leadership.

The ability to influence decisions within international organizations is partially dependent upon having access to - or membership in - an organization. For instance, the South has almost no representation within the OECD, a considerable drawback since the OECD is a strong and influential international body promoting cooperation on economic and development practices among largely Northern industrialized states. ${ }^{161}$ In contrast, the UN has a relatively open membership to its main convening body, the General Assembly, including nearly all countries. Having access to such a venue can be an important place for the South to interact with the North, either to focus attention on Southern concerns or potentially to influence Northern decisions. Nonetheless, it is this organizational structure according to Krasner that allows for North-South disagreement: "...the more accessible the decision-making organizations, the higher the level of conflict." ${ }^{162}$ Consequently, the UN and in particular the General Assembly is subject to North-South divisions because it is inclusive of diverse states rather than exclusive.

The importance of this and North-South divisions becomes more apparent when considering the ability to influence decisions connected to participation. As discussed with the IFIs, level of participation such as voting privileges based on other qualifiers (i.e. financial contributions), greatly limits Southern voices even if they do have membership to an organization. Within the UN, level of participation becomes subject to North-South divisions in two ways. In the General Assembly (and some other UN bodies such as the United Nations Educational, Scientific and Cultural Organization; the International Labour Organization; ECOSOC and the UNDP), the South is dominant due

161 The OECD is considering expanding its membership to additional non-typical Northern countries (Estonia, Israel, Russia and Slovenia) and one Southern country (Chile). In addition, it has proposed "enhanced engagement" with other Southern countries such as Brazil, India, Indonesia and South Africa. "About OECD," n.d., Web.

${ }^{162}$ Krasner, 1985, 116. 
to its large membership, ${ }^{163}$ whereas within the Security Council, significant members of the North are dominant through Permanent member status and veto power. The North has often felt "forced" to accept General Assembly resolutions pushed through by majority voting among Southern members, ${ }^{164}$ while the South has often felt marginalized by Permanent 5 decisions. As a result, according to the literature, North-South divisions have contributed to weakening the Assembly as Northern actors choose either to ignore Assembly decisions (such as the call for the NIEO) or circumvent the UN (as seen during the 'lost decade' of the 1980s). Likewise, divisions around the Security Council and actions by the P5 to disregard the voices of Southern members have contributed to increased lack of legitimacy and consensus in Council actions. ${ }^{165}$

The General Assembly and the Security Council often reflect the dichotomy between the North and the South within the UN system. As such, North-South tensions have often been the result of power struggles between the two as each attempt to exercise their authority. As the stronger of the two, the Council more often has been able to exert its influence over and above the Assembly. According to the literature, confrontations often occur in areas involving the setting of international agendas or when the Assembly is concerned that the Council is overstepping its boundaries. For instance, Zifcak states that after 11 September, the Council became increasingly involved in decisions that carry a 'legislative' or law making impact. The Assembly, having few mechanisms to exert this type of formal power, became concerned that Council decisions in "exceptional" situations would progress into "general" international law making, which necessarily

${ }^{163}$ Hewson, 2005, n. pag.; Hansen, 1979, 26; Krasner, 1985, 166-67.

164 Weiss et al., 2001, 240. For example, The South managed to push through The Charter of Rights and Duties of States despite strong Northern opposition, which was directed at the economic policies of the IFIs and Northern actors (Weiss et al., 2001, 240). In another example, the South was temporarily able to remove Israel from the United Nations Educational, Scientific and Cultural Organization (Hansen, 1979, 26).

${ }^{165}$ For more on legitimacy of the Security Council and P5 decisions, see: UNSG, In Larger Freedom: Towards Development, Security and Human Rights for All, A/59/2005, 21 Mar. 2005. 
diminishes the power of the General Assembly among international actors. ${ }^{166}$ Although space constraints prevent other detailed examinations, numerous examples of NorthSouth power struggles exist, such as the selection of the Secretary-General or environmental issues. ${ }^{167}$ According to the literature, these power struggles over agenda setting and attempts to limit the jurisdiction of the Security Council often sideline focus on the important issues.

When UN agencies and offices in New York become entangled in debates that threaten to impede its functions and operations, the Secretary-General has the potential to act as the mediator. As the executive head, this position of leadership acts as the official arbitrator between all members, representing their 'common interests,' especially the frequent confrontations between the North and the South. ${ }^{168}$ Several authors maintain that North-South divergence has proved to be a significant test of the position. For instance, the Secretary-General is to convey to the Security Council any potential threats to peace and security, yet, the Council frequently has not acted upon the Secretary-General's recommendations. ${ }^{169}$ Furthermore, lack of power in the role has lessened the SecretaryGeneral's ability in being an advocate for the South. However, Weiss points out that some Southern states oppose proposals to increase the Secretary-General's authority because they believe the administrative aspects would be exposed to greater Western influence. Yet, increased power, he maintains, would put the Secretary-General in a better position to ameliorate or even bypass New York differences in order to allow UN operations and projects to be more effective for those at the country level. ${ }^{170}$ Overall, the

${ }^{166}$ Spencer M. Zifcak, "United Nations Reform: Heading North or South?" Global Change, Peace \& Security 18.3 (2006): 143.

${ }_{167}^{167}$ For example, see: Zifcak, 2006, 141 and Jaggard, 2008, 231-34.

${ }^{168}$ Pérez de Cuéllar, 1993, 141; Weiss et al., 2001, 31.

${ }^{169}$ Pérez de Cuéllar, 1993, 129; Korany, 1994, 11. Weiss et al., 2001,, for example, describe how in 1992, Secretary-General Boutros Boutros-Ghali continually requested the Security Council "show the same interest in Somalia during 1992 that they were showing for the former Yugoslavia, 'a rich man's war"' (243).

${ }^{170}$ Weiss, 2009, 196. 
role of the Secretary-General is at times reduced due to lack of power to encourage Security Council attention to Southern issues, while Southern states are reluctant to provide the role more power, concerned about additional Northern influences. NorthSouth divergence thus plays a part in diminishing the role of the Secretary-General to act as moderator when the UN system is weighed down by North-South debates.

Overall, the analysis here suggests that the operational procedures and functions of the UN have experienced various problems and the North-South debate has either been intensified by them or been at the root of some of the problems. The literature on the UN system, as the final dimension to the North-South framework, suggests that disagreements will erupt around UN membership and participation, that power struggles will occur between the Assembly and the Council and that the ability of the SecretaryGeneral to perform leadership tasks will be reduced.

\subsection{Chapter Summary}

As the prominent global organization, the UN has significant 'potential' to influence decisions at the international level, yet these internal North-South struggles have often reduced the organization's effectiveness and presence. The primary objective of this chapter was to analyze the presence of and general components to North-South divisions affecting the United Nations. A brief history of the rise of North-South divisions began the chapter, highlighting key historical moments and trends. The remainder of the chapter then focused on analysis of each of the five key dimensions to North-South division - development, economic practices, aid, sovereignty and the UN system.

In the first dimension, development, the literature suggests two key areas of North-South division. First, the North and South are likely to divide when the question of who holds responsibility for developmental problems arises, most likely to emerge around discussions of external vs. internal causal factors. Second, divergence is also 
likely to occur when the Southern priority of development is confronted with the Northern priority of security.

Closely related to development, the literature proposes that the North and South have divided over economic practices, thus forming the second dimension. Here, the South is likely to oppose Northern economic policy prescriptions as well as the role of IFIs in managing and implementing economic policies, proving more problematic for the South in that they operate outside of the UN.

Identified as the third dimension to North-South divergence, aid has experienced various issues. However, analysis of the literature suggests that the North and South will likely divide around who should control aid, the level of commitments to aid and the quality of aid provided. In addition, there appears to be a trade-off occurring between control and commitments, where areas that are more strongly controlled by the North tend to receive higher amounts of aid but also have more conditionalities; whereas areas with lower Northern control have less conditions, but also lower and unreliable commitments to aid.

The fourth dimension identified is North-South issues related to sovereignty. Specifically, the literature suggests that the North and South in principle are likely to disagree over the interpretation of sovereignty, while in practice, divisions have occurred over the potential role of the Security Council to intervene (or not) in the affairs of states.

The final dimension identified demonstrating strong North-South divergence is that of sub-factors related to the UN system itself. Although there are various instances of North-South divisions, the literature focuses on four areas of greatest division. The North and South are likely to divide around membership, participation, power struggles and the leadership role of the Secretary-General.

Despite the strong presence of North-South divergence, there have been points of North-South convergence. Scholars argue that these have occurred for a variety of 
reasons, such as the involvement of key actors from both sides, persistence despite lack of universal support, search for common ground, and most importantly, actors chose to focus on practical aspects rather than ideological ones. ${ }^{171}$

Overall, this chapter has argued that there are five key dimensions to North-South divergence that are impeding the operations of the UN - development, economic practices, aid, sovereignty and the UN system. The identification of these dimensions does not exclude other potential areas of division; however, they tend to represent the strongest and most frequently re-occurring divisions affecting the UN. Within the broader scope of this thesis, this chapter sets the foundation to the analysis conducted in the remaining chapters. The next chapter will use the five-dimensional framework developed here to analyze the potential presence of North-South divisions affecting the Peacebuilding Architecture.

${ }^{171}$ See Krasner, 1985, or Weiss, 2009,. 


\section{THE PEACEBUILDING ARCHITECTURE: OLD INFLUENCES?}

\subsection{Introduction}

The new UN Peacebuilding Architecture represents a potentially significant contribution to improving the peacebuilding efforts of the international community. However, its impact on peacebuilding has been limited and it faces several challenges. Scholarly analysis thus far has largely focused on procedural and programmatic issues. ${ }^{172}$ The purpose of this chapter instead is to analyze the Architecture through a political lens, that is, the significance of its institutional setting. Specifically, this chapter will explore the effects of North-South dynamics upon the Architecture through the five dimensions identified by the author as creating strong points of divergence - development, economic practices, aid, sovereignty and the UN system. Are North-South divisions (or agreements) impeding (or improving) the ability of the Architecture to carry out its objectives?

This chapter argues that the same North-South divisions within the larger UN system, identified in Chapter 2, also affect the Architecture, both exerted externally from the broader UN system and reproduced internally from inside the three bodies. Varying degrees of divergence were seen in all dimensions, where some sub-factors appeared to have strong divergence (such as development vs. security or the role of IFIs) across to some that displayed moments of convergence (as in sovereignty). There were also instances where North-South dynamics as a whole appeared absent (for instance, the responsibility of development), potentially suggesting new understandings in NorthSouth relations in the peacebuilding context. Other smaller divisions occurred, such as North-North divisions over the role of the Security Council in the Peacebuilding Commission or South-South divisions around the selection of a Chair for the CountrySpecific Configurations. Nevertheless, the overriding analysis suggests that North-South

\footnotetext{
${ }^{172}$ See IPI, 2006,; NYU CIC and the IPI, 2008,; Malone, "UN Reform," 2006; Murthy, 2007, Scott, 2008,; Street et al., 2008,.
} 
divisions are a significant factor influencing the operations and outcomes of the Peacebuilding Architecture.

The chapter will begin with a brief background to the formation of the Peacebuilding Architecture, followed by an outline of its key features, highlighting any aspects that may be affected by North-South issues. The Architecture will then be analyzed against each of the five dimensions of North-South divergence. Finally, the chapter will conclude with a summary of the main findings.

\subsubsection{Brief Background Leading up to the Peacebuilding Architecture}

For much of the $20^{\text {th }}$ century, the international community was focused largely on peace as it related to the resolution of interstate conflict. Two World Wars and the ensuing Cold War underscored the very real tensions that existed across state borders. With the end of the Cold War, the United Nations found itself shifting focus to the outbreak of civil wars predominately within the South. ${ }^{173}$ In the span of a few years, however, Northern responses to civil wars through the UN became controversial, either unable to prevent conflict, unable to bring peace or unwillingness to take action. Although the 1992 Agenda for Peace was hoped to bring greater awareness to the new concept of peacebuilding, the 1990s were characterized by varying Northern responses to this mainly Southern issue. ${ }^{174}$ Furthermore, declining Northern engagement with the UN, in particular by the US, reduced the organization's effectiveness in responding to Southern conflicts. ${ }^{175}$

After 11 September, peacebuilding seemed to become a shared focus between the North and South, but it was quickly fractured again with the invasion of Iraq. ${ }^{176}$

${ }^{173}$ Paris, At War's End, 2004, 16.

${ }^{174}$ Roland Paris, "Post-Conflict Peacebuilding" The Oxford Handbook on the United Nation,. Ed. Thomas G. Weiss and Sam Daws. (New York: Oxford UP, 2007) 410.

${ }^{175}$ David Moore, "Levelling the Playing Fields \& Ebedding Illusions: 'Post-Conflict' Discourse \& Neo-Liberal 'Development' in War-Torn Africa," Review of African Political Economy 27.83 (2000): 18.

176 The actions of the United States and the United Kingdom also divided the North, but overwhelmingly angered the South (Hewson, 2005, n. pag.). 
Meanwhile, Afghanistan, Iraq, Sudan, Somalia, Haiti, Burundi, the Democratic Republic of the Congo and other states continued to remind the global community of the prevalence of civil conflict. The UNHLP on Threats, Challenges and Change report issued in 2005 thus brought peacebuilding and the threat of global insecurity back to the table, indirectly emphasizing the connection between Northern and Southern objectives: “Today's threats recognize no national boundaries, are connected, and must be addressed at the global and regional as well as the national levels." ${ }^{177}$ The Panel suggested that the United Nations was in a 'unique' position to provide peacebuilding and highlighted the absence of a peacebuilding structure. It subsequently outlined the basis for the Peacebuilding Architecture. ${ }^{178}$ Divisions between the North and the South seemed to subside when both sides agreed to endorse the establishment of the Peacebuilding Architecture at the 2005 World Summit, not only demonstrating a willingness by countries from all sides to work together, but also because the Architecture was intended to link up several key areas of disagreement in peacebuilding - political, economical, security and developmental. ${ }^{179}$ By December 2005, however, the two concurrent resolutions in the General Assembly and the Security Council establishing the Peacebuilding Architecture began to show signs of underlying North-South disagreement, as will be discussed below. ${ }^{180}$

\subsubsection{Structure and Functions of the UN Peacebuilding Architecture}

The Architecture's functions and structure were specifically designed to overcome North-South differences, but also reveal areas where North-South tensions might impede its ability to carry out its operations. For the countries on its agenda in 2010 - Sierra Leone, Burundi, Guinea-Bissau and the Central African Republic - this can

\footnotetext{
${ }^{177}$ UNHLP on Threats, Challenges and Change, 2004, 1.

${ }^{178}$ UNHLP on Threats, Challenges and Change, 2004, art. XV.

${ }^{179}$ NYU CIC and the IPI, 2008, par. 91.

${ }^{180}$ Paris, "Post-Conflict Peacebuilding," 2007, 423; UNGA, Resolution A/RES/60/180. 2005.
} 
have a significant impact. Structurally, the Peacebuilding Architecture is comprised of three bodies: the Peacebuilding Commission, the Peacebuilding Support Office and the Peacebuilding Fund. Functionally, several broad objectives across the three peacebuilding bodies are aimed at common problems to peacebuilding. The Architecture is meant to be the link between immediate post-conflict security concerns and long-term development issues. It aims to bring together and help coordinate all relevant actors engaged in inter-related peacebuilding activities. It also endeavors to raise and maintain international attention on the post-conflict country, including predictable medium- and long-term financing. It was also created to provide support during the transition period and attempt to design improved approaches to peacebuilding. ${ }^{181}$ Thus, are North-South divisions (or agreements) impeding (or improving) the ability of the Architecture (the PBC, PBSO or PBC) to carry out its objectives?

As the main body of the Architecture, the PBC has received the greatest attention. ${ }^{182}$ It was established as an intergovernmental subsidiary advisory body to both the Security Council and the General Assembly - to help balance Northern and Southern interests. At the same time, it is also to maintain a link with ECOSOC - to ensure development concerns are not lost amongst security concerns. ${ }^{183}$ As an advisory body, the PBC is non-operational and must rely upon other $\mathrm{UN}$ bodies and actors to put in effect any of its recommendations, with the proviso that no other UN entity can make decisions for or requests on behalf of the PBC that are already under consideration by the Security Council. The PBC thus has the potential to be limited to Security Council authority and the problems associated with P5 power. Structurally, the PBC is comprised of an

${ }^{181}$ UNGA, Resolution A/RES/60/180, 2005: preamble; United Nations, The United Nations Today, $2008,74$.

${ }^{182}$ Note that within the literature and in practice, the PBC is often generalized, referring to all three bodies of the Architecture (Jenkins, 2008, 3), the OC and the CSCs, which at times has led to confusion in recognizing the individual roles and responsibilities of each component.

${ }^{183}$ Scott, 2008, 9; UNGA, Resolution A/RES/60/180, 2005: par. 17. 
Organizational Committee (OC), Country-Specific Configurations (CSCs) and a Working Group on Lessons Learned.

The OC guides the overall PBC operations, receiving its agenda (country cases) from a combination of Northern and Southern sources: the Security Council, General Assembly, ECOSOC, the Secretary-General and in exceptional cases from member states at risk of conflict or a return to conflict. In order to balance North-South representation, the $\mathrm{OC}$ is comprised of 31 states drawn from various Northern and Southern dominated groups within the UN. In total, 7 members are selected from the Security Council, 7 members from ECOSOC, 7 are elected from the General Assembly, 5 are selected from the top troop contributing countries and 5 are selected from the top financial donors. ${ }^{184}$ The OC is headed by a Chair elected from the members, to facilitate committee discussions and liaise with other. ${ }^{185}$

Falling under the $\mathrm{OC}$, the country configurations were created to respond to the individual peacebuilding needs of each post-conflict country. The CSC is not limited to member states and can include a wide variety of Northern and Southern actors pertinent to the country's situation. ${ }^{186}$ Frequent Country-Specific Meetings (CSMs) are convened between the CSC actors and the country in order to coordinate and integrate common objectives. The CSCs/CSMs are also headed by a Chair selected from the OC countries participating in the specific country configuration. Finally, the Working Group on Lessons Learned consolidates understandings and experiences to develop 'forwardlooking' peacebuilding strategies. ${ }^{187}$

As the second arm of the Peacebuilding Architecture, the PBSO - falling under the Secretary-General within the Secretariat - is to provide administrative and analytical

\footnotetext{
${ }^{184}$ UNGA, Resolution A/RES/60/180, 2005: par. 4.

${ }^{185}$ NYU CIC and the IPI, 2008, par. 66.

${ }^{186}$ NYU CIC and the IPI, 2008, par. 38.

187 "Working Group on Lessons Learned," n.d. United Nations Peacebuilding Commission, Web.
} 30 Apr. 2009. 
support to the PBC, provide 'direction and guidance' of the PBF, and also to work with the Secretary-General in advising and coordinating other relevant UN bodies in conjunction with the peacebuilding aims of the PBC. ${ }^{188}$ Since the PBC is not designed to coordinate other UN bodies involved in the post-conflict country, the role of the PBSO becomes critical as the PBC's connection vis-à-vis the UN system.

Finally, the third arm, the Peacebuilding Fund was established as a multi-year standing fund to provide immediate financial assistance in critical moments of funding gaps in the post-conflict period, or to support other peacebuilding resources where it is not possible to arrange funding through existing means. ${ }^{189}$ The PBF is not intended to be the central funding resource for the PBC. ${ }^{190}$ Finally, the PBSO and the United Nations Development Programme (under the Multi-Donor Trust Fund) jointly operate the PBF, where the PBSO oversees the fund through evaluating and monitoring programs, while the Development Programme administers and manages the fund. ${ }^{191}$

Structurally, the three bodies have a broad yet interdependent function towards peacebuilding. The PBC as the intergovernmental body works to bring relevant actors outside the UN system together, the PBSO works to support the PBC and coordinate other UN bodies with the PBC's work and the PBF is to provide for funding gaps related to immediate peacebuilding needs. Functionally, however, the Architecture faced substantial problems in its launch and has equally come under criticism for demonstrating minimal 'value-added. ${ }^{192}$ At the same time, some emphasize its potential importance in

188 Jenkins, 2008, 3; Weiss, 2009, 187; "Memorandum of Understanding Between the United Nations and the United Nations Development Programme Relating to the Management of the Peacebuilding Fund," 28 Nov. 2006, United Nations Peacebuilding Fund, Web, 23 May 2009: art. IV (1).

${ }^{189}$ CPHS, 2007, 12; Jenkins, 2008, 3; PBF, "PBF Mission." n.d. United Nations Peacebuilding Fund. Web. 2 Aug. 2009.

${ }^{190} \mathrm{CPHS}, 2007,12$; NYU CIC and the IPI, 2008, 5; PBF, "UN Peacebuilding Fund: Bridging the Gap Between Conflict and Recovery," n.d. United Nations Peacebuilding Fund, Web, 2 Aug. 2009.

191 "Memorandum of Understanding," 2006.

192 IPI, 2006, 3; NYU CIC and the IPI, 2008, 2. 
bringing relevant actors together, something which other actors or UN bodies are not necessarily designed to navigate. ${ }^{193}$

It is in this context that this thesis seeks to make a new contribution to research on the Architecture by considering how understandings of the presence of North-South divisions from the larger UN system and from within the Architecture itself may offer alternative understandings to the experiences of the Architecture thus far. The remainder of the chapter will analyze the Peacebuilding Architecture for North-South divisions along the five dimensions identified in Chapter 2: development, economic practices, aid, sovereignty and the UN system.

\section{NORTH-SOUTH DIVISIONS IN THE ARCHITECTURE}

\subsection{Development: Where Priorities Lie}

In the first of these dimensions, development, the literature analyzed within Chapter 2 suggests that the North and the South are likely to divide along two aspects: which side holds responsibility for development problems; and the prioritization of development when faced with security. In terms of the Architecture, however, it appears that there are mixed North-South dynamics occurring around these two sub-factors as the following analysis will explore.

As the literature suggests, when development practices are in question each side is likely to hold the other as more responsible for the developmental problems of the South, thus also implying who should correct the problem. However, in analyzing the Architecture against this sub-factor, there do not appear to be any North-South divisions. Moreover, it does not seem that discussions pertaining to responsibilities (or potential blame) have occurred. This might be a new finding in terms of North-South dynamics around responsibility and peacebuilding, which will be discussed in Chapter 5.

${ }^{193}$ CPHS, 2007, 8; NYU CIC and the IPI, 2008, par. 90. 
In the second sub-factor, the literature suggests that the North and South typically divide over the priority of development (emphasized by the South) vs. security (stressed by the North). Within the Architecture, similar North-South divisions have occurred. During the PBC's formation, the G-77 and NAM felt that peacebuilding should be about development, whereas the North pressed for the Commission to "bridge the gap between security and development." ${ }^{\prime 194}$ The resolution documents establishing the PBC reflected the Northern 'bridging' emphasis, declaring that security and development are “...interlinked and mutually reinforcing." 195 The PBC also was placed under the Security Council chiefly because peacebuilding is still seen as a security issue. ${ }^{196}$ Further separating development from the PBC was the Resolution's emphasis on framing it as something that occurs largely after peacebuilding, where the $\mathrm{PBC}$ is to support strategies that will eventually "...lay the foundation for sustainable development."197 The PBC would instead create the atmosphere for development to occur at some later point. During OC meetings and deliberations, Southern members continue to feel this Northern influence: "The South is frustrated that development concerns are not pushed further in the PBC's agenda." 198 As a result, meetings, especially those in the beginning, often saw members divide as they advocated for either a development or security focus. ${ }^{199}$ NorthSouth dynamics around development both externally during its formation and internally

${ }^{194}$ Interview No. 4; IPI, 2006, 13.

${ }^{195}$ UNGA, Resolution A/RES/60/180, 2005: par. 4 of the preamble.

${ }^{196}$ Interview No. 4.

${ }^{197}$ UNGA, Resolution A/RES/60/180, 2005: par. 6 of the preamble; ActionAid et al., 2007, 12-13; CPHS, 2007, 13.

${ }^{198}$ Interview No. 2; See also Interview No. 4.

${ }^{199}$ Interview No. 2. A review of several Summary Records of the CSMs displayed a range of differences in emphasis on what should be prioritized. While some participants simply suggested improving the links between security and development (see, for example PBC, Sierra Leone Configuration PBC/1/SLE/SR.2, 12 Oct. 2006: par. 31, 57;PBC, Sierra Leone Configurarion PBC/1/SLE/SR.5, 22 June 2007: par. 37), while others strongly emphasized that either security or development be the priority (see, for example PBC, Sierra Leone Configuration PBC/1/SLE/SR.2, par. 46 ;PBC, Sierra Leone Configurarion PBC/1/SLE/SR.5, par. 25, 46 ). In addition, there were a few instances where Northern and Southern actors emphasized the importance of the other side's priority (see PBC, Sierra Leone Configuration PBC/2/SLE/SR.3, 19 May 2008: par. 5-8). 
amongst members have thus strongly shaped the focus of the PBC towards a security agenda.

Along with the PBC, it appears that the PBF also has been influenced by NorthSouth dynamics that emphasize security. Its funding is geared mainly towards reducing potential conflict problems and improving immediate stability. ${ }^{200}$ While this was the intended aim - to provide both emergency and catalytic funding to prevent potential threats to peace - it has been argued that no connections have been made between its short-term objectives to relieve pressure with long-term development objectives to which much of the emergency issues must transition. ${ }^{201}$

In summary, the Architecture is experiencing mixed North-South dynamics around the development dimension. Although there appear no divisions affecting it in terms of responsibility for development, the analysis suggests that North-South disagreements have reduced the priority of development within the Architecture, which instead has emphasized security or reframed development concerns into security issues. The effect has served to restrict both the PBC and the PBF from engaging in the development needs of peacebuilding - development largely has been separated from the PBC, OC meetings have seen ongoing debates between members, while short-term security objectives do not connect to long-term development objectives in the PBF.

\subsection{Economic Practices: Disconnected Agendas}

Like development, there has been a mixture of North-South dynamics affecting the Architecture around the dimension of economic practices, specifically around economic policies and the role of financial institutions. As the literature suggests, the South is likely to oppose economic policies prescribed by the North, as well as try to

\footnotetext{
${ }^{200}$ PBF, "UN Peacebuilding Fund: Bridging," n.d.

${ }^{201}$ ActionAid et al., 2007, 13.
} 
limit the involvement of IFIs in economic and development decisions, while the North is likely to push for economic matters be dealt with by the IFIs.

Economic policies have been one of the longest-running and strongest sources of friction between the North and the South within and outside of the UN. As of yet, however, discussions around policies do not appear to have entered the meetings and debates of the Architecture, therefore not affected by North-South divisions. The previous chapter noted that economic policies are generally considered a significant part of the development agenda, thus, the absence of North-South divergence may in part be due to the separation of development from the PBC, as discussed in Chapter 4.

In strong contrast, the Architecture appears to have been affected by North-South divisions around the role of financial institutions, namely the World Bank and the IMF. Originally, to help promote coordinated efforts between the policies of the financial institutions with other peacebuilding objectives, the PBC was intended to 'build up connections with the IFIs. ${ }^{202}$ Attempts to include them as members on the OC, however, became subject to an intense year-long North-South debate, where many members of the South were against the inclusion of IFIs in any format. ${ }^{203}$ This was in part due to the bodies not being intergovernmental in nature, ${ }^{204}$ but also because the South was concerned with the additional Northern influence they would bring. ${ }^{205}$ Eventually it was decided that the IFIs be included as 'invited participants;' though, they could be excluded at any time at the discretion of the Chair. ${ }^{206}$ The effect of this North-South division

${ }^{202}$ IPI, 2006, 13; Scott, 2008, 9.

${ }^{203}$ Interview No. 4; Security Council Report, Special Research Report: Peacebuilding Commission, No. 2. (New York: Security Council Report, 5 Oct. 2007) 6-7. For instance, see Venezuela's objections in the UNGA, Plenary Meeting A/60/PV.66. 20 Dec. 2005: 4.

${ }^{204}$ Interview No. 4.

${ }^{205}$ The debate was reduced to semantics over the interpretation of "participate" as outlined in paragraph 9 of the joint resolutions establishing the Commission, where institutional donors would be "invited to participate in all meetings of the Commission..." (UNGA, Resolution A/RES/60/180: par. 9).

${ }^{206}$ Security Council Report, 2007, 6-7; PBC, Organizational Committee PBC/1/OC/SR.7, 16 May 2007. 
replicated within the Architecture has been the continued distancing of IFIs from the PBC.

Some observers feel that operationally, it would have been difficult to include the IFIs as participants on the $\mathrm{OC},{ }^{207}$ while it also has been argued that their exclusion has been a "big mistake" as they have not been engaged enough with the PBC. ${ }^{208}$ This seems to have occurred in practice, where North-South divisions that distanced the financial institutions affected the operations of the PBC in Burundi. Concerns by the IMF over "economic governance and allegations of corruption" caused the World Bank to halt funding to the country. ${ }^{209}$ This had an immediate impact on the economic situation at the country level, increasing tensions and worry of renewed violence. The Burundi CSC attempted to engage with the IFIs to reinstate financial support, having to do extensive work behind-the-scenes with the World Bank. ${ }^{210}$ Members of the Burundi CSC questioned whether the IMF was working in conjunction with the Commission's objectives. $^{211}$ Eventually negotiations resulted in changes on the part of the Government to address governance issues, while funding was resumed from the financial institutions. $^{212}$ North-South divisions that distanced the IFIs from the Architecture in part appear to have impeded coordination of joint objectives - as well as the possibility of avoiding the dilemma altogether - and raised potential security problems. ${ }^{213}$

In general, North-South dynamics around the dimension of economic practices is having mixed effects upon the Architecture. Economic policies appear to be absent from discussions or debates, thus giving the impression that there are no North-South debates occurring in this area. This will be explored further under the development section of the

\footnotetext{
${ }^{207}$ Interview No. 6.

${ }^{208}$ Interview No. 4.

${ }^{209}$ Scott, 2008, 15.

${ }^{210}$ Interview No. 4.

${ }^{211}$ PBC, Burundi Configuration PBC/2/BDI/SR.1, 19 Sep. 2007.

${ }^{212}$ Scott, 2008, 15.

${ }^{213}$ NYU CIC and the IPI, 2008, 3.
} 
following chapter. However, the Architecture seems to be affected by North-South divergence around the roles of the IFIs. The effect has impeded the ability of the PBC and the IFIs to coordinate and integrate their objectives, which in part appears to have reduced the effectiveness of the PBC in dealing with an IFI-related security issue in Burundi.

\subsection{Aid: Arms-length Control, Minimal Commitments and Quality Concerns}

In the third dimension, the literature suggests that the North and the South are apt to disagree on who should control aid, the level of commitment in meeting aid requirements and the quality of aid given. Within the Architecture, aid for post-conflict peacebuilding in countries on the PBC agenda originates from two main sources: the PBF for immediate or 'catalytic' needs; and country-level pledging conferences for long-term needs. Analysis of North-South divisions affecting the PBF and aid will form the basis of this section, while country-level pledging conferences will be examined in the subsequent Sierra Leone chapter. The following analysis suggests that North-South divisions around aid are having strong affects on the capacity of the Architecture to meet its peacebuilding needs.

North-South divisions arose around the control of and access to the PBF and its funds. Within and outside of the Architecture, there was initially a general misconception of the anticipated relationship between the PBC and the PBF. The South had wanted and, along with others, thought that the $\mathrm{PBF}$ would be managed by the $\mathrm{PBC}$, whereas Northern donors and the UN Secretariat wanted and eventually designed the Fund to be independent of the Commission. ${ }^{214}$ Furthermore, funds would be allocated according to country-specific "Priority Plans," strategies to address key peace issues, based on recommendations from relevant stakeholders; whereas, the PBC might be given the

${ }^{214}$ Interview No. 8; NYU CIC and the IPI, 2008,: par. 58. The confusion surrounding the implementation of the PBF in its early days, to a certain extent, was initially perceived incorrectly as a problem of the PBC. 
opportunity to provide advice during the planning stage, but is mostly relegated to receiving progress updates. ${ }^{215}$ PBC members are disappointed that they must make requests for money, which many feel limits its capacity to act on behalf of the postconflict countries. ${ }^{216}$ On the other hand, part of the original appeal for Sierra Leone and Burundi to be on the PBC agenda was the perceived access to funds. At times, this focus on funding overshadowed and shifted attention away from the $\mathrm{PBC}$ and its peacebuilding initiatives as the Government became preoccupied with how to spend the PBF funding. ${ }^{217}$ In general, North-South divisions over the control of aid has seen Northern actions limit the access the PBC has both to funds in the PBF and to the strategies that allocate the funds for peacebuilding, while Southern post-conflict country actions at times has reduced focus on $\mathrm{PBC}$ peacebuilding objectives.

Connected to the above, the literature suggests that when the North has greater control of aid (such as in the IFIs), commitments are likely to be higher but with more conditions, whereas if the South has greater control over aid (such as the UNDP), commitments are likely to be less substantial and are voluntary. The PBF mirrors many of the North-South issues found in other Southern-driven UN bodies. Its budget is small relative to other programs, US $\$ 250$ million, especially to that of peacekeeping, around US $\$ 8$ billion. ${ }^{218}$ Contributions are voluntary and thus unreliable, it has been slow to reach its funding targets, as well as other issues, although space constraints prevent their discussion here. ${ }^{219}$ Thus, North-South divisions around aid appear to have reduced

215 Malone, "UN Reform," 2006, 91; UNGA, Report of the Secretary General on the Peacebuilding Fund A/63/818, 13 Apr. 2009: Annex 3.6, par. 3.1.

${ }^{216}$ Interview No. 4; Interview No. 1.

${ }^{217}$ ActionAid et al., 2007, 14; CPHS, 2007, 13. This has been especially 'challenging to deal with' for the PBC in the case of the Burundi Government, where the Government maintains a strong focus on the funding (Interview No. 1; Interview No. 2; Street et al., 2008, 39-40).

${ }^{218}$ Carolyn McAskie, "The International Peacebuilding Challenge: Can New Players and New Approaches Bring New Results?" The Lloyd Shaw, Lecture in Public Affair, Halifax, NS, 22 Nov. 2007: 13; PBF, "UN Peacebuilding Fund: Bridging," n.d.

${ }^{219}$ PBF, "UN Peacebuilding Fund: Bridging," n.d.; See ActionAid et al., 2007, 15 for additional issues around the PBF advisory body. 
commitments and the reliability of funding to the PBF, lowering the capacity of the Architecture to meet its peacebuilding aims.

Finally, the literature suggests that the quality of aid has become a source of North-South divergence due to disagreements over what constitutes aid and how aid is implemented. This research did not reveal issues related to the quality of financial contributions made through the PBF, in large part because fund dispersal is still in the beginning stages (only initiated in 2007), thus further investigation is required. However, aid quality was affected by North-South dynamics during the implementation of the quick release of US $\$ 35$ million by the PBF to jumpstart PBC peacebuilding projects. In an unexpected finding, North-South agreement to release the funds quickly, created a 'sequencing' issue for the PBC, since money was allocated before an agreement with the post-conflict government had been reached on what to do with it. ${ }^{220}$ The joint decision between the two sides, though, was based on different reasons, where the North wanted to show the "impact" of the PBC, while Sierra Leone and Burundi were focused on receiving the funds. ${ }^{221}$ North-South convergence around the implementation of aid instead impeded the PBC from fulfilling its role to establish an agreement and peacebuilding priorities with the post-conflict governments.

Within the aid dimension, North-South dynamics around control, commitments and quality of aid implementation limited the capacity or impeded the operations of the Architecture. Unexpectedly, this also included an area of North-South convergence. Overall, the effects on the Architecture included limited access by the PBC to emergency funds and influence on PBF Priority Plans, reduced and unreliable financial contributions to the PBF and interference in the PBC's ability to establish a peacebuilding agreement with the post-conflict countries.

${ }^{220}$ ActionAid et al., 2007, 14. It is important to note that this created several problems for the PBC that cannot be explored here due to space constraints.

${ }^{221}$ ActionAid et al., 2007, 14. 


\subsection{Sovereignty: Early Divisions}

Within the dimension of sovereignty, the literature suggests that each side has divided over the interpretation of state sovereignty (in principle), as well as the role of the Security Council and its potential to intervene or not intervene in the affairs of states (in practice). The analysis here suggests that North-South dynamics in both areas of the sovereignty dimension are affecting the Architecture, but the effects have been mixed.

During discussions around the setup of the PBC, countries such as Iran strongly stressed that the sovereignty of states be respected, that the Commission could not intervene in post-conflict countries of its own accord. ${ }^{222}$ The South's argument for protection of state sovereignty resulted in the addition of a stipulation to the resolution document where placement on the PBC agenda would be contingent upon a country request. ${ }^{223}$ Although this helped to allay Southern concerns of uninvited intervention, the request also becomes a tacit agreement to allow outside involvement and examination. Thus, this North-South division from the external UN system appears to have created an unexpected effect on the Architecture, where Northern and Southern PBC members can be said to have reached a certain level of convergence. Both sides have agreed in principle that the combination of a formal request and acceptance of the request will entail intervention in the country's operations in order to build peace. This has the potential to improve PBC engagement with the post-conflict country as a strong NorthSouth barrier has been overcome.

In contrast, original conceptions of the $\mathrm{PBC}$ also indicated that it would work to prevent conflict in countries at risk. Southern actors were concerned that this would legitimize pre-emptive intervention and argued for the removal of wording that would have established the Commission as a conflict prevention body. ${ }^{224}$ The PBC lost an

\footnotetext{
${ }^{222}$ UNGA, Plenary Meeting A/60/PV.66, par. 14.

${ }^{223}$ Murthy, 2007, 47-48.

${ }^{224}$ CPHS, 2007, 11-12; Murthy, 2007, 47-48; UNGA, Plenary Meeting A/60/PV.66: 4.
} 
important function and instead remains a 'tool of the recovery process. ${ }^{225}$ Thus, as a result of external North-South divergence, the PBC was reduced in both scope and power.

Internally, North-South divisions around the role of the Security Council appear to have been replicated in the design of the PBC. The Security Council often has been considered a problem amongst the South with respect to state sovereignty. Originally the G-77/NAM had hoped the PBC would be operational and offer some form of 'counter' to the intervening power of the Security Council. Instead, Northern interests within the UN appeared to prevail, as the $\mathrm{PBC}$ was made non-operational and placed primarily under the Council, effectively eliminating any opportunity for the PBC to take independent actions. ${ }^{226}$ Furthermore, the PBC is prohibited from providing advice to other actors if the post-conflict country is on the agenda of the Security Council, and equally that it will provide advice to the Council only at the Council's request. ${ }^{227}$ Consequently, this NorthSouth division also has reduced the scope and power of the PBC, making it nonoperational and largely dependent upon the Council or, more specifically, the political will of the P5. ${ }^{228}$ Of note, there also were signs of a smaller North-North division where some countries, such as Switzerland, were concerned about the power given to the Security Council over the PBC. ${ }^{229}$ Nonetheless, the overriding division was between the North and the South.

In practice, whether or not the Security Council will demonstrate the political will to engage with peacebuilding matters on the PBC agenda appears weak. The country request may open the door for engagement; however, this does not mean that the Council,

\footnotetext{
${ }^{225}$ Malone, "UN Reform," 2006, 90.

${ }^{226}$ Murthy, 2007, 47-48.

${ }^{227}$ UNGA, Resolution A/RES/60/180, 2005: par. 12(b), 12(c), 16.

${ }^{228}$ Murthy, 2007, 47-48.

${ }^{229}$ UNGA, Plenary Meeting A/60/PV.66: 12; This research recognizes that North-North divisions occur, but the scope and limitations of this thesis prevents further exploration. Nonetheless, the overriding division is between the North and the South.
} 
with its inconsistent track record, will take the necessary interest or action if needed. It appears that this has been the case within the $\mathrm{PBC}$, where the Council has shown mixed actions, with some convergence but more often divergence. In the former, some members of the Security Council are looking to the PBC as a place to shift some of their workload, thus ensuring that smaller security concerns are not "abandoned" by the Council. ${ }^{230}$ For instance, the Council had asked for specific advice on the situation in Guinea-Bissau in December of 2007 to assist in its work on the country. ${ }^{231}$ In large part, however, this has been rare and the Security Council does not appear to have made many attempts to seek the advice of the PBC. For instance, the Council did not request an annual report from the $\mathrm{PBC}$ on its operations until the General Assembly itself requested to receive one. ${ }^{232}$ In another example, immediately after the assassination of Guinea-Bissau's President in March 2009, people in the Commission looked to the Brazilian Chair of the GuineaBissau CSC for leadership. The Chair had already been working with the post-conflict country for over a year, had been on the ground and was current on the tensions and situation in the country, yet the Security Council began discussions on the situation without approaching the CSC or the PBC for advice. ${ }^{233}$ On the whole, North-South divisions within the greater UN system around the Security Council and its willingness to engage seem to be affecting the $\mathrm{PBC}$, where the Council does not seek advice or input from the PBC.

North-South divergence exerted from the broader UN system onto the Architecture around the dimension of sovereignty has had the overall effect of limiting the scope and operational power of the PBC to perform its peacebuilding objectives. The effects have made the PBC dependent upon Southern countries to engage with it, and

${ }^{230}$ Interview No. 3.

${ }^{231}$ United Nations General Assembly/Security Council (UNGA/SC), Letter from the President of the Security Counci to the Chairperson of the Peacebuilding Commission A/62/736-S/2007/744, 14 Dec. 2007.

${ }^{232}$ UNSC, Resolution S/RES/1646 (2005), 20 Dec. 2005.

${ }^{233}$ Interview No. 2a; Interview No. 4. 
dependent upon the Security Council to take actions on its behalf. However, one unexpected result saw North-South disagreements emanating from the broader UN system around the principle of sovereignty produce a 'form' of convergence within the $\mathrm{PBC}$, where the acceptance of a country request creates an implied agreement that intervention will occur, and thus improve PBC engagement with the country.

\subsection{UN System: Design Flaws}

Within the dimension of the UN system, the literature suggests that the North and South have divided around membership, participation, jurisdiction between the General Assembly and the Security Council (power struggles), and leadership of the SecretaryGeneral. These same divisions also appear to be affecting the Peacebuilding Architecture from both the broader organization and from within the Peacebuilding Commission.

As the literature in the previous chapter suggests, the North and South are likely to divide over membership in $\mathrm{UN}$ bodies, especially when there is potential for an imbalance that could give greater say (or voting power) to one side or the other. Within the PBC, similar North-South divisions also emerged over the allocation of seats in the OC. Unique to the PBC an attempt has been made to keep a balance between members from different regions, from the two main UN bodies, as well as from top financial- and top troop-contributing countries. ${ }^{234}$ However, North-South rivalry for inclusion enlarged the initial 20-member proposal for the OC to 31 members, in large part the result of a push by the South to include the General Assembly, which had not been a part of the original proposal. ${ }^{235}$ There have been concerns that the larger size has made the OC too cumbersome to be effective and decision-making at times has been drawn out, as much as

${ }^{234}$ UNGA, Resolution A/RES/60/180, 2005: par.1-2, par. 4. See 3.1.2 for breakdown of seats. Lists of members can be found in the Annexes of the annual reports to the General Assembly and the Security Council of the Peacebuilding Commission. The most recent list is from the PBC's second session, June 2008, and therefore is not current. However, it may be used for general reference purposes (UNGA/SC, Report of the Peacebuilding Commission on its Second Session, A/63/92-S/2008/417, 24 June 2008: 19).

${ }^{235}$ Scott, $2008,14$. 
12 months; yet, others feel that the viewpoints brought to the discussions are broader and more representative, producing greater consensus. ${ }^{236}$ There were also other North-South debates concerning the ratio of members from different bodies, however, space limitations prevent further discussion here. ${ }^{237}$ Likewise, after the PBC's formation, divisions similar to those seen around IFI membership (discussed above) also plagued OC meetings around membership of the European Community, eventually resolved in the same manner. ${ }^{238}$ These various ongoing disagreements preoccupied initial OC discussions to the extent that making decisions on other areas critical to the Architecture were delayed. ${ }^{239}$ Therefore, North-South divisions around membership affected the PBC from the broader UN system and were replicated within it, producing a trade-off where deliberations have detracted from other important discussions, but as the $\mathrm{OC}$ has developed, decisions between members have become more inclusive.

Closely related to membership, the literature suggests that North-South divisions will surface around the level of participation of members with greater influence in a UN body, such as the Southern majority in the Assembly or the P5 veto power in the Council. Participation on the OC also became subject to these North-South divisions when a contentious argument over the participation of the P5 emerged. The South was opposed to the P5 having the same permanent representation on the OC. ${ }^{240}$ However, at the same time as establishing the $\mathrm{PBC}$, the Security Council also passed a resolution declaring that the P5 permanently would hold 5 of the Council's 7 allotted seats on the OC. ${ }^{241}$ This move strongly angered many in the South who saw this as a way to bring veto power into

${ }^{236}$ CPHS, 2007, 9; Interview No. 2; Interview No. 3; Interview No. 4; Murthy, 2007, 42; Security Council Report, 2007, 6-7.

${ }^{237}$ For example, see Venezuela's arguments in the plenary meeting prior to acceptance of the Resolution document establishing the PBC. UNGA, Plenary Meeting A/60/PV.66: 4-5.

${ }^{238}$ For further information, see: Scott, 2008, 14-15; PBC, Organizational Committee PBC/1/OC/SR.2, 13 July 2006: par. 77.

${ }^{239}$ See: Malone, "UN Reform," 2006, 91.

${ }^{240}$ Interview No. 2; Interview No. 5.

${ }^{241}$ UNSC, Resolution S/RES/1646, 2005. 
the PBC through a "back door" channel. ${ }^{242}$ As one official explained, this "led the G-77 to claim that the Security Council wanted to dominate and control the $[\mathrm{PBC}]$ agenda. This became the overriding focus." ${ }^{243}$ Instead of trying to improve engagement with Northern members by obtaining promises of commitments to the PBC, the G-77 focused their attention on opposing P5 participation. Equally so, after establishing their permanent status on the OC, most have not made important attempts to further their engagement or their responsibilities as members, such as with long-term commitments to the PBC or the post-conflict countries, either financially or operationally. ${ }^{244}$ Thus, the effect of North-South confrontations over participation in the OC substantially reduced involvement and commitment from some of the most significant Northern actors, weakening the foundations of the $\mathrm{PBC} .^{245}$

North-South divisions also have affected the participation of civil society organizations (CSOs) in the PBC. ${ }^{246}$ It has been argued that CSOs can be instrumental in developing consensus and peacebuilding support within the population, as well as become a voice and connection to the population for post-conflict governments. ${ }^{247}$ At the same time, issues of transparency, politicization and state dependency have contributed to negative images of CSOs. ${ }^{248}$ Thus, Southern members opposed inclusion over concerns of interference in "national ownership." 249 The end result contributed to a restrictive

${ }^{242}$ United Nations General Assembly (UNGA), Department of Public Information, Press Release GA/10439, 20 Dec. 2005.

${ }^{243}$ Interview No. 5.

244 An exception to this is the United Kingdom, which made significant financial, security, political and long-term commitments to Sierra Leone long before the creation of the Architecture. Interview No. 5; NYU CIC and the IPI, 2008,: par. 48; PBF, "Pledges, Commitments and Deposits." n.d. United Nations Peacebuilding Fund. Web. 25 Mar. 2010; United Nations Peacebuilding Support Office (PBSO), "Mapping External Resource Flows to Burundi," 10 Mar. 2007; PBSO, "Mapping External Resource Flows to Sierra Leone," Aug. 2007).

${ }^{245}$ One interviewee commented that interest from strong Southern countries is also missing, but appears to be due to indifference rather than North-South issues (Interview No. 5).

${ }^{246}$ Interview No. 2; Scott, 2008, 10.

${ }^{247}$ ActionAid et al., 2007, 8.

${ }^{248}$ ActionAid et al., 2007, 8, 16; Busumtwi-Sam, 2004, 363-64, 371; Costy, 2004, $169-71$.

249 PBC, Organizational Committee PBC/1/OC/SR.2, 2006; PBC, Organizational Committee PBC/1/OC/SR.3, 2006; PBC, Organizational Committee PBC/1/OC/SR.7, 2007. 
selection process for CSOs, "making participation possible only under fairly complicated procedures." 250 Therefore, another effect of North-South divisions replicated within the PBC appears to be limited participation of CSOs, often an important advocate and representative of the people.

Frequently, North-South divisions are linked to power struggles between the General Assembly and the Security Council. As the literature suggests, these two prominent bodies are apt to confront each other as they vie for control and influence over the setting of international agendas, while the Assembly often attempts to contain the more powerful Council. The PBC became the main object of this power struggle between the Assembly and the Council, especially during its first session in 2006-07. ${ }^{251}$ Among the South, it was hoped that the PBC would answer to and reinvigorate the Assembly, counter the Security Council and support the role of the largely reduced utility of ECOSOC. ${ }^{252}$ The PBC instead was placed under the Security Council, and to compensate for the feared overshadowing of the Council, the Commission was also made a subsidiary body of the General Assembly. ${ }^{253}$ Some of the Commission's responsibilities consequently were divided between the two bodies. ${ }^{254}$ Furthermore, the power struggle alienated the PBC's link to ECOSOC, failing to connect its development focus with the security focus of the Council as was originally hoped. ${ }^{255}$ Additionally, the power struggle created other issues that are not possible to explore here. ${ }^{256}$ Hence, the effect of NorthSouth divisions from the broader UN system on the PBC has, among other things, divided its reporting responsibilities and distanced it from ECOSOC and development.

${ }^{250}$ Security Council Report, 2007, 2. For specifics on CSO inclusion, refer to PBC, Organizational Committee, Provisional Guidelines for the Participation of Civil Society PBC/1/OC/12, 6 June 2007.

${ }^{251}$ NYU CIC and the IPI, 2008, par. 63; UNGA, Plenary Meeting A/60/PV.66: 9-10.

${ }^{252}$ Scott, $2008,9$.

${ }^{253}$ UNGA, Plenary Meeting A/60/PV.66: 10.

${ }^{254}$ Murthy, 2007, 45; UNSC, Resolution S/RES/1646, 2005.

${ }^{255}$ Jenkins, 2008, 2; Murthy, 2007, 54; Scott, 2008, 9; UNGA, Plenary Meeting A/60/PV.66: 10.

${ }^{256}$ For example, see: NYU CIC and the IPI, 2008, par. 63. 
When North-South tensions do arise within the UN system, the leadership of the Secretary-General can be potentially significant in mitigating problems. However, the literature suggests that North-South divergence often will limit the power and effectiveness of the Secretary-General to play this role. This research discovered issues around the role of the Secretary-General and the Architecture, but they do not appear to be a result of North-South confrontations. As of yet, the role of the Secretary-General in mitigating differences within or around the PBC has not occurred, and it is therefore not yet possible to determine the significance of this role. In contrast, North-South tensions have affected leadership within the Commission itself. Space does not permit discussion of the effects on the PBC Chair; ${ }^{257}$ however, the effect of North-South dynamics on the Chair of the CSCs is noteworthy. CSC chairs have "tremendous power," the state occupying this position will have a strong influence on the direction and decisions made around the peacebuilding processes for the post-conflict country. ${ }^{258}$ Southern countries were concerned that a Northern Chair would be too strong and generate a top-down approach to peacebuilding. ${ }^{259}$ Norway already had been named for the Burundi CSC and the South wanted a Southern state to Chair the Sierra Leone CSC, thus, El Salvador was chosen. Sierra Leone however rejected this choice and instead requested a Northern Chair, creating a small South-South split within the CSC. ${ }^{260}$ The Government of Sierra Leone felt a Northern Chair would have the financial capacity and the broader influence required to handle the post-conflict peacebuilding needs of Sierra Leone, resulting in the appointment of the Netherlands. ${ }^{261}$ To a certain extent, this represents North-South

${ }^{257}$ For more information see NYU CIC and the IPI, 2008, par. 63

${ }^{258}$ Interview No. 2.

${ }^{259}$ Interview No. 1.

${ }^{260}$ Interview No. 4; Interview No. 3. This research recognizes that South-South divisions occur, but the scope and limitations of this thesis prevents further exploration.

${ }^{261}$ Interview No. 3; Interview No. 4. 
convergence, where both sides appear to have focused on practical issues rather than ideological, ${ }^{262}$ potentially improving internal discussions and decision-making. ${ }^{263}$

In summary, the analysis of the Architecture within the dimension of the UN system suggests that North-South divisions are affecting the PBC around membership, participation and power struggles. The effects have been varied including increasing the size of the $\mathrm{OC}-$ prolonging deliberations in meetings but improving consensus, limiting engagement and commitment from important Northern actors, minimizing interactions with CSOs, dividing the responsibilities of the PBC between the General Assembly and the Security Council, no effects on the leadership role of the Secretary-General, impeding the leadership role of the PBC Chair (not explored here) and some North-South agreement over the CSC Chair. Thus, the overall analysis reveals that the PBC is affected largely by North-South divergence, mainly as external influences upon the PBC, which appears more often to limit its peacebuilding functions.

\subsection{Chapter Summary}

The primary objective of this chapter was to analyze the effects of North-South dynamics, exerted both externally and internally, on the Peacebuilding Architecture through five dimensions typical of strong North-South divergence - development, economic practices, aid, sovereignty and the UN system. The chapter began by presenting a brief background leading up to the establishment of the Architecture, along with a synopsis of its key structures and functions that also highlighted potential areas for North-South confrontations. Each dimension was then analyzed against the Architecture.

In the first dimension, development, North-South debates do not appear to have emerged around who holds responsibility for development problems. However, North-

\footnotetext{
${ }^{262}$ Recall Weiss's (2009) description for preferred convergence, 154-172

${ }^{263}$ Interview No. 2.
} 
South divisions have prioritized security issues and therefore have impeded the $\mathrm{PBC}$ and the PBF from engaging in peacebuilding activities that support development.

Within the dimension of economic practices, there do not appear to be NorthSouth discussions around economic policies. In contrast, North-South disagreements have distanced the IFIs from the Architecture, which appears to have limited the ability of the PBC and the IFIs to coordinate and integrate their peacebuilding objectives. This in part contributed to a potential risk to peace in Burundi, as discussed above.

Analysis of the third dimension, aid, overwhelmingly appeared to suggest that North-South dynamics were restraining the capacity or inhibiting the operations of the Architecture. An unexpected finding here was that North-South convergence also contributed to these effects. Connections between the PBC and the PBF and its emergency funds are limited, financial contributions are low and voluntary - thus unreliable and interference in creating a peacebuilding agreement between the PBC and the post-conflict countries.

North-South divergence around the dimension of sovereignty has in practice appeared to reduce the scope and operational power of the PBC, making it dependent upon both the Southern post-conflict country for engagement and dependent upon the Security Council to take actions if required. In principle, however, North-South divergence exerted from the broader UN system created a form of convergence within the $\mathrm{PBC}$, where the acceptance of a country request is a tacit agreement of intervention, improving the PBC's ability to engage with the post-conflict country.

In the final dimension, the UN system, the majority of sub-factors (membership, participation and power struggles) demonstrated North-South divergence, having had mixed effects on the Architecture. The size of the OC membership has been enlarged improving consensus but extending discussions in meetings. The participation of important Northern actors in the PBC - such as some of the P5 - has been reduced, while 
PBC interactions with CSOs have been restricted. Power struggles have divided the responsibilities of the PBC between the General Assembly and the Security Council. The leadership role of the Secretary-General has not been affected as of yet, while some North-South agreement around the leadership of the CSC Chair has occurred. Despite the mixed effects, the overall analysis suggests that the PBC is impeded by North-South divisions within the dimension of the UN system.

In applying the five-dimensional framework to the Architecture, this chapter has argued that North-South divergence is impeding the operations of the Peacebuilding Architecture. This chapter thus presents the central analysis and argument to the overall thesis. It does not suggest that these are the sole factors reducing the ability of the Architecture to reach its objectives, as peacebuilding is complex and there always will be a combination of factors involved. Furthermore, this chapter also revealed the presence of North-North or South-South divisions. However, as has been shown, North-South disagreements appear to be the most common divisions, with a significant impact and in some cases critical to UN peacebuilding. The next chapter will extend this analysis from an international level to a consideration of these dynamics within a specific case by examining the extent of these North-South divergences within one of the Architecture's country cases: Sierra Leone. 


\section{SIERRA LEONE}

\subsection{Introduction}

As one of the first two cases on the Peacebuilding Architecture's agenda, the case of Sierra Leone offers the possibility to observe the effects North-South interactions may be having on the country's peacebuilding process. Analysis in Chapter 3 suggests that North-South dynamics, in particular divisions, both externally and internally have impeded the capabilities of the Architecture and therefore potentially its peacebuilding efforts in Sierra Leone. To explore this, the chapter will begin by presenting a brief background to Sierra Leone, including the factors contributing to and present during the conflict. Then, using the author's five-dimensional framework of predominant NorthSouth divisions (development, economic practices, aid, sovereignty and the UN system), the remainder of the chapter will examine North-South effects and outcomes within Sierra Leone. The main purpose of this chapter is to examine the extent of North-South effects on the ability of the Architecture to carry out its own peacebuilding objectives. A synopsis of the main findings of the above analysis will conclude the chapter.

The general findings indicated that the range of North-South divisions connected to the Architecture also is impeding Sierra Leone's peacebuilding process. The outcomes were found to have varying effects, where some divisions had the potential to risk peace (development vs. security) while areas that experienced a certain level of convergence (sovereignty) appeared to improve some issues (at least in principle, such as those around human rights). Some divisions also produced unexpected outcomes, where strong divisions at the level of the Architecture did not appear to have substantial bearing in the country (such as the power struggles between the General Assembly and the Security Council).

It should be reiterated that the author was not able to conduct field research in Sierra Leone, thus the findings in this chapter of the effects on peacebuilding are limited 
and future research is necessary, as will be discussed in the Concluding chapter. Furthermore, the PBC is not the only peacebuilding actor involved in Sierra Leone, ${ }^{264}$ thus the effects to peacebuilding referred to within this chapter are in relation to the work of the Peacebuilding Architecture. At the same time, although an examination of the effects of North-South dynamics on the Architecture's work in Sierra Leone is intended to extend and deepen the analysis (as noted in the methodology); it is possible to analyze the Architecture without looking to the country level.

\subsubsection{A Brief History of Sierra Leone}

Sierra Leone has a long and rich history but more recently has been known as one of the world's poorest states, as well as for its violent civil war. The conflict, which began on 23 March 1991 and declared officially over in January of 2002, was decades if not two centuries in the making. Several of the factors that contributed to and sustained the conflict continue to affect the post-conflict recovery period; and, while other causes have diminished, new ones appear to have taken their place. Given the limits of space, the intention of this section is to provide only a very brief overview of Sierra Leone's history and conflict, highlighting root causes most relevant to this thesis.

Sierra Leone is a tropical country located on the West Coast of Africa, bordered by Guinea, Liberia and the Atlantic Ocean. The current population of 5.1 million is approximately $30 \%$ Mende, $30 \%$ Temne, $30 \%$ of other smaller groups and $10 \%$ Krio. $^{265}$ During the second half of the $18^{\text {th }}$ century, the current capital of Sierra Leone, Freetown, originally was established as a British colony for freed slaves (Krios), and developed largely independently of the surrounding rural areas. As colonial powers sought to

${ }^{264}$ For instance, some of the other peacebuilding actors involved in Sierra Leone include the United Kingdom, in particular the Department for International Development; the African Union; the Economic Community of Central African States, the World Bank; and USAID.

265 "The World Factbook - Sierra Leone." 22 Jan. 2009. Central Intelligence Agency. Web. 30 Jan. 2009. Note, Krios (Creole) is the cultural term attributed to the formation of the group of descendents from immigrating freed black African slaves who adopted British culture. 
solidify their territorial claims in Africa during the late $19^{\text {th }}$ century, the areas surrounding Freetown were declared a British Protectorate in 1896 and rural chiefs were appointed as administrators. Due to a rebellion led by chiefs within the Protectorate two years later (the "Hut Tax" war), many were replaced by new 'paramount' chiefs loyal to the central Government. ${ }^{266}$ Subsequently, the rural areas were treated poorly and the government appointed chiefs frequently abused their position (corruption, slavery, favouritism, etc.). Young 'non-native' men in particular were aggravated with the chiefs, who largely determined the men's status and rights in the community. ${ }^{267}$ The rural-urban divide, the increasing focus on Freetown and the patron-client relationship between chieftaincies and the government as well as their abuses, would later become some of the key factors leading to the conflict.

On 27 April 1961, the Freetown colony and the surrounding indigenous Protectorate were together declared an independent state. Lead by Prime Minister Sir Milton Margai of the Mende tribe, the Sierra Leone People's Party (SLPP) headed the first government. ${ }^{268}$ Space limitations of this thesis prevent a more detailed account of the political leadership between independence and the conflict; however, the problems of Albert Margai (successor to his brother) were mirrored and intensified by the later longest-running political leader, Siaka Stephens of the All People's Congress (APC). ${ }^{269}$

Stevens' rule, which began in 1968, was characterized by numerous governance challenges, eventually leading to the creation of a "shadow state. ${ }^{270}$ Through multiple

\footnotetext{
${ }^{266}$ Paul Jackson, "Chiefs, Money and Politicians: Rebulding Local Government in Post-War Sierra Leone." Public Administration and Development, 25, (2005): 50; J. Peter Pham, The Sierra Leonean Tragedy: History and Global Dimensions, (New York: Nova Science Publishers, 2006) 20-21.

267 Jackson, 2005, 53. Many of the previous chiefs also had engaged in poor practices, however, these were intensified with the several new paramount chiefs now loyal to Freetown rather than their rural populations (Pham, 2006, 18-21).

${ }^{268}$ See: David Keen, Conflict \& Collusion in Sierra Leone. (New York: Palgrave, 2005) 14; Allan Rosenbaum and Maria Victoria Rojas, "Decentralization, Local Governance and Centre-Periphery Conflict in Sierra Leone," Public Administration and Development, 17 1997: 532; Pham, 2006, 28.

${ }^{269}$ Jackson, 2005,, 21; Keen, Conflict \& Collusion, 2005, 17; Barry Riddell, "Sierra Leone: UrbanElite Bias, Atrocity \& Debt," Review of African Political Economy. 32.103 (2005): 118-19.

${ }^{270}$ Jackson, 2005,, 21; Keen, Conflict \& Collusion, 2005, 17; Riddell, 2005, 118-19.
} 
constitutional amendments, he changed the state from a parliamentary system to a republic, created a one-party centralized government, transferred all decision-making powers to himself as the new President, diverted revenues to his office and made it constitutionally illegal to challenge Presidential rule. ${ }^{271}$ Being from a smaller tribe, he purged the Sierra Leone Army (SLA) of Mende people (Margai's tribe), and replaced them with Temne people - the other largest tribe in the country - to gain their support. ${ }^{272}$ Overall, Stevens' leadership intensified or added to causes of the conflict, such as further marginalizing the rural people through the centralization of the state; depleting financial resources that increased state indebtedness and poverty while also reducing or eliminating state services; reinforcing corrupt political elite; politicizing and reduced the functional capacity of the military; and intensified tensions between the different tribes. $^{273}$

In 1986, Joseph Momoh became President following the retirement of Stephens. The state began to rapidly decline as increasing pressures from three areas took their toll. Internally, Momoh attempted to rectify some of Sierra Leone's problems with moves such as the reintroduction of a multi-party state, attempts to eliminate illicit diamond mining, and reduce corruption; however, the problems created during Stephens' rule were deeply entrenched. ${ }^{274}$ Momoh's weak position and inability to re-establish effective and responsible governance after Stevens' rule added to growing dissatisfaction amongst the people. Regionally, Charles Taylor of neighbouring Liberia was, among other things, seeking to entrench his own power through the prospect of Sierra Leone's diamonds. Prior to and during the conflict, his external support helped to initiate and maintain the

${ }^{271}$ Pham, 2006, 41-47; Rosenbaum and Rojas, 1997, 532.

${ }^{272}$ Stevens was a member of the Limba tribe. Of note is that throughout his rule, he frequently had to pay patronage to various ethnic groups to maintain power, thus in a 'few' instances his actions reduced ethnic tensions.

${ }^{273}$ Riddell, 2005, 116-17.

274 Jackson, 2005, 51; Keen, Conflict \& Collusion, 2005, 32-35; William Reno, "Political Networks in a Failing State: The Roots and Future of Violent Conflict in Sierra Leone," International Politics and Society, 10.2 (2003): 56-59. 
conflict. $^{275}$ At the international level, the IFIs imposed adjustment policies to reduce spending on state services. This served to build up further tensions amongst the majority of the population who were employed in or relied upon these industries. ${ }^{276}$

\subsubsection{The Conflict (1991-2002)}

In March 1991, the Revolutionary United Front (RUF) rebels staged their first attacks. The subsequent eleven-year civil war would be characterized by coups, brief periods of peace, competition for diamonds, growth in civil society development and violent acts perpetrated by both rebels and security forces. The duration and extensive nature of the conflict exacerbated and entrenched many of its root causes. Within the security sector, the politicized army and other security forces had been made ineffective and at times had joined the rebels in attacks, creating what were known as sobels (soldierrebels). ${ }^{277}$ Conversely, rural areas created their own non-sanctioned 'civil defense forces,' or kamajors. ${ }^{278}$ Governance had been a significant issue before the conflict, but the inability and/or unwillingness of successive national leaders during the conflict to address problems further antagonized the population. Coups and uprisings became the common response during the civil war. ${ }^{279}$ According to one report, governance is considered the second largest threat to peace in Sierra Leone. ${ }^{280}$ Competition for diamonds and other resources fueled the conflict, as well as were linked to corruption at all levels of government. $^{281}$ With poor governance and significantly destroyed infrastructure, civil society groups developed as a support response and advocate for much of the

${ }^{275}$ Pham, 2006, 82-83; Reno, 2003, 62.

${ }^{276}$ Adekeye Adebajo, Building Peace in West Africa: Liberia, Sierra Leone, and Guinea-Bissau. (Boulder, CO: Lynne Rienner Publishers, 2002) 98; David Keen, "Liberalization and Conflict," International Political Science Review, 26.1 (2005): 79; Riddell, 2005, 121.

${ }^{277}$ Adebajo, 2002, 79.

278 Wendy Lambourne, "Towards Sustainable Peace and Development in Sierra Leone: Civil Society and the Peacebuilding Commission," Journal of Peacebuilding \& Development 4.2 (2008): 50; Pham, 2006, 92-94, 105; Reno, 2003, 69.

${ }^{279}$ Lambourne, 2008, 51; Pham, 2006, 88-92 ; Rosenbaum and Rojas, 1997, 532

${ }^{280}$ ICG 7-9.

${ }^{281}$ Lambourne, 2008, 50-51; Pham, 2006, 94-95. 
population. ${ }^{282}$ Many became strongly connected to and representative of the people, especially within the largely marginalized rural areas. Rebels in part were formed by marginalized youth, but also from abducted children forced to become child soldiers. ${ }^{283}$ In addition, prior to and during the conflict, unemployment, illegal employment and the largely destroyed state capacity aggravated tensions and instability. ${ }^{284}$

\subsubsection{Synopsis of Key Peacebuilding Challenges}

Overall, the strongest of the root causes include a politicized security sector, poor infrastructure, corrupt centralized government and rural chiefdoms, ethnic and urbanrural divisions, resource exploitation and a largely marginalized society, especially the youth. ${ }^{285}$ It is important to note that these and many other conflict issues are intricately connected to the five dimensions of North-South divisions. These already potentially high destabilizing factors may be put at greater risk if they become the object of North-South confrontations already being felt within the Architecture. The remainder of this chapter will investigate whether peacebuilding processes connected to these issues are affected by the North-South dynamics occurring around the Architecture along the development, economic policy, sovereignty, aid and UN system dimensions.

\subsection{Development: Only if a Security Threat?}

The first dimension, development, is a significant component to Sierra Leone's peace, but also affected by North-South divisions within the Peacebuilding Architecture. As analyzed in the previous chapter, Northern objectives appear to be dominating the development-security relationship. When this happens, the literature suggests that the North is likely to place security issues ahead of development, consider development

${ }^{282}$ Pham, 2006, 144-48; Rosenbaum and Rojas, 1997, 532-33.

${ }^{283}$ Keen, Conflict \& Collusion, 2005, 51-53; Pham, 2006, 109.

${ }^{284}$ Lambourne, 2008, 51; Riddell, 2005, 126; Reno, 2003, 49.

${ }^{285}$ See Jackson, 2005, 51; Keen, Conflict \& Collusion, 2005, 32-35; Reno, 2003, 56-59; Riddell, 2005, 116-17. 
issues only when they are reframed as a security threat and focus on short-term objectives. A further examination at the country level demonstrates that the North-South dynamics affecting the Architecture in terms of the priority of development have also carried over into Sierra Leone.

To help start the work of the Architecture in the peacebuilding process for Sierra Leone (and Burundi) the PBF announced the release of an initial US\$35 million dollars to support peacebuilding activities. In response, Sierra Leone created a list of priority projects for the funding that reflected long-term development objectives mostly found within the existing PRSPs. However, many of these projects either were rejected or modified by Northern donors in part due to favouring of projects that responded to peace and security issues. ${ }^{286}$ A new PBF Priority Plan was subsequently established that emphasized short-term projects (one year in duration) where most projects have a security focus and almost half of the funds are allocated (US\$13.7 million) to the security and justice sector. Furthermore, two other objectives within this Plan labeled as high "security" risks, energy and youth, make up another US\$13.1 million, combined with the above represents over $75 \%$ of the initial funds. Thus, funding and strategies of the PBF in Sierra Leone have been at least partly guided by Northern security objectives. ${ }^{287}$

The Sierra Leone Country-Specific Configuration also has prioritized security over development. Within the country, North-South divisions persisted as the CSC was asked to focus on long-term, sustainable objectives. However, it was reported that the Chair of the CSC felt it was important to address security issues to prevent war recurrence, choosing to pursue short-term security goals. They "do not believe that focus should be on long-term [objectives] since they feel this falls within the development

${ }^{286}$ ActionAid et al., 2007, 13-14, 30.

287 "Sierra Leone Peacebuilding Fund Approved Projects and Progress Updates." n.d. United Nations Peacebuilding Fund. Web. 21 Nov. 2009. The allocation of funds can be found in the most recent Priority Plan (Republic of Sierra Leone and United Nations Peacebuilding Fund, Priority Plan for Peacebuilding Fund (PBF): Sierra Leone, Oct. 2008. United Nations Peacebuilding Fund, Web. 12 Feb. 2009 4.) 
framework [of the IFIs] rather than peacebuilding." 288 Furthermore, it was felt that Sierra Leone was not yet in the development phase; thus, the CSC also situated development after and not part of peacebuilding. A focus on immediate security issues are reflected in meetings and discussions within the $\mathrm{CSCs},{ }^{289}$ as well as the Peacebuilding Cooperation Framework (PBCF), a compact between the Government of Sierra Leone and the Commission outlining the strategies that will be pursued in order to consolidate peace. ${ }^{290}$ Although the PBCF acknowledges the importance of long-term objectives, they fall under the purview of the IFIs while the general focus of the framework is on short- and medium-term objectives around security. ${ }^{291}$

This overall emphasis on security by the North may have diverted necessary early attention from a development issue occurring within the country, that of insufficient energy. It was considered a problem that was close to destabilizing the peace in Sierra Leone. At first, the CSC deemed it a development concern, falling under the responsibility of the World Bank. ${ }^{292}$ The Government, however, continued to stress concerns of the risk it posed to security. ${ }^{293}$ As the energy problem intensified within the country it was relabeled as a security threat by the CSC, which eventually led to its later inclusion onto the PBCF as well as what triggered emergency funding from the PBF to acquire generators. ${ }^{294}$ Overall, as a development issue, energy had to become a threat to peace and security in the country before it was considered a priority by the PBC and PBF.

${ }^{288}$ Interview No. 3.

${ }^{289}$ Interview No. 2.

${ }^{290}$ Note: the Peacebuilding Cooperation Framework (official document name) is also known as or sometimes referred to as the Integrated Peacebuilding Strategy (to which the PBCF is a part of), Strategic Peacebuilding Framework, Cooperation Framework, Sierra Leone Compact and Integration Strategy.

${ }^{291}$ United Nations Peacebuilding Commission (PBC), Sierra Leone Peacebuiding Cooperation Framework (PBCF) PBC/2/SLE/1, 3 Dec. 2007. See for example paragraphs 12, 21 and 23.

${ }^{292}$ Interview No. 2; Interview No. 3.

${ }^{293}$ Interview No. 8.

${ }^{294}$ Interview No. 2; NYU CIC and the IPI, 2008, par. 29. Other North-South issues related to energy, the generators and the building of a hydroelectric dam also emerged, however, due to space constraints cannot be detailed here. 
The prioritization of development within the $\mathrm{PBC}$ and the $\mathrm{PBF}$ has in part been guided by Northern interests emphasizing security, which appears to have affected peacebuilding in Sierra Leone. Funding largely has been directed to short-term security objectives while the CSC has chosen to respond to security threats. Within the PBCF, long-term development objectives are largely excluded, falling under the IFIs as something that occurs after peacebuilding; or, such as energy, have been reframed as a security threat. Furthermore, the CSC missed an important development problem, energy, until it escalated to become a critical security concern. Overall, North-South divisions around development affecting the Architecture appear to have inhibited its ability to carry out peacebuilding within Sierra Leone, potentially contributing to risking peace.

\subsection{Economic Practices: Cooperation Impeded}

As discussed in the previous chapter, the Architecture experienced North-South divisions along the second dimension, economic practices, where the international financial institutions have been kept at a distance from the PBC by limiting them to 'invited' participants at the CSC level. As argued in the literature, when the South is distanced from the IFIs, economic policy and developmental decisions are likely to be made with less consultation and agreement from the South, often resulting in situations where past policies (SAPs, PRSPs, etc.) have been problematic to Southern economies and development. The distancing of the IFIs at the PBC level appears to have produced problems for it and peace within Sierra Leone.

As argued in the previous section, Northern influences have largely left development priorities out of PBC objectives, preferring instead to place them and therefore economic policy in the hands of the IFIs. ${ }^{295}$ In the case of Sierra Leone, this is especially noticeable in the country's Cooperation Framework with the PBC, where long-

${ }^{295}$ Interview No. 3. Recall that in Chapter 2 economic policy often is a significant component to development discussions. 
term economic and development issues, such as youth unemployment, have been made the responsibility of the IFIs. ${ }^{296}$ Therefore, not only does the PBC appear not to have engaged with economic policies, it also has not made attempts to connect and integrate with IFI economic development policies for Sierra Leone. ${ }^{297}$

This lack of connection appears to have impeded the ability of the PBC to engage with the World Bank to rectify the energy crisis in Sierra Leone. For several years the Bank had been supporting the construction of a hydroelectric dam as part of its PRSP with Sierra Leone; however, it was still far from completion. Once energy had been labeled a security issue, the CSC attempted to raise their concerns with the World Bank in an effort to generate immediate action. ${ }^{298}$ The Bank, however opposed the CSC, emphasizing that plans were already in place (i.e. the dam), that addressing these largescale issues takes a long time and to let the Bank handle the situation. Concerned that energy would destabilize the peace before the dam was in place, the PBC had to do extensive work behind the scenes in order to engage the World Bank, and eventually the issue was resolved. ${ }^{299}$ Although the PBC was instrumental in this, it appears that its efforts were a struggle, where they were inhibited first by the absence of a connection with the Bank's objectives - which missed recognizing a potential gap until it became an issue; and second, lack of a strong relationship with the Bank impeded the PBC from working with the institution to quickly resolve the problem.

Within the Architecture, Chapter 3 suggested that North-South divergence around the dimension of economic practices pushed away and maintained a distance from the IFIs. Combined with a further lack of integration with IFI objectives for Sierra Leone, one of the results impeded the ability of the $\mathrm{PBC}$ to engage the financial institutions

\footnotetext{
${ }^{296}$ PBC, Sierra Leone PBCF, 2007: par. 12.

${ }^{297}$ IPI, 2006, 13; Scott, 2008, 9.

${ }^{298}$ Interview No. 3.

${ }^{299}$ Interview No. 3; Interview No. 4
} 
during a critical period, the energy crisis. Furthermore, although the issue was resolved, the situation had the potential to undermine peace in Sierra Leone.

\subsection{Aid: Limited Access and Reduced Predictability}

Analysis of North-South divisions around the dimension of aid revealed that the PBC has been limited in its ability to access aid for its peacebuilding objectives. Control of PBF funds is largely in the hands of Northern actors, commitments to aid in the PBF have been minimal, while quality of PBF aid has been affected by poor implementation of the initial disbursement. For its part, the literature suggests that there is likely to be conditions connected to aid when the North is in control, that when the North has less control commitments to aid from Northern donors will be low and less reliable, and that poor management of aid will affect its impact in the country. These North-South divisions related to the Architecture appear to have constrained its ability to access and raise substantial resources, as well as to create reliable funding for Sierra Leone.

It has already been discussed that the Sierra Leone PBF Priority Plan was guided mainly by Northern peace and security concerns. The original Plan submitted by the Government had been rejected by donors in large part because it did not fall in line with Northern objectives. ${ }^{300}$ In this sense, subtle conditionalities appear present since aid is being directed to what the North deems important, and possibly not what Sierra Leone may need. This limited influence over and access to the PBF funds by both the Government of Sierra Leone and the PBC impeded the ability to respond more quickly to the emerging energy issue. The Government had been unable to convince actors to add the impending issue to the PBF Priority Plan (and the PBCF) during its original design. Likewise, once the CSC had been convinced of the emergency, it too had to conduct several meetings in order to persuade donors of the energy risk. Eventually, the PBF (and

\footnotetext{
${ }^{300}$ ActionAid et al., 2007, 30.
} 
the World Bank) released emergency funds making it possible to acquire generators. ${ }^{301}$ Consequently, energy was added to the Priority Plan and the PBCF. North-South divisions around control of aid inhibited one of the key purposes of PBF funding - to support "activities designed to respond to imminent threats to the peace process." 302 As one official commented, "donors decide in the end what will happen because decisions are based on what donors will fund."303

Despite the limitations surrounding the PBF, it is only meant to be a source of emergency stopgap funding thus the PBC has been charged with the task of 'raising additional resources' to build long-term financial commitments in the country. ${ }^{304}$ This is to be accomplished through the CSCs by way of pledging conferences. Aid raised in pledging conferences is generally based on filling needs, thus is subject to less Northern control, and as the literature suggests, this often results in lower donor contributions. In Sierra Leone, although the conferences have produced some increased assistance, funding from bilateral donors has been very small and much appears to have come from Southern countries. $^{305}$ According to one official, donors have been unwilling to commit to peacebuilding projects outside of their own interests. ${ }^{306}$ This may in part be due to the PBC's late entry into Sierra Leone, where donors were unlikely to divert aid from their existing projects - further emphasizing the importance of situating the work of the PBC within its broader peacebuilding work in Sierra Leone, as noted above. However, that the PBC has not been able to mobilize any substantial amounts of funds beyond this seems to support the image of an unwilling North to make commitments. One official commented how even the Chair of the Sierra Leone CSC, the Netherlands, has had difficulties in

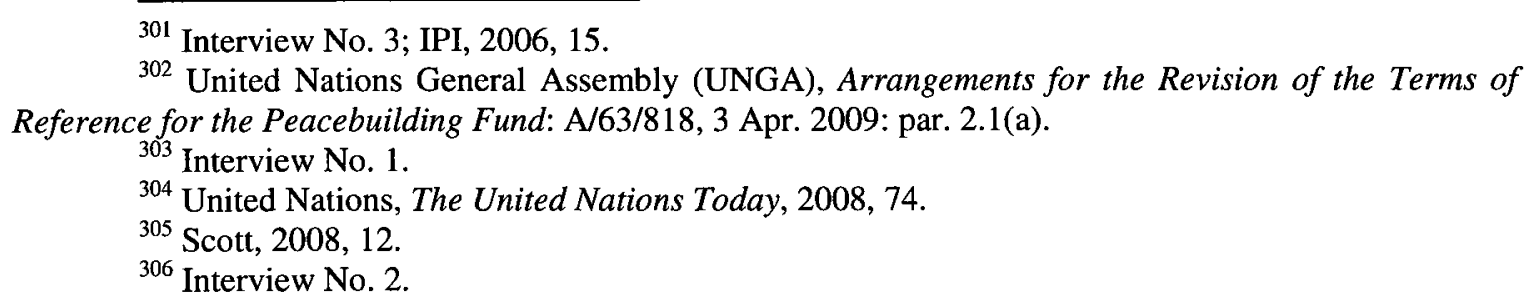


motivating their own government to commit aid to the fundraising process. ${ }^{307}$ According to one report, the lack of commitments is raising concerns in Sierra Leone as to the sustainability of the Architecture's peacebuilding projects started by PBF seed money. ${ }^{308}$ Thus, North-South divisions resulting in poor commitments to aid in the CSC pledging conferences suggest that the Architecture's peacebuilding projects in Sierra Leone may not be sustainable and potentially suspended.

Finally, analysis of North-South convergence where each pushed for quick dispersal of PBF funding before making decisions about what it would be spent on, in contrast, appears to have created problems around the quality of aid implementation for the PBC in Sierra Leone. As one observer put it, "it was determined that peacebuilding would cost $\$ 35$ million;", ${ }^{309}$ therefore, projects funded by this money would have to fit within this constraint. This partially contributed to the approval of projects with short terms and appearing to lack interconnected objectives: “...the focus on developing PBF projects fostered an operational approach that treated the question of peacebuilding on a short-term, project-by-project basis at the expense of analyzing the overarching strategic priorities and political risks to peace." ${ }^{310}$ For example, of the funding that has been released to support youth in Sierra Leone, much has been directed towards short-term, non-sustainable employment projects. ${ }^{311}$ While this research revealed a number of other issues around the quality of aid management, including slow dispersal and problems reaching the intended people in the country, limitations of space preclude further exploration here.

In summary, within the aid dimension, funds and fundraising within the PBF and the PBC have been impeded by both North-South divergence and convergence that have

\footnotetext{
${ }^{307}$ Interview No. 5.

${ }^{308}$ ActionAid et al., 2007, 13.

${ }^{309}$ Interview No. 8.

${ }^{310}$ NYU CIC and the IPI, 2008, par. 20.

${ }^{311}$ Interview No. 8.
} 
been largely felt at the country level. Lack of access to and control of PBF funds in part prevented the PBC from responding quickly to the energy issue, the pledging conferences have not seen significant donor contributions for the Commission's peacebuilding projects and the quality of aid has reduced the scope of PBC projects due to implementation problems around the US\$35 million disbursement.

\subsection{Sovereignty: Agreement but Mixed Results}

The fourth dimension in the framework, sovereignty, experienced North-South divisions within the Architecture that had the effect of limiting its operational capacity, either making it dependent upon the Southern country to request the external engagement of the PBC or dependent upon the Security Council to take actions. The literature suggests that when the South is able to uphold traditional concepts of sovereignty that restrict intervention, then issues around human rights and governance are likely to be marginalized in favour of state and regime security. Likewise, when the North is able to uphold the role of the Council in sovereignty issues it is likely to act inconsistently, either becoming indifferent or acting upon its own interests. These divergences around sovereignty related to the PBC have produced both mixed results and untested analysis within Sierra Leone.

Actions by the South during the formation of the PBC made external engagement contingent upon a country request, thus making the PBC dependent upon the Southern country to engage with it. Yet, this also produced a certain level of convergence, where acceptance of the request by the Commission implies that intervention in Sierra Leone will not only occur, but is expected to by the PBC. However, that this tacit agreement has occurred in principle does not mean that this will occur in practice. As suggested by the literature, issues around governance and human rights are important sovereignty issues. These types of issues were raised in the Sierra Leone CSMs, which promoted discussions on sensitive North-South topics, specifically concerns around corruption, the Truth and 
Reconciliation Commission (TRC) recommendations and resource extraction. ${ }^{312}$ The meetings saw better 'frankness and transparency of senior government officials' with some small progress by the Government in a few areas. ${ }^{313}$ Nonetheless, despite this improved dialogue and willingness to discuss issues sensitive to sovereignty, many still feel that not enough has been done in practice by the $\mathrm{PBC} / \mathrm{CSC}$ to push the recommendations or governance issues, especially around corruption. ${ }^{314}$ It appears that North-South convergence in principle has not transferred to convergence in practice.

As argued in Chapter 3, actions by the North during the setup of the Architecture limited the PBC by making it non-operational and dependent upon the Security Council to take actions if required. As of yet, the PBC and Sierra Leone have not experienced a situation requiring action be taken by the Council. Therefore, the effects of this NorthSouth division on the PBC and peacebuilding are inconclusive at this time.

North-South divergence affecting the PBC around the dimension of sovereignty is having mixed effects on its peacebuilding work in Sierra Leone. The implied agreement to allow intervention by the $\mathrm{PBC}$ has improved discussions on sensitive sovereignty areas in principle, but in practice it appears not enough has been done by the Commission/CSC to push for stronger actions from Sierra Leone. On the other hand, whether the Security Council will take action on behalf of the PBC and Sierra Leone if the country's peace is put at risk has not been tested. Overall, North-South convergence around the dimension of sovereignty in the PBC has improved peacebuilding discussions on sensitive issues for Sierra Leone, but does not appear to have transformed these discussions into action.

${ }^{312}$ Interview No. 1; IPI, 2006, 6.

${ }^{313}$ Interview No. 3; Interview No. 2; NYU CIC and the IPI, 2008, par.` 21; Street et al., 2008, 36.

${ }^{314}$ CPHS, 2007, 11; Interview No. 8; Street et al., 2008, 39. It is also worth noting, however, that many feel the TRC itself has several problems and that its implementation may not be as useful as hoped. See: Amadu Sesay, Does One Size Fit All? The Sierra Leone Truth and Reconciliation Commission Revisited. Vol. 36. Stockholm: The Nordic Africa Institute/Nordiska Afrikainstitutet, 2007: 5, 19; J. Andrew Grant, "Diamonds, Foreign Aid and the Uncertain Prospects for Post-Conflict Reconstruction in Sierra Leone," The Round Table 94.381 (2005): 449; Pham, 2006, 168-69. 


\subsection{UN System: Trickle-Down Effects}

In the last dimension, the UN system, the Architecture was inhibited significantly by North-South divisions around the areas of membership, participation and power struggles, but had mixed effects in leadership. Confrontations over membership resulted in a larger OC body, participation debates seems to have reduced engagement of the P5 and the minimized inclusion of CSOs, power struggles split the responsibilities of the PBC between the General Assembly and the Security Council and while leadership of the Secretary-General did not appear affected by North-South divisions, leadership of the PBC Chair was hindered. These North-South divisions around the Architecture, however, appear mixed and have been felt by Sierra Leone only in two areas, participation and leadership.

Within the dimension of the UN system, North-South confrontations over participation and the PBC appear to have produced the most and varied effects on its peacebuilding objectives within Sierra Leone. Analysis in Chapter 3 suggests that confrontations between the North and South over the inclusion of the P5 as permanent members on the $\mathrm{OC}$ have reduced $\mathrm{P} 5$ engagement in the PBC. ${ }^{315}$ For instance, financial contributions to Sierra Leone from the P5 via the PBF are low (and at the time of this writing, completely absent from potentially the biggest donor, the United States). ${ }^{316}$ Additionally, as discussed previously, similar participation issues were found with the IFIs. Likewise, North-South divisions which restricted the ability of CSOs to participate within the PBC also appear to have marginalized an extensive section of the population in Sierra Leone. In the initial CSC meetings, only one representative of civil society from Sierra Leone participated, while only two participated in the PBF Priority Plans. ${ }^{317}$

${ }^{315}$ With the exception of the UK.

${ }^{316}$ PBF, "Pledges, Commitments and Deposits," n.d.

${ }^{317}$ One Board member from the West Africa Network for Peacebuilding (WANEP) participated in PBC meetings, while WANEP and the Mano River Women's Peace Network (MARWOPNET) participated on the PBF Steering Committees (ActionAid et al., 2007, 11). 
Although both representatives held consultative meetings with various CSOs in Sierra Leone, the overall impression, according to many, was that they were focused on Freetown to the exclusion of the vast rural population, and generally unrepresentative of the broader country issues. ${ }^{318}$ As one report has indicated, this segregation of people in Sierra Leone, especially the rural population, was one of the major root causes to the conflict; thus, marginalization by the PBC, the report argues, may only serve to reignite these issues at the country level. ${ }^{319}$ North-South divisions have constrained the ability of the PBC to engage better with actors important to peacebuilding in Sierra Leone.

In contrast, North-South convergence around CSC leadership in Sierra Leone saw the Government intentionally request a Northern Chair for its potentially stronger capacity and influence within the international community. This choice has had mixed affects in the country. As discussed earlier, the Netherlands as Chair generally has followed a Northern approach to peacebuilding, such as the emphasis on security or the desire to have development placed in the hands of the IFIs. However, it also appears that the peacebuilding process requires a Chair with enough international links and capacity necessary to help lead the CSC peacebuilding process. For example, it has been felt that the Chair has been important in dealing with the donors and the IFIs, which the Government of Sierra Leone appears to value. ${ }^{320}$ At the same time, the role is both demanding and time-consuming both the Netherlands and Norway chose to step down as Chairs in part due to this reason. ${ }^{321}$ It appears that North-South convergence within the CSC around a leader required a trade-off at the country level. It improved peacebuilding for Sierra Leone in so far as the Northern Chair appears to be an important advocate amongst other actors, but also has inhibited peacebuilding in Sierra Leone by bringing a dominant Northern approach to some areas.

\footnotetext{
${ }^{318}$ ActionAid et al., 2007, 16; Interview No. 7; Jenkins, 2008, 6; Lambourne, $2008,54$.

${ }^{319}$ ActionAid et al., 2007, 16.

${ }^{320}$ Interview No. 2.

${ }^{321}$ Interview No. 1; Interview No. 2; Interview No. 3.
} 
Finally, this research did not reveal any substantial effects on the Architecture's ability to carry out its peacebuilding objectives in Sierra Leone originating from the debates around membership or power struggles. It is possible that the alienation of ECOSOC during the General Assembly-Security Council power struggles may have reduced its potential to bring a greater focus on development; however, the ability to observe this connection and its effects would require further research.

Overall, it has been shown that North-South divisions affecting the Architecture in the dimension of the UN system have produced mixed effects. Power struggles and membership issues do not appear to have impeded the ability of the Architecture to carry out its peacebuilding work in Sierra Leone, while North-South divisions over participation seem to have made considerable problems for the PBC to engage other actors towards its peacebuilding objectives. On the other hand, North-South convergence around CSC leadership appears to have created a trade-off in Sierra Leone between Northern focused objectives and Northern advocacy amongst other actors.

\subsection{Chapter Summary}

This chapter presented a brief history of Sierra Leone and its conflict, followed by an individual analysis of the effects of North-South divergence around five dimensions development, economic practices, aid, sovereignty and the UN system. The purpose of analyzing the case of Sierra Leone was to explore the potential extent of the effects of North-South divisions in the Architecture, specifically, to examine whether divergence (or convergence) is impeding (or improving) the ability of the Architecture to carry out its peacebuilding objectives. Historically, some of the strongest root causes leading up to and intensified during the conflict include a politicized security sector, poor infrastructure, corrupt centralized government and rural cheifdoms, ethnic and urbanrural divisions, resource exploitation and a largely marginalized society, especially the youth. Again, although the researcher was unable to conduct field research, the initial 
findings discussed above indicate that the efforts at peacebuilding in Sierra Leone, on the whole, have been in part impeded by North-South divisions occurring in and around the Architecture, and in some cases, had the potential to undermine peace.

Within the development dimension, the PBC and the PBF have directed their focus on short-term security objectives, have placed development into the hands of the IFIs, have deemed development as something that occurs after peacebuilding and do not appear to respond to development issues until they are reframed as a security concern. North-South divergence appears to have separated development from the PBC's peacebuilding objectives, which at times has contributed to putting peace at risk.

North-South divergence in the dimension of economic practices also seems to have impaired the ability of the Architecture to carry out peacebuilding by distancing the IFIs from the PBC. The effect appeared to result in contradictory objectives and poor coordination, while there was also a concern of a disconnect between short-term and long-term peacebuilding goals.

Similar to the above, both North-South divergence and convergence concerning the aid dimension also appears to have hindered the Architecture in managing and raising additional funds. Restricted access to and control of PBF funding partially prevented the PBC from quickly responding to an imminent emergency around energy, while pledging conferences do not appear to be marshalling additional resources and the reduced quality of aid through the rushed disbursement of the US\$35 million led to the design of shortterm peacebuilding projects.

North-South convergence around intervention in the sovereignty dimension created mixed results in the Architecture's peacebuilding work in Sierra Leone. In principle, the tacit agreement for intervention saw improved dialogue around sensitive peacebuilding issues, but in practice, it appears the PBC has not been able to push for 
enough action by the Government. Divergence around the role of the Security Council to intervene if requested by the $\mathrm{PBC}$ has not been tested, remaining inconclusive.

In the last dimension, the UN system, North-South dynamics seen in the Architecture did not always impede its peacebuilding work in Sierra Leone. Divergence around membership and power struggles did not appear to produce effects within the country, where, in contrast, North-South divergence around participation considerably reduced the ability of the PBC to engage with other peacebuilding actors. And, convergence around CSC leadership seemed to produce a trade-off between Northern directed objectives and international advocacy for Sierra Leone.

Overall, this chapter has argued that the majority of North-South dynamics affecting the Peacebuilding Architecture both externally and internally have affected Sierra Leone and its peace process. The use of the framework across the five dimensions (development, economic practices, aid, sovereignty and the UN system) appears to suggest that the ability of the Architecture to engage in peacebuilding objectives within Sierra Leone is largely impeded by North-South divergence. The next chapter will synthesize and discuss the analysis from this case study of Sierra Leone, with the analyses of the preceding chapters on the Architecture and North-South divisions within the broader UN system. 


\section{SYNTHESIS AND CONCLUSION}

This objective of this thesis was to analyze the effects of North-South dynamics on the Peacebuilding Architecture and the outcomes in one of its country cases, Sierra Leone. In order to connect and analyze North-South dynamics to the Peacebuilding Architecture, Chapter 2 identified five key dimensions to North-South divergence development, economic practices, aid, sovereignty and the UN system - to act as a framework from which to work. Overall, the thesis has argued that North-South divisions, both endogenously (from within the Architecture) and exogenously (from the greater UN system), have impeded the Architecture's ability to carry out its objectives and perform its operations. While divisions were the predominant occurrence, the thesis also attempted to argue that instances of North-South convergence could improve the capabilities of the Architecture. The overall finding of this research suggests that NorthSouth divisions are having an effect on the ability of the Architecture to carry out its peacebuilding objectives.

\subsection{Main Findings}

To arrive at these findings, Chapter 2 began by examining the development of North-South divisions across the history of the UN. Five key dimensions to North-South divisions and their related sub-factors were identified and subsequently explored. First, the development dimension revealed that the North and South are likely to divide around who holds responsibility for creating development challenges and the priority development receives relative to security. Second, literature around the economic practices dimension suggested that the North and South are likely to divide over economic policy and the role of financial institutions. Third, divisions around the aid dimension suggested that each side is likely to disagree over the control, commitment and quality of aid. Fourth, the sovereignty dimension revealed that the North and South are likely to divide over the interpretation of sovereignty (in principle) and actions that 
interfere with sovereignty (in practice). Finally, the literature around the UN systems dimension suggested that divisions are likely to occur around membership, participation, power struggles between the General Assembly and the Security Council (jurisdiction) and the leadership role of the Secretary-General. Also examined were a few instances of varying levels of North-South convergence. Overall, however, the majority of the history of the UN has been characterized by a division between the North and South.

Chapter 3 focused on the Peacebuilding Architecture, beginning with a brief look at the lead-up to the creation of the Architecture, as well as concise overview of its structure and functions. Then, the five-dimensional framework developed in Chapter 2 was used to analyze Architecture. In the development dimension, while there appeared no divisions around responsibility for development problems, there were strong divisions between the priority of development and security. Likewise, economic practices revealed no divisions around economic policy, but strong divisions around the role of IFIs. Within the aid dimension, divisions were also strong around control and commitment but mixed around quality of aid. Analysis of the sovereignty dimension revealed mixed affects in principle and in practice pertaining to the process of the country request and the political will of the Security Council, respectively. The UN dimension also revealed mixed effects around membership and enlargement of the OC and no effects on the leadership of the Secretary-General, but effects on the CSC Chairs; while both participation and power struggles revealed effects of divisions upon the Architecture. In general, North-South dynamics around and within the Architecture have impeded its ability to carry out its peacebuilding mandates.

Finally, to observe the extent of the effects of North-South divisions on the operations of the Architecture, Chapter 4 used the five-dimensional framework to analyze Sierra Leone, one of the country cases on the agenda of the Architecture. The chapter began with a brief look at the history of Sierra Leone and its conflict, as well as the root 
causes to the conflict that may affect peacebuilding. North-South divisions around the priority of development vs. security had strong effects on the Architecture's peacebuilding work, potentially contributing to risking peace. Similarly, divisions around the role of the IFIs in the economic dimension also produced various problems and a potential risk to peace. Within the aid dimension, divisions have impeded the control and commitment of aid, while convergence around quality and the implementation of aid (quick release of funds) inhibited the PBC in its work in creating the PBCF. The tacit agreement for intervention created around the country request in principle improved the ability of the PBC to bring up sensitive sovereignty issues around governance and human rights; however, this did not appear to create much action in practice at the country level. The UN system showed mixed effects where North-South divisions around membership and power struggles did not appear to have any affects on the Architecture's work in Sierra Leone. However, the effects of divisions around participation saw reduced engagement of the P5 while convergence on the leadership of the CSC has created a trade-off between Northern capabilities and Northern-led objectives. In summary, some of the North-South effects felt by the Architecture did not translate to the country level; however, a number of the effects that were felt had a strong impact around peacebuilding.

\subsubsection{Strongest Divisions}

The strongest divisions were found in development, economic practices and aid. These were deemed as having strong effects as divisions were felt both in the Architecture and Sierra Leone, there were no points of convergence and because the effects had at times added to putting peace at risk. Specifically, the sub-factors priority of development vis-à-vis security, the role of the IFIs and control and commitment of aid impeded the Architecture the most. Within the development dimension, Northern interests prioritized security rather than connecting the two. As a result, long-term development issues have not been addressed in the PBCF, they are not connected to the 
CSC's short-term goals and they appear to be considered by the PBC only when deemed a risk to security. Within the economic practices dimension, the IFIs were kept at a distance from the PBC and long-term development objectives were put in the hands of the IFIs. Within aid, control of the PBF is mostly influenced by Northern interests, which have placed an emphasis on funding responses to peace and security concerns. Moreover, commitments to the PBF are small and voluntary, while pledging conferences conducted by the PBC have been largely unable to acquire ongoing support for long-term development needs in Sierra Leone. Considering the above together, a critical observation appears common to all areas. The overriding influence that has shaped and been replicated within the PBC and the PBF has been a Northern emphasis on security issues and the marginalization of development objectives, the implications of which will be discussed below.

\subsubsection{Lesser-Felt Divisions}

Although the effects of North-South divisions within the dimensions of sovereignty and the UN system were not as strong as the above as they did not appear to put peace at risk in the country or some did not appear to have an effect at the country level, they still contributed to impeding the Architecture from pursuing its mandates. Specifically, divisions around the role of the Security Council (sovereignty), participation (UN system) and power struggles between the Assembly and the Council (UN system) all created problems. Within the sovereignty dimension, Northern interests elevated the role the Security Council would play in the Architecture, which reduced the scope and power of the PBC as well as made it dependent upon the Council to take action. The Council has 
not demonstrated its willingness to seek out advice from the $\mathrm{PBC}$, which raises concerns if it will demonstrate the necessary political will if the PBC calls upon it. ${ }^{322}$

North-South disagreements around the participation of the P5 in the PBC also appear to have contributed to reduced engagement and political will (financially and operationally) from some of the most important Northern actors, substantially reducing the Architecture's capacity to engage in peacebuilding initiatives. Likewise, North-South divisions significantly reduced the Architecture's connection to CSOs, which appears to have distanced parts of the population who might be represented by some of the CSOs. Divisions also reduced the participation of other major actors (IFIs, the European Community). The overall effect appears to have reduced the ability of the Architecture to engage with, coordinate and integrate with a variety of other actors on peacebuilding objectives. North-South divisions that fueled the power struggles between the General Assembly and the Security Council split the reporting functions of the PBC between the two bodies, as well as created other problems for the $\mathrm{PBC}$, although limitations of space within the thesis prevented a detailed examination of these dynamics. Rather than resolving the jurisdiction of the two $\mathrm{UN}$ bodies over the $\mathrm{PBC}$, its placement instead has permanently positioned it in the middle of the two sides. Thus, although power struggles seem to have subsided, a flare-up may again see the PBC caught between competing interests. Amongst the above lesser-felt divisions, the overriding commonality appears to be that all are rooted in structural or operational issues, the implications of which will be discussed below.

${ }^{322}$ This was also noted recently in the Report of the Secretary-General on Peacebuilding in the Immediate Aftermath of Conflict, created as a response to a request made by the Security Council on how peacebuilding in the immediate recovery period (first two years) could be improved upon. The report indicated that "the Security Council should consider more proactively how the advice of the Commission could contribute to its work during the early phase of the Council's consideration of post-conflict situations...(emphasis in original)." UNGA/SC, Report of the Secretary-General on Peacebuilding in the Immediate Aftermath of Conflict, A/63/881-S/2009/304, 11 June 2009, par. 82. 
An important difference observed between the divisions exerting strong effects upon the Architecture and the ones that are not as strong, is the difference in the nature of the divisions. North-South divergence around the lesser-felt divisions appears largely concerned with 'operational or structural' issues, whereas the stronger-felt divisions appear rooted in 'normative' issues around security and development. Thus, the impact of North-South divergence on the Architecture may vary depending on the nature of the division. In addition, some of the North-South divides did not replicate themselves within the PBC. This may suggest that many of the structural issues of the UN system in the broader North-South debate were effectively dealt with in the formation of the PBC. If this is the case, this may imply that the final structure and operational aspects of the PBC have reduced North-South divergence and thus offer potential insights into overcoming these divisions in the greater North-South debate that occurs around other UN bodies. Further research could usefully examine these dynamics.

\subsubsection{Absence of Dynamics}

North-South dynamics, either divergence or convergence, were expected to occur within each dimension; however, in three instances North-South dynamics appeared absent. The research did not observe findings in who holds responsibility for development (development dimension), economic policy (economic practices dimension) and the role of the Secretary-General (UN system dimension) at either the institutional or country level.

Within the first sub-factor, neither side appears to have been concerned with who is responsible for causing development problems within Sierra Leone. It may be that both sides agree that the civil war itself is the most likely cause of Sierra Leone's current development situation. This might be a new feature of the North-South debate, where responsibility for development is not a North-South issue for actors involved in post-civil war peacebuilding. On the other hand, it also may be that this debate is not practical for 
either side to engage in, suggesting that convergence may be occurring, when, as Weiss argues, both sides focus on practical issues, convergence is likely to occur. ${ }^{323}$ Either of these explanations would require further investigation and a potential area for future research.

The absence of divisions around economic policy may have two possible explanations. The internal structures of a post-conflict country are often destroyed or significantly distorted, thus initial focus is often on restoring the system not on the policies that should guide the system. It may be that it is too early for significant discussions around economic policies to enter peacebuilding objectives. However, as was discussed within the thesis, economic and development policy has been left in the hands of the IFIs. North-South divisions here may not be affecting the Architecture because the economic policies are not part of the Architecture's objectives.

In the last finding, there was an absence of divisions around the role of the Secretary-General in the Architecture. This absence is due to the likelihood that the leadership role has not yet been tested, that is, a situation has not yet arisen within the Architecture where the Secretary-General may need to become involved. However, other issues related to the minimal level of engagement of the Secretary-General with the PBSO were discovered during the research, possibly indicating a North-South issue around leadership and the Secretariat. Further investigation of this would be required before determining whether North-South divergence is a factor.

\subsubsection{Convergence}

North-South dynamics have been a considerable influence on the Peacebuilding Architecture; however, there have been instances of convergence, as well as situations that did not produce the expected outcomes. Furthermore, some of these instances of mixed influences and outcomes appear to be producing 'trade-offs,' potentially

\footnotetext{
${ }^{323}$ Weiss, 2009, 154-172.
} 
cancelling each other out. Within the dimensions of sovereignty, aid and the UN system, four sub-factors appear to reflect these mixed and unexpected results, the principle of sovereignty, quality of aid, membership of PBC and leadership (Chair) of the CSC.

North-South divergence around sovereignty in principle can be said to have produced convergence within the Architecture, where a country request and subsequent acceptance by the Commission creates a tacit agreement that external engagement will occur. In one respect, this improved the work of the Architecture as it opened up the arena to allow for discussion of sensitive governance and human rights issues. In practice, however, some of these issues have remained largely at the discussion stage. A review of the North-South literature did not appear to have an explanation for instances where divergence created convergence. Therefore, this may be a new understanding in the North-South debate that requires further investigation and another potential area for future research.

North-South convergence that led to the quick release of the initial US $\$ 35$ million PBF funds did not improve but instead impeded the work of the Architecture, creating sequencing issues related to the PBCF agreement within the country. That convergence did not produce improved results in part might be explained by Krasner who explains that cooperation may occur when there are only short-term gains at hand. ${ }^{324}$ The author of this thesis takes this a step further by suggesting that this self-interested cooperation has the potential to miss important consequences.

North-South dynamics around the membership of the OC and the selection of the Chair of the Sierra Leone CSC both produced mixed results. Due to space limitations and that each example is similar, only leadership will be discussed. North-South convergence occurred when Sierra Leone chose a Northern Chair over a Southern Chair, despite concerns by other Southern members of the dominance of a Northern Chair. The

\footnotetext{
${ }^{324}$ Krasner, 1985, 13.
} 
outcome, however, appears mixed. The result was increased capacity and influence in representing and responding to Sierra Leone with a trade-off that has seen largely Northern directed objectives. Despite these problems, the overriding choice for a Chair is likely to come down to a matter of practicality - whatever state holds the position must be able to handle the responsibilities and demands of leadership, be a strong representative amongst donors and have the capacity in New York (usually through the country's Mission to the UN) to work with the United Nations. Thus, agreement on the Chair also may be partially explained by Weiss' observation that the most important factor to convergence is when both sides opt to be pragmatic rather than ideological. ${ }^{325}$ Further supporting this, subsequent to the appointment of the original two countries, Brazil has been made Chair of the Guinea-Bissau CSC. Although Brazil is a Southern country, it is stronger and much closer to the Northern industrialized 'threshold,' thus its selection seems based just as much upon its capacity to assist than its placement within the North-South arena. However, given that the choice of Chairs seems to be leaning towards stronger countries, chairmanship is likely to be Northern dominated. The recent changeover in Chairs for Burundi (Sweden) and Sierra Leone (Canada) appears to support this trend. ${ }^{326}$

In summary, although there have been instances of North-South convergence or absences of North-South dynamics, divisions have been the prevailing influence on the Architecture. However, there appear to be some differences between the effects of these divisions. Divisions that have had the strongest effects on the Architecture are those concerning security found within the development, economic practices and aid dimensions. Divisions in the sovereignty and UN systems dimensions seem to be

\footnotetext{
${ }^{325}$ Weiss, 2009, 154-172.
}

${ }^{326}$ See United Nations Peacebuilding Support Office (PBSO), Unofficial Summary: Informal Meeting of the PBC Burundi Configuration, 29 Oct 2008 and United Nations Peacebuilding Commission (PBC), Sierra Leone Configuration PBC/3/SLE/L.2, 5 June 2009, both documents indirectly indicating the new Chairs. 
producing lesser effects and more often are focused on structural or operational issues. Divisions have been absent in some sub-factors, but it seems these it may be too early to see any North-South dynamics in these areas. Finally, there are instances of mixed observations where divergence has brought a small improvement to the Architecture, while convergence has either created problems or produced trade-offs.

\subsection{Implications of Research}

This research and its findings have important implications in several areas. For the UN, contrary to some claims outlined at the beginning of this thesis - that the NorthSouth divide is out-of-date or that it no longer exists - appear to be incorrect. Confrontations between the two sides were at times extremely contentious, have in part impeded the operations of the Architecture and contributed to putting peace at risk in Sierra Leone. The relevancy of the North-South divide seems just as important now, especially given that the $\mathrm{UN}$ is often the platform for global issues affecting all states. This research also brings a new tool - the five-dimensional framework - to understanding North-South dynamics and their potential effects on UN operations. This may be especially useful in other areas with a strong North-South mix, or may contribute to ongoing efforts to reform the UN.

For the Peacebuilding Architecture, this research has brought a new perspective to understanding factors that both may improve and impede its operations. Peacebuilding is complex and there are many factors influencing the ability of the Architecture in reaching its goals; therefore, it is important that the institutional context of the UN and the ongoing North-South divide is recognized, especially as it builds upon other understandings and analyses of the Architecture. Another important implication for the Architecture is the finding that security vs. development appears to be the most prevalent and divisive North-South divide. This seems unsurprising considering that North-South dynamics experienced a decisive shift after the events of 11 September 2001, which not only 
reframed development as a security concern, but also that this new conceptualization of the security-development relationship became the overriding focus amongst many Northern actors. Security is an essential requirement of the post-conflict period; but it will mean little and be short lived if the developmental, political or economical factors that are frequently the root causes to conflict are not addressed. Furthermore, this emphasis on security may blur the work of the Architecture with other bodies or actors already focused on security. This may be contributing to the image that the PBC has not demonstrated its added valued.

For Sierra Leone, this research also brings improved understandings around the effects of North-South divisions on peacebuilding work in the country. For instance, working with the Architecture may mean an emphasis on security concerns rather than development. It seems that the Government of Sierra Leone may already recognize this, as it no longer wants to be considered a post-conflict country, but rather a developing country. ${ }^{327}$

This research also suggests implications for understanding North-South divisions within the broader international community. International institutions that have both Northern and Southern members are likely, to some extent, to be subject to North-South dynamics. Likewise, other international actors attempting to engage in peacebuilding also may be afflicted by similar North-South issues. And, other issues that cut across the international arena, such as the environment, are also likely to be affected by North-South dynamics. Thus, in these and other situations where Northern and Southern actors will be brought together, this research may help to bring new perspectives and approaches to challenges faced in other areas.

Although this research has contributed to understandings and implications around North-South divisions and the Peacebuilding Architecture, it also is important to reiterate ${ }^{327}$ Interview No. 2; Interview No. 3; Interview No. 8. 
its limitations. Financial and time constraints prevented the author from conducting field research in Sierra Leone and additional interviews, especially with Southern actors, while space and selection constraints prevented the author from conducting a comparative case study. In the former, this limitation restricts the depth and extent of conclusions that can be made about the country-level experience of the Architecture on Sierra Leone. In the latter, this limitation restricts the ability to generalize the findings from this case to other cases. With the above in mind, future studies should look at conducting field research in order to explore more fully the extent of the effects of North-South divisions on the Architecture's country cases. To strengthen North-South understandings around the Architecture and to improve the ability to apply findings to other cases, future research should also analyze the effects on other cases on the PBC agenda.

Beyond these recommendations, the findings from this study also suggest future areas for research. In particular, additional examination around the variances between strongly felt North-South differences and lesser-felt differences could be useful to understanding what brings additional risks to peacebuilding. Furthermore, research around mixed findings and points of convergence may be very valuable in helping to bridge North-South divisions. Future studies may also usefully consider examining why some North-South divisions have been replicated in the PBC and some have not, offering the potential to better understanding factors which may reduce the presence of NorthSouth divisions.

\subsection{Concluding Remarks}

Attempting to better understand the effects of North-South divisions on the Peacebuilding Architecture's ability to carry out its objectives has important bearing in the broader peacebuilding context. Civil war continues to affect millions of people; however, after achieving peace, post-civil war countries are at risk of returning to conflict within as much as five years. For citizens who are increasingly the targets of civil wars, 
effective peacebuilding has tremendous importance. For the state, its capacity and ability to function is often destroyed or significantly distorted and frequently must rely upon the peacebuilding efforts of other actors to help rebuild the state. Regionally, neighbouring countries are at greater risk of conflict due to destabilization and spillover effects, but equally do not have the resources or ability to single-handedly promote peacebuilding efforts; therefore, international peacebuilding efforts are also important to conflict regions. At the international level, the cost of peacebuilding is significant, but even more so are the costs of a return to war. Furthermore, the effects of civil wars can extend well beyond the state's borders. For the international community, it becomes important to improve peacebuilding efforts.

Although the role of the Peacebuilding Architecture to engage with a variety of actors puts it at risk of North-South divisions, this same position in the international community provides the Architecture the opportunity to work with, overcome and move beyond these dynamics. Given the importance of this area of work, it is hoped that the understandings presented in this thesis may contribute in some way to better understandings of both the theory and practice of peacebuilding. As the introduction to this thesis alluded to, the opportunities the Architecture's role may offer to improve peacebuilding for all involved are invaluable, but most importantly for the people who have endured conflict. 


\section{References: Interviews}

McAskie, Carolyn. Former Assistant Secretary-General for the Peacebuilding Support Office, UN, Telephone Interview. 6 Aug. 2009.

Saltonstall, Phil. Adviser, United Kingdom Mission to the UN, Personal Interview. 6 Mar. 2009.

Skran, Claudena. Associate Professor of Government (Fulbright Scholar: role of NGOs in refugee resettlement in post-civil-war Sierra Leone), Telephone Interview. 22 May 2009.

Slotin, Jenna. Senior Program Officer, International Peace Institute, seconded to the Secretary General, Personal Interview. 5 Mar. 2009.

Travers, Patrick. Advisor, Permanent Mission of Canada to the UN, (Canada Mission; Member of Burundi Country-Specific Configuration, Chair of Sierra Leone Country-Specific Configuration), Personal Interview. 4 Mar. 2009. Telephone Interview. 30 June 2009.

Tschirgi, Necla. Senior Policy Advisor, Peacebuilding Support Office, UN, Personal Interview. 2 Mar. 2009.

Wegter, Bartjan. First Secretary, Political Affairs, Permamnent Mission of the Kingdom of the Netherlands to the UN (Netherlands: First Chair of Sierra Leone Country-Specific Configuration), Personal Interview. 3 Mar. 2009.

Wyeth, Vanessa. Statebuilding Advisor, International Peace Institute, Personal Interview. 3 Mar. 2009. 


\section{References: Works Cited}

"About OECD." n.d. Organization for Economic Co-operation and Development. Web. 11 Aug. 2009. <http://www.oecd.org/pages/0,3417,en_36734052_36734103_ 1_1_1_1_1,00.html>.

ActionAid, CAFOD and CARE. Consolidating the Peace? Views from Sierra Leone and Burundi on the United Nations Peacebuilding Commission. June 2007. ActionAid. Web. 9 Mar. 2009.

Adebajo, Adekeye. Building Peace in West Africa: Liberia, Sierra Leone, and GuineaBissau. Boulder, CO: Lynne Rienner Publishers, 2002. Print.

Ali, Taisier M. and Robert O. Mathews. "Conclusion: The Long and Difficult Road to Peace." Durable Peace: Challenges for Peacebuilding in Africa. Ed. Taisier M. Ali and Robert O. Mathews. Toronto: U of Toronto P, 2004. 393-425. Print.

Alker, Hayward, Jr. "Dimensions of Conflict in the General Assembly." American Political Science Association 58.3 (1964): 642-57. JSTOR. Web. 2 June 2009.

Barnett, Michael, Hunjoon Kim, Madalene O'Donnell and Laura Sitea. "Peacebuilding: What Is in a Name?" Global Governance 13.1 (2007): 35-58. EBSCOhost Business Source Complete. Web. 19 Oct. 2008.

Bertrand, Maurice. "The Historical Development of Efforts to Reform the UN." United Nations, Divided World: The UN's Roles in International Relations. Ed. Adam Roberts and Benedict Kingsbury. 2nd ed. New York: Oxford UP, 1993. 420-36. Print.

Brecher, Jeremy, Tim Costello, and Brendan Smith. "Globalization and Its Specter." Globalization: The Transformation of Social Worlds. Ed. D. Stanley Eitzen and Maxine Baca Zinn. Belmont, CA: Thomson Wadsworth, 2006. 32-39. Print.

"Brief History." n.d. The Organization of the Petroleum Exporting Countries (OPEC).

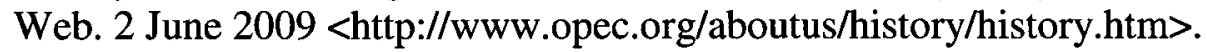

Busumtwi-Sam, James. "Development and Peacebuilding: Conceptual and Operational Deficits in International Assistance." Durable Peace: Challenges for Peacebuilding in Africa. Ed. Taisier M. Ali and Robert O. Mathews. Toronto: U of Toronto P, 2004. 315-53. Print.

Busumtwi-Sam, James, Alexander Costy and Bruce Jones. "Structural Deficits and Institutional Adaptations to Conflict and Peacebuilding in Africa." Durable Peace: Challenges for Peacebuilding in Africa. Toronto: U of Toronto P, 2004. 354-92. Print. 
Call, Charles T. "Ending Wars, Building States." Building States to Build Peace. Ed. Charles T. Call with Vanessa Wyeth. Boulder: Lynne Rienner Publishers, 2008. 1-22. Print.

-. "Knowing Peace When You See It: Setting Standards for Peacebuilding Success." Civil Wars 10.2 (2008): 173-94. Metapress Routledge. Web. 24 Jun. 2008.

CERI Program for Peace and Human Security (CPHS). Integrating for Peace: A Reflection on the Peacebuilding Commission's Strategies for Integration. Conf. Report, Paris, 7 Nov. 2007. Sciences-Po. Web. 3 Oct. 2008.

Commission for Africa. Our Common Interest: Report of the Commission for Africa. 21 March 2005. Web. 26 Nov. 2008.

Conway, Dennis and Nik Heynen. "The Ascendancy of Neoliberalism and Emergence of Contemporary Globalization." Globalization's Contradictions: Geographies of Discipline, Destruction and Transformation. Ed. Dennis Conway and Nik Heynen. New York: Routledge, Taylor and Francis Group, 2006. 17-34. Web. 6 Jun. 2009.

Costy, Alexander. "The Peace Dividend in Mozambique, 1987-1997." Durable Peace: Challenges for Peacebuilding in Africa. Ed. Taisier M. Ali and Robert O. Mathews. Toronto: U of Toronto P, 2004. 142-82. Print.

Cousens, Elizabeth M. "Introduction." Peacebuilding as Politics: Cultivating Peace in Fragile Societies. Ed. Elizabeth M. Cousens and Chetan Kumar. Boulder: Lynne Rienner, 2001. 1-20. Print.

Crossette, Barbara. "The Battle for Human Rights." The Nation 287.21 (2008): 20-22. EBSCOhost International Security \& Counter Terrorism Reference Center. Web. 26 May 2009.

Dadzie, Kenneth. "The UN and the Problem of Economic Development." United Nations, Divided World: The UN's Roles in International Relations. Ed. Adam Roberts and Benedict Kingsbury. 2nd ed. New York: Oxford UP, 1993. 297-326. Print.

Dashwood, Hevina. "Zimbabwe and Sustainable Peace." Durable Peace: Challenges for Peacebuilding. Ed. Taisier M. Ali and Robert O. Mathews. Toronto: U of Toronto P, 2004. 219-50. Print.

Denscombe, Martyn. Ground Rules for Good Research: A 10 Point Guide for Social Researchers. Philadelphia: Open University P., 2002. Print.

Doyle, Michael W. and Nicholas Sambanis. Making War \& Building Peace. Princeton: Princeton UP, 2006. 
Eckstein, Harry. "Case Study and Theory in Political Science." Handbook of Political Science: Strategies of Inquiry. Ed. Fred I. Greenstein and Nelson W. Polsby. Vol. 7. London: Addison-Wesley Publishing Co., Inc., 1975. 79-137. Print.

Fukuyama, Francis. State-Building: Governance and World Order in the 21st Century. Ithaca, NY: Cornell UP, 2004. Print.

Galtung, Johan. "Three Approaches to Peace: Peacekeeping, Peacemaking, and Peacebuilding." Peace, War and Defense. Vol. 2. Copenhagen: Christian Ejlers, 1976. 282-304. Print.

Gawerc, Michelle I. "Peace-building: Theoretical and Concrete Perspectives." Peace \& Change 31.4 (2006): 435-78. Wiley InterScience. Web. 13 Oct. 2008.

Gillespie, James J. and Max H. Bazerman. "Parasitic Integration: Win-Win Agreements Containing Losers." Negotiation Journal 13.3 (1997): 271-82. Wiley Interscience. Web. 5 Oct. 2007.

Grant, J. Andrew. "Diamonds, Foreign Aid and the Uncertain Prospects for Post-Conflict Reconstruction in Sierra Leone." The Round Table 94.381 (2005): 443-57. Informaworld. Web. 17 Nov. 2008.

Hansen, Roger D. Beyond the North-South Stalemate. New York: McGraw-Hill Book Company, 1979. Print.

Hewson, Martin. "The UN After Sixty Years: Progress or Recurrence?" Journal of Military and Strategic Studies 8.1 (2005): n. pag. Web. 26 May 2008.

Holloway, Steven K. and Rodney Tomlinson. "The New World order and the General Assembly: Bloc Realignment at the UN in the Post-Cold War World." Canadian Journal of Political Science / Revue canadianne de science politique. 28.2 (1995): 227-54. JSTOR. Web. 2 Jun 2009.

Human Development Report 2009 - Overcoming Barriers: Human Mobility and Development. New York: Palgrave Macmillan, 2009. 217. Human Development Report. Web. 20 Oct. 2009.

International Peace Institute (IPI, formerly International Peace Academy). "The UN Peacebuilding Commission: Benefits and Challenges." Background paper prepared for the Regional Seminars organized by Friedrich-Ebert-Stiftung. 6 June 2006. Web. 19 Apr. 2009.

Jackson, Paul. "Chiefs, Money and Politicians: Rebulding Local Government in Post-War Sierra Leone." Public Administration and Development. 25. (2005): 49-58. Wiley InterScience. Web. 3 Nov. 2007. 
Jackson, Robert H. and Carl G. Rosberg. "Sovereignty and Underdevelopment: Juridical Statehood in the African Crisis." The Journal of Modern African Studies 24.1 (1986): 1-31. Worldwide Political Science Abstracts. Web. 12 Feb. 2010.

Jaggard, Lyn. "Climate Change Politics, the UN and National Interests." Environmental Policy and Law 38.5 2008: 230-238. Swetswise. Web. 2 Nov. 2009.

Jenkins, Rob. "The UN Peacebuilding Commission and the Dissemination of International Norms." Crisis States Research Centre. Crisis States Research Centre and the London School of Economics, Working Paper 38.2. (2008): 1-24. Web. 20 July 2008.

Kamruzzaman, Palash. "Poverty Reduction Strategy Papers and the Rhetoric of Participation." Development in Practice 19.1 (2009): 61-71. Informaworld. Web. 23 Oct. 2009.

Keen, David. Conflict \& Collusion in Sierra Leone. New York: Palgrave, 2005. Print.

—. "Liberalization and Conflict." International Political Science Review. 26.1 (2005): 73 - 89. Web. 3 Nov. 2007.

Kim, Soo Yeon and Bruce Russett. "The New Politics of Voting Alignments in the United Nations General Assembly." International Organization 50.4 (1996): 62952. JSTOR. Web. 23 May 2009.

Korany, Bahgat. "End of History, or its Continuation and Accentuation? The Global South and the 'New Transformation' Literature." Third World Quarterly 15.1 (1994): 7-15. International Political Science Abstracts. Web. 28 May 2009.

Krasner, Stephen D. Structural Conflict: The Third World Against Global Liberalism. Berkeley: U of Calfornia P, 1985. Print.

Kumar, Krishna. Rebuilding Societies After Civil War: Critical Roles for International Assistance. Boulder, CO: Lynne Rienner Publishers, Inc., 1997. Print.

Lambourne, Wendy. "Towards Sustainable Peace and Development in Sierra Leone: Civil Society and the Peacebuilding Commission." Journal of Peacebuilding \& Development 4.2 (2008): 47-59. Print.

Lederach, John. Building Peace: Sustainable Reconciliation in Divided Societies. Washington: United States Institute of Peace P, 1997. Print.

Malone, David M. and Lotta Hagman. "The North-South Divide at the United Nations: Fading at Last?" Security Dialogue 33.4 (2002): 399-414. Political Science: A SAGE Full-Text Collection. Web. 23 May 2009.

Malone, David M. "Security Council." The Oxford Handbook on the United Nations. Ed. Thomas G. Weiss and Sam Daws. New York: Oxford UP, 2007. 117-35. Print. 
Malone, David M. "UN Reform: A Sisyphean Task." Canada Among Nations: Minorities and Priorities. Ed. Andrew F. Cooper and Dane Rowlands. Montreal: McGillQueen's UP, 2006. 79-108. Google Books. Web. 19 Apr. 2009.

" McAskie, Carolyn. "The International Peacebuilding Challenge: Can New Players and New Approaches Bring New Results?" The Lloyd Shaw Lecture in Public Affairs. Halifax, NS, 22 Nov. 2007. 1-16. Web. 9 Nov. 2008.

McNabb, David E. Research Methods for Political Science: Quantitative and Qualitative Methods. Armonk, NY: M.E. Sharp Inc., 2004. Web. 22 Nov. 2009.

"Memorandum of Understanding Between the United Nations and the United Nations Development Programme Relating to the Management of the Peacebuilding Fund." 28 Nov. 2006. United Nations Peacebuilding Fund. Web. 23 May 2009.

Moore, David. "Levelling the Playing Fields \& Ebedding Illusions: 'Post-Conflict' Discourse \& Neo-Liberal 'Development' in War-Torn Africa." Review of African Political Economy 27.83 (2000): 11-28. JSTOR. Web. 1 Nov. 2008.

Murithi, Tim. "Peacebuilding or 'UN-Building'? African Institutional Responses to the Peacebuilding Commission." Journal of Peacebuilding \& Development 4.2 (2008): 89-94. Print.

Murshed, S. Mansoob. "Globalisation, Marginalisation and Conflict." Globalisation, Poverty and Conflict: A Critical 'Development' Reader. Ed. Max Spoor. New York: Kluwer Academic Publishers, 2004. 67-80. EconLit. Web. 6 June 2009.

Murthy, C.S.R. "New Phase in UN Reforms: Establishment of the Peacebuilding Commission and Human Rights Council." International Studies 44.1 (2007): 3956. Political Science: A SAGE Full-Text Collection. Web. 23 May 2009.

NYU Center on International Cooperation and the International Peace Institute (NYU CIC and the IPI). Taking Stock, Looking Forward: A Strategic Review of the Peacebuilding Commission. April 2008. Center on International Cooperation. Web. 9 Mar. 2009.

Paris Declaration on Aid Effectiveness: Ownershp, Harmonisation, Alignemnt, Results and Mutual Accountability. 28 Feb. - 2 Mar. 2005. Organization for Economic Co-operation and Develeopment. Web. 17 July 2009.

Paris, Roland. At War's End: Building Peace After Civil Conflict. New York: Cambridge UP, 2004. Print.

Paris, Roland. "Post-Conflict Peacebuilding." The Oxford Handbook on the United Nations. Ed. Thomas G. Weiss and Sam Daws. New York: Oxford UP, 2007. 404-426. Print. 
"PBF Mission." n.d. United Nations Peacebuilding Fund. Web. 2 Aug. 2009. $<$ http://www.unpbf.org/mission.shtml $>$.

" Pérez de Cuéllar, Javier. "The Role of the UN Secretary-General." United Nations, Divided World: The UN's Roles in International Relations. Ed. Adam Roberts and Benedict Kingsbury. 2nd. New York: Oxford UP, 1993. 125-42. Print.

Peterson, M. J. "General Assembly." The Oxford Handbook on the United Nations. Ed. Thomas G. Weiss and Sam Daws. New York: Oxford UP, 2007. 97-116. Print.

Pham, J. Peter. The Sierra Leonean Tragedy: History and Global Dimensions. New York: Nova Science Publishers, 2006. Print.

"Pledges, Commitments and Deposits." n.d. United Nations Peacebuilding Fund. Web. 12 Nov. $2009<$ http://www.unpbf.org/pledges.shtml>.

Pugh, Michael. "Why a Merger of Peacebuilding and Development would Reform rather than Transform War-Torn Societies." The RUSI Journal 151.4 (2006): 28-31. Print.

Raffer, Kunibert and H.W. Singer. The Economic North-South Divide: Six Decades of Unequal Development. Northampton, MA: Edward Elgar Publishing, 2001. Print.

Ravenhill, John. "The North-South Balance of Power." International Affairs 66.4 (1990): 731-48. JSTOR. Web. 23 May 2009.

Republic of Sierra Leone and United Nations Peacebuilding Fund. Priority Plan for Peacebuilding Fund (PBF): Sierra Leone. Oct. 2008. United Nations Peacebuilding Fund. Web. 12 Feb. 2009.

Reno, William. "Political Networks in a Failing State: The Roots and Future of Violent Conflict in Sierra Leone." International Politics and Society. 10.2 (2003): 44-66. Web. 25 Jan. 2009.

Riddell, Barry. "Sierra Leone: Urban-Elite Bias, Atrocity \& Debt." Review of African Political Economy. 32.103 (2005): 115-133. Informaworld. Web. 2 Dec. 2008.

Rosenbaum, Allan and Maria Victoria Rojas. "Decentralization, Local Governance and Centre-Periphery Conflict in Sierra Leone." Public Administration and Development. 17 1997: 529-40. Wiley InterScience. Web. 24 Nov. 2007.

Scott, Amy. "The United Nations Peacebuilding Commission: An Early Assessment." Journal of Peacebuilding \& Development 4.2 (2008): 7-19. Print.

Security Council Report. Special Research Report: Peacebuilding Commission. No. 2. New York: Security Council Report, 5 Oct. 2007. Web. 23 May 2009. 
Sesay, Amadu. Does One Size Fit All? The Sierra Leone Truth and Reconciliation Commission Revisited. Vol. 36. Stockholm: The Nordic Africa Institute/Nordiska Afrikainstitutet, 2007. Print.

Shaw, Timothy. "The South in the 'New World (Dis)Order': Towards a Political Economy of Third World Foreign Policy in the 1990s." Third World Quarterly 15.1 (1994): 17-30. JSTOR. Web. 23 Jan. 2008.

Sidhu, Waheguru Pal Singh. "Regional Groups and Alliances." The Oxford Handbook on the United Nations. Ed. Thomas G. Weiss and Sam Daws. New York: Oxford UP, 2007. 217-232. Print.

"Sierra Leone Peacebuilding Fund Approved Projects and Progress Updates." n.d. United $\begin{array}{llllll}\text { Nations Peacebuilding Fund. Web. } 21 & \text { Nov. } 2009\end{array}$ $<$ http://www.unpbf.org/sierraleone/sierraleone-projects.shtml>.

Street, Anne M., Howard Mollett and Jennifer Smith. "Experiences of the United Nations Peacebuidlling Commission in Sierra Leone and Burundi." Journal of Peacebuilding \& Development 4.2 (2008): 33-46. Print.

"The Brandt Equation: 21st Century Blueprint for the New Global Economy." n.d. Centre for Global Negotiations (CGN). Web. 20 Oct. 2009 <http://www.brandt21forum.info/About_BrandtCommission.htm>.

Thérien, Jean-Philippe. "Beyond the North-South Divide: The Two Tales of World Poverty." Third World Quarterly 20.4 (1999): 723-42. Sociological Abstracts. Web. 26 May 2009.

"The World Factbook - Sierra Leone." 22 Jan. 2009. Central Intelligence Agency. Web. 30 Jan. 2009. <https://www.cia.gov/library/publications/the-worldfactbook/geos/sl.html>.

"UN Peacebuilding Fund: Bridging the Gap Between Conflict and Recovery." n.d. United Nations Peacebuilding Fund. Web. 2 Aug. 2009. $<$ http://www.unpbf.org/index.shtml>.

United Nations. Charter of the United Nations. 26 June 1945. Web. 29 Mar. 2010.

United Nations General Assembly (UNGA), Department of Public Information. Press Release GA/10439. 20 Dec. 2005. Web. 13 Nov. 2009.

-. Arrangements for the Revision of the Terms of Reference for the Peacebuilding Fund: A/63/818. 3 Apr. 2009. Web. 3 Mar. 2010.

-. International Development Strategy for the Second United Nations Development Decade (A/8124 and Add.1): Resolution 2626 (XXV). 24 Oct. 1970. Web. 10 Apr. 2010. 
—. Resolution A/RES/55/2. United Nations Millennium Declaration. 18 Sep. 2000. Web. 13 Nov. 2009.

—. Plenary Meeting A/60/PV.66. 20 Dec. 2005. Web. 5 July 2009.

—. Resolution A/RES/60/180. 30 Dec. 2005. Web. 7 July 2009.

-. Report of the Secretary General on the Peacebuilding Fund A/63/818. 13 Apr. 2009. Web. 23 Aug. 2009.

-. Resolution A/RES/60/1.2005 World Summit Outcome. 16 Sep. 2005. Web. 26 June 2009.

United Nations General Assembly/Security Council (UNGA/SC). Report of the Peacebuilding Commission on its Second Session, A/63/92-S/2008/417, 24 June 2008. Web. 14 Nov. 2009.

-. Report of the Secretary-General on Peacebuilding in the Immediate Aftermath of Conflict, A/63/881-S/2009/304, 11 June 2009. Web. 5 Aug. 2009.

- Letter from the President of the Security Counci to the Chairperson of the Peacebuilding Commission A/62/736-S/2007/744. 14 Dec. 2007. Web. 23 Feb. 2010.

—. Sierra Leone Configuration PBC/3/SLE/2. 15 Dec. 2008. Web. 24 July 2009.

—. Sierra Leone Configuration PBC/2/SLE/SR.4. 19 June 2008. Web. 25 July 2009.

-. Sierra Leone Configuration PBC/2/SLE/SR.2. 19 May 2008. Web. 24 July 2009.

United Nations Peacebuilding Commission (PBC). Sierra Leone Peacebuiding Cooperation Framework (PBCF) PBC/2/SLE/1. 3 Dec. 2007. Web. 13 Feb. 2009.

—. Burundi Configuration PBC/2/BDI/SR.1. 19 Sep. 2007. Web. 28 July 2009.

—. Organizational Committee PBC/1/OC/SR.7. 16 May 2007. Web. 12 Nov. 2009.

—. Organizational Committee PBC/1/OC/SR.2. 13 July 2006. Web. 4 Nov. 2009.

—. Organizational Committee PBC/1/OC/SR.5. 12 Dec. 2006. Web. 26 Nov. 2009.

—. Organizational Committee PBC/1/OC/SR.3. 9 Oct. 2006. Web. 26 Nov. 2009.

-. Organizational Committee, Provisional guidelines for the participation of civil society PBC/1/OC/12. 6 June 2007. Web. 16 Aug. 2009.

—. Sierra Leone Configuration PBC/1/SLE/SR.2. 12 Oct. 2006. Web. 10 Apr. 2010.

—. Sierra Leone Configurarion PBC/1/SLE/SR.5. 22 June 2007. Web. 10 Apr. 2010. 
—. Sierra Leone Configuration PBC/2/SLE/SR.3. 19 May 2008. Web. 10 Apr. 2010.

—. Sierra Leone Configuration PBC/3/SLE/L.2. 5 June 2009. Web. 22 Nov. 2009.

United Nations Peacebuilding Support Office (PBSO). "Mapping External Resource Flows to Burundi." 10 Mar. 2007. Web. 1 Dec. 2009.

—. "Mapping External Resource Flows to Sierra Leone." Aug. 2007. Web. 23 Jan. 2009.

-. Unofficial Summary: Informal Meeting of the PBC Burundi Configuration. 29 Oct 2008. Web. 22 Nov. 2009.

United Nations Report of the Secretary General's High-level Panel (UNHLP) on Threats, Challenges and Change. A More Secure World: Our Shared Responsibility. New York: UN Department of Publice Information, 2004. Web. 19 Oct. 2008.

United Nations Secretary General (UNSG). An Agenda for Peace: Preventive Diplomacy, Peacemaking and Peace-Keeping. A/47/277-S/24111. 1992. Web. 22 Sept. 2008.

-. In Larger Freedom: Towards Development, Security and Human Rights for All. A/59/2005. 21 Mar. 2005. Web. 26 Nov. 2008.

United Nations Security Council (UNSC). Resolution S/RES/1645 (2005). 20 Dec. 2005. Web. 26 June 2009.

—. Resolution S/RES/1646 (2005). 20 Dec. 2005. Web. 13 Nov. 2009.

United Nations. The United Nations Today. New York: United Nations, Department of Public Information, 2008. Print.

Vandemoortele, Jan. "The MDG Conundrum: Meeting the Targets Without Missing the Point." Development Policy Review 27.4 (2009): 355-71. Pais International. Web. 9 Feb. 2010.

Venter, Elaine. "A Work in Progress: The Paris Declaration Renews Focus on Aid Reform but is Still Donor-Centric." Finance and Development 45.3 (2008): 20-22. Pais International. Web. 13 Feb. 2010.

Weiss, Thomas G. What's Wrong with the United Nations and How to Fix It. Malden, MA: Polity, 2009. Print.

Working Group on Lessons Learned. n.d. United Nations Peacebuilding Commission. Web. 30 Apr. 2009 <http://www.un.org/peace/peacebuilding/memlessons.shtml>.

Yin, Robert K. Case Study Research: Design and Methods. 3rd ed. Thousand Oaks, CA: Sage Publications, Inc., 2003. Print. 
Zifcak, Spencer M. "United Nations Reform: Heading North or South?" Global Change, Peace \& Security 18.3 (2006): 135-152. Worldwide Political Science Abstracts. Web. 2 Nov. 2009. 